Universidade de São Paulo

Instituto de Física

\title{
Propriedades estruturais e eletrônicas das nanopartículas puras e core-shell de prata e de ouro
}

\author{
Luiz Henrique de Melo dos Santos
}

Orientador: Prof. Dr. Armando Corbani Ferraz

Dissertação de mestrado apresentada ao Instituto de Física da Universidade de São Paulo como requisito parcial para a obtenção do título de Mestre em Ciências

Banca Examinadora:

Prof. Dr. Armando Corbani Ferraz (IFUSP)

Profa. Dra. Lucy Vitória Credidio Assali (IFUSP)

Prof. Dr. Roberto Hiroki Miwa (UFU) 


\section{FICHA CATALOGRÁFICA}

Preparada pelo Serviço de Biblioteca e Informação do Instituto de Física da Universidade de São Paulo

Santos, Luiz Henrique de Melo dos

Propriedades estruturais e eletrônicas das nanopartículas puras e core-shell de prata e de ouro. São Paulo, 2015.

Dissertação (Mestrado) - Universidade de São Paulo. Instituto de Física. Depto. Física dos Materiais e Mecânica.

Orientador: Prof. Dr. Armando Corbani Ferraz

Área de Concentração: Física.

Unitermos: 1. Teoria do funcional da densidade; 2.

Nanopartículas; 3. Ouro e prata; 4. Core-Shell; 5. Estrutura eletrônica. 


\section{Agradecimentos}

Agradeço aos meus familiares, em especial à minha mãe, Roza Soares Melo dos Santos, e a minha filha, Melissa Chagas Santos, por tudo.

À minha esposa, Fabiana Andrade Miranda, pelo apoio e carinho constantes.

Aos meus amigos, Carlos Vinicius Xavier, Carlos Henrique da Silva e Samuel Silva dos Santos, pelas conversas e incentivos.

Agradeço também a Michel Marcondes de Lacerda dos Santos, pelas dicas de computação, ao LCCA-USP e a Bluegene system-Rice University-USA, pelos recursos computacionais disponibilizados, aos colegas do DFMT, e a Sandra Regina Ribeiro, pela gentileza e solicitude sempre presentes.

À assistência estudantil da Universidade de São Paulo, de importância extrema, à CPG, à Rosana Gimenez, secretária do DFMT, e aos demais funcionários do Instituto de Física da USP, pelo atendimento sempre cortês.

Agradeço muito ao prof. Dr. Ronei Miotto, por sua ajuda precisa, desafios propostos, atendimentos e pelas discussões esclarecedoras.

Agradeço fortemente ao Dr. Ferenc Diniz Kiss, uma pessoa boa, do bem, me ajudou de tantas maneiras, imprescindíveis, sem as quais esse trabalho não teria chegado ao seu desfecho.

E, finalmente, ao prof. Dr. Armando Corbani Ferraz, pelo desafio proposto, por acreditar que eu poderia enfrentá-lo, por suas orientações precisas, seus conselhos, pela amizade, por sua atenção e compreensão constantes, pelos conhecimentos transmitidos e por me ajudar a concluir este trabalho. 


\section{Resumo}

Neste trabalho estudamos as propriedades estruturais, energéticas e eletrônicas das nanopartículas puras de prata $(\mathrm{Ag})$ e de ouro $(\mathrm{Au})$ e estruturas do tipo core-shell com número total de átomos variando de 147 à 923, no formato cubooctaédrico. Estudamos também a adsorção da molécula de metanotiol $\left(\mathrm{SCH}_{4}\right)$ sobre os sítios de coordenação dessas nanoestruturas, analisando, entre outros aspectos, os efeitos da interação de van de Waals. Para tanto, foram feitos cálculos teóricos de primeiros princípios dentro da Teoria do Funcional da Densidade (DFT) usando a Aproximação do Gradiente Generalizado (GGA) e Pseudopotenciais Ultrassuaves (USPP).

Concluímos que as maiores nanopartículas puras e core-shell apresentam uma superfície mais esférica e suas energias de formação tendem às energias das superfícies [001] e [111] e dos bulks de Ag e de Au. Uma única camada de shell de ouro ou de prata na core-shell já determina praticamente o comportamento energético e as propriedades da nanopartícula. A inclusão da interação de van der Waals nos cálculos uniformiza, de certa forma, os padrões de deslocamento atômico das superfícies das nanopartículas e o comportamento energético das core-shell, sem entretanto alterar o perfil das densidades de estado. A adsorção da molécula de metanotiol nas nanopartículas puras de Ag e de Au e suas coreshell foi analisada verificando-se que ela praticamente não perturba os estados eletrônicos das nanopartículas e que sua estrutura molecular é preservada. Nas nanopartículas maiores verifica-se um único padrão de adsorção independente do número de camadas de shell nas estruturas core-shell. 


\section{Abstract}

In this work we study the structural, energetic and electronic properties of the pure nanoparticles of silver $(\mathrm{Ag})$ and gold $(\mathrm{Au})$ and their core-shell with total number of atoms ranging from 147 to 923 in cube-octahedral shape. We also investigated the adsorption of the methanethiol molecule $\left(\mathrm{SCH}_{4}\right)$ in the coordination sites of these nanoparticles, analyzing, among other things, the influence of dispersion(van der Waals) interactions. Our simulations are performed using first principles theoretical calculations within of the Density Functional Theory (DFT) framework, described in terms of the Generalized Gradient Approximation (GGA), and by using Ultra-Soft Pseudo-potentials (USPP).

We conclude that the largest pure nanoparticles and core-shell have a more spherical surface and their formation energies tend to formation energies of bare surfaces [001] and [111] and bulks of Ag and Au. A single layer of gold or silver shell already determines the properties and energetic behavior of the nanoparticles. The inclusion of van der Waals' dispersion interaction in the calculations makes uniform, in certain way, the atomic displacement patterns surfaces of the nanoparticles and energetic behavior of core-shell, without change the form of the density of states. The adsorption of methanethiol molecule on the surface of the Ag and Au pure nanoparticles and their core-shell was analyzed and we verified that it almost does not disturb the electronic states of the nanoparticles and their molecular structure is preserved. In the largest nanoparticles we checking only one pattern of adsorption independent of the number of layers shell in the core-shell. 


\section{Sumário}

Agradecimentos $\quad$ i

Resumo ii

Abstract

Introdução vi vi v v v

1 Fundamentos teóricos 1

1.1 Interações eletrônicas e a DFT . . . . . . . . . . . . . . 2

1.1.1 Os Teoremas de Hohenberg e Kohn . . . . . . . . . . . . . 3

1.1.2 O esquema e as equações de Kohn-Sham . . . . . . . . . . 6

1.1.3 A energia de Troca e Correlação . . . . . . . . . . . . . . . 9

1.2 Interações entre núcleos e elétrons . . . . . . . . . . . . . . . . 11

1.2.1 Teoria do Pseudopotencial . . . . . . . . . . . . 12

1.2.2 Pseudopotenciais de primeiros princípios . . . . . . . . 15

1.2.3 Pseudopotencial de norma conservada . . . . . . . . . . . 16

1.2.4 Pseudopotencial separável . . . . . . . . . . . . . . . . 17

1.2.5 Pseudopotencial Ultrassuave-USPP . . . . . . . . . . . . 18

1.3 Energia total e relaxação estrutural . . . . . . . . . . . . . . . 22

1.3.1 Forças sobre os íons . . . . . . . . . . . . . . . . . . . . . . . . . . . . 22

1.3.2 Interações de van der Waals e a energia total . . . . . . . . 24

1.3.3 Correção na energia total . . . . . . . . . . . . . . 25

1.3.4 Esquema de supercélula . . . . . . . . . . . . . 26

1.3.5 Pacote de simulação Vienna Ab-initio-VASP . . . . . . . . 27

2 Construção das nanopartículas $\quad \mathbf{2 8}$

2.1 Nanopartículas poliédricas . . . . . . . . . . . . . . . 30

2.1.1 Nanopartículas cubo-octaédricas . . . . . . . . . . . . 32

2.1.2 Comparação entre as nanopartículas poliédricas . . . . . . 32

2.2 Nanopartículas puras e core-shell de prata e de ouro . . . . . . . 33 
3 Resultados e Discussão das nanopartículas puras e core-shell $\quad 37$ 3.1 Propriedades estruturais das nanopartículas puras e core-shell . . 38

3.2 Propriedades energéticas das nanopartículas puras e core-shell . . 46

3.3 Propriedades eletrônicas das nanopartículas puras e core-shell . . 56

4 Adsorção da molécula de metanotiol nas nanopartículas puras e core-shell

4.1 Propriedades energéticas das adsorções . . . . . . . . . . . . . 70

4.2 Propriedades estruturais das adsorções . . . . . . . . . . . . . 77

4.3 Propriedades eletrônicas das adsorções . . . . . . . . . . . . . . . 84

5 Conclusões

A Funções $F_{x}(s)$ e $H\left(r_{s}, t, \xi\right)$ das energias de troca e correlação PW91 90

B Resultados preliminares para o ouro, prata e molécula de metanotiol

Referências Bibliográficas 


\section{Introdução}

A ciência dos materiais é, atualmente, rica em novos desenvolvimentos resultantes do conhecimento das propriedades físicas e químicas dos sistemas considerados. Estas propriedades abrangem composição química, possíveis arranjos atômicos, estrutura eletrônica, dimensões entre outras. Desse modo, devido aos mais diversos tipos de sistemas que podem ser obtidos e suas potenciais aplicações, é grande o interesse de boa parte da comunidade científica, envolvendo áreas que vão da física à biomedicina. Um dos segmentos desta ciência dos materiais é a nanotecnologia, onde as dimensões dos sistemas são da ordem de nanômetros e podem ser nanopartículas metálicas e não metálicas, nanotubos, nanofios, pontos quânticos entre outros [1, 2, 3].

Nanopartículas metálicas e bimetálicas tem atraído grande interesse recentemente por parte dos pesquisadores devido às suas potenciais aplicações em tecnologias tais como catálises, dispositivos óticos e eletrônicos. As propriedades físicas e químicas dessas nanopartículas bimetálicas podem ser de certa forma ajustadas, variando-se tanto a sua dimensão quanto a sua composição. Nesse aspecto, as denominadas core-shell, nanopartículas de um metal recobertas com camadas de outro, tem o seu uso atualmente bastante difundido devido à sua estruturação e também porque suas propriedades são de grande utilidade em aplicações biomédicas, bem como tem sido demonstrado terem propriedades ópticas diferenciadas das nanopartículas puras de prata $(\mathrm{Ag})$ e ouro $(\mathrm{Au})$ no caso dos sensores óticos [4].

As nanopartículas puras e core-shell já tem sido amplamente utilizadas em aplicações biomédicas com inúmeras patentes nos mais diversos campos das indústrias químico-farmacêuticas tais como bio-imagem, portadores de drogas (drugdelivery), biomarcadores, transplantes e sensores em geral [5].

Dentre as nanopartículas metálicas, as de ouro tem sido investigadas mais extensivamente por causa da sua fácil preparação, resistência à oxidação e estados SPR (Surface Plasmon Ressonance) que podem absorver e espalhar a luz visível [6]. As nanopartículas core-shell e ligas bimetálicas, especialmente sistemas de ouro e prata, são de particular interesse porque têm a possibilidade de transitar os estados SPR entre $\sim 520 \mathrm{~nm}$ para o $\mathrm{Au}$ [7] e $\sim 410 \mathrm{~nm}$ para a Ag [8]. Além 
disso, Shore e colaboradores [9], já verificaram, por exemplo, que a deposição de novas camadas de shell de prata em uma core-shell com shell de Ag e caroço de $\mathrm{Au}$, se tornam menos favoráveis energeticamente, implicando talvez em um limite superior à quantidade de Ag incorporada como camadas shell. De forma complementar, Suzuki e colaboradores [10] indicam que a influência de uma fina camada nas core-shell de Au e Ag somente aparecem ligeiramente no espectro de absorção na região do visível mas, significativamente, na região do infravermelho. O espectro do material da superfície da nanopartícula (core-shell) aparece no espectro infravermelho, enquanto o espectro do material das camadas mais internas é observado na região do visível.

As nanopartículas de ouro são particularmente fáceis de se modificar porque elas são frequentemente estabilizadas com uma camada de ligantes, por exemplo, citrato, que pode ser substituído por moléculas com funcionalidades químicas que se ligam mais fortemente à sua superfície do que esses ligantes [11, 12], como é o caso de tióis, aminas e sulfonatos, podendo até passivar sua superfície. Em contrapartida, nenhum mecanismo de sucesso foi desenvolvido para se criar oligonucleotídeos conjugados estáveis nas superfícies de nanopartículas de prata, principalmente por se degradarem quimicamente ao se utilizar um método de hibridização de ácido desoxirribonucleico. Nesse caso, core-shell com finas camadas de ouro nas camadas de shell e de prata em seu caroço têm sido utilizados para evitar tais efeitos $[12,13]$.

Do ponto de vista teórico inúmeros foram os trabalhos desenvolvidos com cristais moleculares desprezando, entretanto, a dispersão de longo alcance ou interação de van der Waals, que pode ser essencial para a formação de sólidos moleculares [14]. Enquanto isso, para sistemas fracamente quemisorvidos, as forças de dispersão tem atraído cada vez mais a atenção dos pesquisadores e vários estudos tem estimado a sua contribuição para a energia de adsorção [15]. Em particular, recente trabalho de Yildirim e outros [16] aponta variações significativas na energia de adsorção de benzeno sobre a superfície de vários metais, utilizandose ou não as interações de van der Waals em seus cálculos, aumentando o valor da energia de adsorção com o uso da interação. De forma geral, os resultados revelam que o uso das interações de van der Waals descrevem de forma mais adequada as características de adsorção, mesmo em sistemas fortemente ligados.

Além disso, propriedades de estado sólido têm sido recalculadas para um grande conjunto de sólidos utilizando-se a implementação da interação de van der Waals nos cálculos com o funcional da densidade (DFT) [17, 18].

Todas estas possíveis aplicações associadas às nanoestruturas, decorrem dos efeitos oriundos do confinamento quântico de elétrons e pela presença significativa de superfícies. Nas nanopartículas, a quantidade de átomos destas superfícies é comparável ao número de átomos do volume total, influenciando em suas proprie- 
dades físicas e químicas. De outra forma, o tamanho das nanopartículas também influência estas propriedades.

Neste trabalho, estudamos as propriedades estruturais, energéticas e eletrônicas das nanoparticulas puras de Ag e Au e de estruturas do tipo core-shell com 147, 309, 561 e 923 átomos em formação cubo-octaédrica, usando o formalismo da Teoria do Funcional da Densidade (DFT)[19, 20] dentro da Aproximação do Gradiente Generalizado (GGA)[21, 22] e Pseudopotenciais Ultrassuaves (USPP) $[23,24,25,26,27,28,29,30,31,32]$, considerando ou não os efeitos das interações de van der Waals [33, 34, 35, 36, 37, 38]. Do mesmo modo, estudamos a adsorção da molécula de metanotiol $\left(\mathrm{SCH}_{4}\right)$ nessas nanoparticulas puras e core-shell.

No capítulo 1 apresentamos o formalismo teórico utilizado, onde explicitamos os principais elementos da Teoria do Funcional da Densidade (DFT) e aspectos técnicos utilizados na aplicação desse formalismo como a teoria de Pseudopotenciais Ultrassuaves usado. Também, apresentamos a forma pela qual as interações de van der Waals serão computadas.

No segundo capítulo, abordamos os aspectos geométricos e de construção das nanopartículas não relaxadas estudadas, enfocando o formato cubo-octaédrico.

No capítulo 3, analisamos os resultados obtidos no tratamento (DFT) para as nanopartículas puras e core-shell de ouro e prata, através da relaxação eletrônica e estrutural, analisando as quantidades físicas de interesse.

No capítulo 4, analisamos as propriedades estruturais, energéticas e eletrônicas da adsorção da molécula de metanotiol $\left(\mathrm{SCH}_{4}\right)$ nas nanopartículas puras de $\mathrm{Ag}$ e $\mathrm{Au}$ e em estruturas do tipo core-shell. Estudamos a molécula de metanotiol por causa da presença de seus átomos em moléculas orgânicas de interesse biológico e ligação dos tióis com nanopartículas de prata e de ouro, e analisamos suas principais propriedades envolvendo o processo de adsorção dessa molécula na superfície das nanoestruturas estudadas. 


\section{Capítulo 1}

\section{Fundamentos teóricos}

Uma das principais questões em física da matéria condensada é a determinação do comportamento de átomos, moléculas, nanoestruturas, sólidos entre outros materiais à partir de suas propriedades eletrônicas. Essas propriedades são estudadas resolvendo-se problemas de muitos corpos governados pela mêcanica quântica e descritos pela equação de Schrödinger independente do tempo,

$$
\hat{H} \Psi(\mathbf{r})=E \Psi(\mathbf{r}),
$$

onde a função de onda $\Psi(\mathbf{r})$ contém todas as informações que se pode obter do sistema em questão. Os sistemas de muitos corpos considerados são compostos por núcleos e elétrons interagindo, e a determinação de suas estruturas são obtidas por meio da minimização da energia total e das forças, em relação as coordenadas eletrônicas e nucleares. Essa energia total é obtida, da equação 1.1, para uma função de onda total eletrônica e nuclear $\Psi_{t o t}(\mathbf{r})$,

$$
E_{t o t}=\left\langle\Psi_{t o t}\left|\hat{T}_{N}+\hat{T}_{e}+\hat{V}_{N N}+\hat{V}_{N e}+\hat{V}_{e e}\right| \Psi_{t o t}\right\rangle,
$$

onde $\hat{T}_{N}$ e $\hat{T}_{e}$ são os operadores energias cinéticas dos núcleos e elétrons, respectivamente. Os operadores $\hat{V}_{N N}, \hat{V}_{N e}$ e $\hat{V}_{e e}$, representam as interações de Coulomb entre os núcleos, entre núcleos e elétrons e entre os elétrons, respectivamente. Para resolver a equação 1.1, algumas aproximações são necessárias. Uma delas é a aproximação adiabática ou de Born-Oppenheimer. Nela, considera-se o fato de que a massa dos elétrons é muito menor que a dos núcleos, isso implica que a energia cinética dos núcleos pode ser desprezada quando comparada com a dos elétrons. Desse modo, assume-se que os elétrons se movem em um potencial criado por determinada configuração nuclear, tal que o potencial de interação entre os núcleos torna-se uma constante. Assim, efetua-se a separação entre as coordenadas nucleares e eletrônicas na função de onda total, tal que a mesma seja escrita como o produto das funções de onda nuclear $\Psi_{N}(\mathbf{R})$ e eletrônica $\Psi_{e}(\mathbf{R}, \mathbf{r})$, 


$$
\Psi_{t o t}(\mathbf{R}, \mathbf{r}) \equiv \Psi_{N}(\mathbf{R}) \Psi_{e}(\mathbf{R}, \mathbf{r}) .
$$

Note-se que na equação 1.3, a função de onda dos núcleos depende de coordenadas nucleares $(\mathbf{R})$, enquanto as eletrônicas dependem de ambas as coordenadas $(\mathbf{R}, \mathbf{r})$. Dessa forma, das equações 1.1 e 1.3, a energia total pode ser escrita separadamente em duas parcelas devidas aos núcleos $\left(E_{N}\right)$ e a todas as interações eletrônicas $\left(E_{e}\right)$,

$$
E_{t o t}=\left\langle\Psi_{N}\left|\hat{V}_{N N}\right| \Psi_{N}\right\rangle+\left\langle\Psi_{e}\left|\hat{T}_{e}+\hat{V}_{N e}+\hat{V}_{e e}\right| \Psi_{e}\right\rangle,
$$

onde o primeiro termo na equação 1.4 representa as interações nucleares, que é uma constante característica do sistema, e o segundo envolve as interações entre elétrons, entre elétrons e núcleos e há o termo de energia cinética dos elétrons. Esta equação 1.4, mesmo com a aproximação adiabática, possui solução desconhecida. Outras simplificações são necessárias e as mesmas envolvem tanto a energia cinética dos elétrons, quanto as interações entre os elétrons e entre estes e os núcleos. Abordaremos as mesmas nas próximas seções.

\subsection{Interações eletrônicas e a DFT}

O estudo das interações eletrônicas, neste trabalho, é feito usando-se a Teoria do Funcional da Densidade (DFT) desenvolvida por P.C. Hohenberg e Walter Kohn [39] em 1.964 que, a partir de então, tornou-se um dos principais métodos $a b$ initio para cálculos relacionados às propriedades dos sólidos. Antes, métodos do tipo Hartree-Fock(HF)[40] foram bastante utilizados, principalmente em sistemas envolvendo átomos e moléculas, sendo menos preciso no caso de sólidos. Ele era baseado na escolha de uma base de funções de onda escritas na forma de um determinante de Slater, levando em conta o fato de que elétrons são férmions indistuinguíveis implicando que a função de onda total deve ser antissimétrica quando se troca dois elétrons. Como consequência há o surgimento de um termo de troca no Hamiltoniano do sistema, o qual, no método (HF)[40] é tratado de modo exato.

No esquema da (DFT), a variável central é a densidade eletrônica, onde a energia, e outras propriedades de um sistema complexo, são descritas por um funcional dessa densidade. Este método tornou-se uma importante ferramenta para o estudo de sistemas com muitos corpos interagentes partindo de primeiros princípios. Resolver um sistema de muitos corpos interagentes tem como abordagem o mapeamento de um sistema efetivo não interagente com a mesma densidade total do problema de muitos corpos, baseando-se em dois teoremas enunciados por Hohenberg e Kohn[39]. Partindo destes teoremas, Kohn e Sham[41], com o 
objetivo de encontrar o funcional exato para a energia cinética, desenvolveram um método que leva às equações auto-consistentes de Kohn-Sham, nas quais, apareceem os termos das energias de troca e correlação.

\subsubsection{Os Teoremas de Hohenberg e Kohn}

A Teoria do Funcional da Densidade tem como idéia básica que a energia total de um sistema de elétrons interagentes, no estado fundamental, movendo-se em um potencial externo, é obtida conhecendo-se a densidade eletrônica deste sistema de forma autoconsistente. Essa idéia foi proposta por Hohenberg e Kohn [20] na forma de dois teoremas. O primeiro deles é, de modo geral, enunciado do seguinte modo,

Teorema 1.1.1.1 O potencial externo $v(\mathbf{r})$ sentido pelos elétrons, que pode ser devido a configuração nuclear, é um funcional único da densidade eletrônica.

Seja $\Psi$ a função de onda do estado fundamental do sistema, caracterizado pelo hamiltoniano,

$$
\hat{H}^{0}=\hat{T}+\hat{U}+\hat{V}^{0}
$$

onde o potencial externo é dado por $\hat{V}^{0}$, a energia cinética é representada por $\hat{T}$ e a energia de interação elétron-elétron mais a energia potencial é escrita como $\hat{U}$. Suponhamos que o mesmo estado fundamental seja caracterizado por outro potencial externo $\hat{V}^{\prime}$ e função de onda $\Psi^{\prime}$ tal que o hamiltoniano seja dado por,

$$
\hat{H}^{\prime}=\hat{T}+\hat{U}+\hat{V}^{\prime},
$$

onde a energia cinética é representada por $\hat{T}$ e a energia de interação elétronelétron mais a energia potencial é escrita como $\hat{U}$. Por hipótese, os dois potenciais externos, $\hat{V}^{0}$ e $\hat{V}^{\prime}$, resultam na mesma densidade eletrônica, $\rho(\mathbf{r})$, do estado fundamental.

Dessa forma, tem-se, pelo princípio variacional de Rayleigh-Ritz,

$$
\begin{aligned}
& E^{0}=\left\langle\Psi\left|H^{0}\right| \Psi\right\rangle\left\langle\left\langle\Psi^{\prime}\left|H^{0}\right| \Psi^{\prime}\right\rangle,\right. \\
& E^{\prime}=\left\langle\Psi^{\prime}\left|H^{\prime}\right| \Psi^{\prime}\right\rangle\left\langle\left\langle\Psi\left|H^{\prime}\right| \Psi\right\rangle .\right.
\end{aligned}
$$

Da equação 1.7 , tem-se

$$
E^{0}<\left\langle\Psi\left|\hat{T}+\hat{U}+\hat{V}^{0}\right| \Psi\right\rangle<\left\langle\Psi^{\prime}\left|H^{0}\right| \Psi^{\prime}\right\rangle .
$$

Somando e subtraindo $\hat{V}^{\prime}$ em 1.9 resulta em, 


$$
E^{0}<E^{\prime}+\left\langle\Psi\left|\hat{V}^{0}-\hat{V}^{\prime}\right| \Psi\right\rangle
$$

Procedendo de modo análogo em 1.8,

$$
E^{\prime}<E^{0}+\left\langle\Psi\left|\hat{V}^{\prime}-\hat{V}^{0}\right| \Psi\right\rangle .
$$

Somando membro a membro as equações 1.10 e 1.11, tem-se,

$$
E^{0}+E^{\prime}<E^{\prime}+E^{0}
$$

O que é um absurdo. Este resultado mostra que não existe outro potencial externo, diferindo apenas por uma constante, associado à mesma densidade de carga do estado fundamental não degenerado. Portanto, a densidade eletrônica determina, de forma unívoca, o potencial externo. A próxima etapa, após o estabelecimento de que o potencial externo é um funcional da densidade eletrônica do estado fundamental, foi relacionar a densidade de carga e a energia total do estado fundamental do sistema, como consequência direta do primeiro teorema. Esta relação é o segundo teorema de Hohenberg Kohn:

Teorema 1.1.1.2 A energia do estado fundamental $E_{0}[\rho(\mathbf{r})]$ é minima se a densidade eletrônica do estado fundamental $\rho(\mathbf{r})$ for conhecida exatamente,

$$
E[\rho]=\langle\Psi|\hat{T}+\hat{U}+\hat{V}| \Psi\rangle .
$$

Seja $\rho_{0}$ a densidade do estado fundamental, caracterizado por $\Psi_{0}$ cuja dinâmica é dada por $\hat{H}=\hat{T}+\hat{U}+\hat{V}$. Para uma densidade eletrônica $\rho(\mathbf{r})$ de um estado determinado por $\Psi$, temos,

$$
\begin{aligned}
& \rho(\mathbf{r}) \neq \rho_{0} \Longrightarrow E>E_{0}, \\
& \rho(\mathbf{r})=\rho_{0} \Longrightarrow E=E_{0} .
\end{aligned}
$$

Desse modo, o segundo teorema expressa que a energia $E[\rho]$ é um funcional da densidade eletrônica $\rho(\mathbf{r})$, cujo valor mínimo é determinado à partir da densidade eletrônica do estado fundamental.

Reescrevendo a equação 1.13 de outra forma, tem-se,

$$
E[\rho]=\langle\Psi|\hat{T}+\hat{U}| \Psi\rangle+\langle\Psi|\hat{V}| \Psi\rangle=F[\rho(\mathbf{r})]+\langle\Psi|\hat{V}| \Psi\rangle,
$$

onde o termo $F[\rho(\mathbf{r})]$ é um funcional universal válido para qualquer sistema com interações Coulombianas e o termo $\langle\Psi|\hat{V}| \Psi\rangle$ depende do sistema considerado.

De modo análogo, da equação 1.13, tem-se, 


$$
E\left[\rho_{0}(\mathbf{r})\right]=F\left[\rho_{0}(\mathbf{r})\right]+\left\langle\Psi_{0}|\hat{V}| \Psi_{0}\right\rangle,
$$

onde $\Psi_{0}$ é a função de onda do estado fundamental. Os estados $\Psi_{0}$ e $\Psi$ são determinados, respectivamente, por $\rho_{0}(\mathbf{r})$ e $\rho(\mathbf{r})$, e, assumindo que essas densidades são dadas por algum potencial externo, podemos aplicar o princípio variacional, de modo que,

$$
\begin{gathered}
E[\Psi]<E\left[\Psi_{0}\right], \\
\left\langle\Psi_{0}|\hat{T}+\hat{U}| \Psi_{0}\right\rangle+\left\langle\Psi_{0}|\hat{V}| \Psi_{0}\right\rangle<\langle\Psi|\hat{T}+\hat{U}| \Psi\rangle+\langle\Psi|\hat{V}| \Psi\rangle, \\
F\left[\rho_{0}(\mathbf{r})\right]+\left\langle\Psi_{0}|\hat{V}| \Psi_{0}\right\rangle<F[\rho(\mathbf{r})]+\langle\Psi|\hat{V}| \Psi\rangle,
\end{gathered}
$$

o que implica em,

$$
E\left[\rho_{0}(\mathbf{r})\right]<E[\rho(\mathbf{r})]
$$

Portanto, de acordo com o teorema 1.1.1.2, o funcional que representa a energia eletrônica, $E_{e}[n]$, obedece ao princípio variacional relativamente à $n(\mathbf{r})$ e é o mínimo quando esta densidade é igual a densidade de carga do estado fundamental $\rho(\mathbf{r})$,

$$
E_{e}^{0}=E_{e}^{0}[\rho(\mathbf{r})]=F[\rho(\mathbf{r})]+\int V_{e x t}(\mathbf{r}) \rho(\mathbf{r}) d(\mathbf{r}),
$$

tal que, $F[\rho(\mathbf{r})]=$ mínimo de $\left\langle\Psi_{e}\left|\hat{T}_{e}+\hat{V}_{e e}\right| \Psi_{e}\right\rangle$ e $E_{e}^{0}$ é a energia do estado fundamental.

Os efeitos magnéticos são devidos as diferenças e interações entre as componentes do spin dos elétrons[42]. A inclusão destes efeitos na (DFT) faz-se escrevendo separadamente as densidades eletrônicas de cada componente do spin, $n_{\uparrow}(\mathbf{r})$ e $n_{\downarrow}(\mathbf{r})$. Assim, a densidade total é dada pela soma dessas densidades,

$$
n(\mathbf{r})=n_{\uparrow}(\mathbf{r})+n_{\downarrow}(\mathbf{r}) .
$$

Desse modo, reescreve-se o funcional energia eletrônica explicitando a sua dependência com o spin dos elétrons,

$$
E_{e}\left[n_{\uparrow}, n_{\downarrow}\right]=F\left[n_{\uparrow}, n_{\downarrow}\right]+\int V_{e x t}(\mathbf{r})\left(n_{\uparrow}(\mathbf{r})+n_{\downarrow}(\mathbf{r})\right) d(\mathbf{r}) .
$$




\subsubsection{O esquema e as equações de Kohn-Sham}

A partir do formalismo de Hohenberg e Kohn, Sham e Kohn[41] obtiveram um conjunto de equações auto-consistentes tornando a (DFT) uma ferramenta útil para a obtenção das propriedades eletrônicas de sistemas químicos e físicos. A (DFT) é formulada sem aproximações, sendo, portanto, exata na resolução do problema de muitos elétrons interagentes, no estado fundamental, sujeitos a um potencial externo $V_{\text {ext }}(\mathbf{r})$. Na prática, há, basicamente, duas dificuldades que não permitem o tratamento exato:

1. o funcional energia eletrônica $F\left[n_{\uparrow}, n_{\downarrow}\right]=\left\langle\Psi_{e}\left|\hat{T}_{e}+\hat{V}_{e e}\right| \Psi_{e}\right\rangle$ não é conhecido; e,

2. é necessário um método para se obter a densidade eletrônica que minimize o funcional energia eletrônica $E_{e}$.

A abordagem utilizada para contornar estas dificuldades foi substituir a variação direta em relação a densidade de carga por um enfoque baseado em orbitais. Fez-se isso usando os formalismos de Hartree-Fock[39, 41] e de Thomas-Fermi[40]. Para tanto, Kohn e Sham [41] descreveram a função de onda total eletrônica $\Psi_{e}$ em termos de um produto de funções orbitais $\Psi_{s}(\mathbf{r})$,

$$
\Psi_{e}=\prod_{s=i, \sigma} \Psi_{s}=\Psi_{1 \uparrow} \cdot \Psi_{1 \downarrow} \ldots \Psi_{i \uparrow} \cdot \Psi_{i \downarrow}
$$

e, dessa forma, escreve-se a densidade como,

$$
n(\mathbf{r})=\sum_{s=i, \sigma} n_{s}(\mathbf{r})=\sum_{s=i, \sigma} f_{s}\left|\Psi_{s}\right|^{2}
$$

onde $n_{s}(\mathbf{r})$ é a densidade eletrônica de cada estado, representado pelo índice $s$. Ele representa os estados eletrônicos, $i=1,2,3 \ldots$, e, de spin, $\sigma=\uparrow, \downarrow$. Os fatores $f_{s}$, que obedecem à estatística de Fermi-Dirac, relacionam-se com a ocupação eletrônica de cada um dos $s$ estados.

Para resolver a primeira das dificuldades, de acordo com o esquema de Hohenberg e Kohn, Kohn e Sham [41] propuseram que o funcional energia do estado fundamental de um gás de elétrons interagentes não homogêneo submetido a um potencial externo $V_{\text {ext }}(\mathbf{r})$, escreve-se sob a forma seguinte,

$$
E\left[n_{\uparrow}, n_{\downarrow},\left\{\Psi_{s}\right\}, V_{e x t}\right]=\int V_{e x t}(\mathbf{r}) n(\mathbf{r}) d \mathbf{r}+F\left[n_{\uparrow}, n_{\downarrow}\left\{\Psi_{s}\right\}\right],
$$

onde o funcional $F\left[n_{\uparrow}, n_{\downarrow},\left\{\Psi_{s}\right\}\right]$, é dado por, 


$$
F\left[n_{\uparrow}, n_{\downarrow},\left\{\Psi_{s}\right\}\right]=\frac{1}{2} \int \frac{n(\mathbf{r}) n\left(\mathbf{r}^{\prime}\right)}{\left|\mathbf{r}-\mathbf{r}^{\prime}\right|} d \mathbf{r} d \mathbf{r}^{\prime}+T_{n i}\left[\left\{\Psi_{s}\right\}\right]+E_{x c}\left[n_{\uparrow}, n_{\downarrow}\right]
$$

com o termo $T_{n i}\left[\left\{\Psi_{s}\right\}\right]$ representando o funcional energia cinética de um gás de elétrons não interagentes (ni) com densidade $n(\mathbf{r})$. O primeiro termo da equação 1.28, é funcional energia de Coulomb e o último termo representa o funcional energia de troca e correlação, que é um funcional universal da densidade, incluíndo as correções para a energia exata do gás de elétrons interagentes, que, porém, não é conhecido exatamente, exceto para alguns sistemas simples, necessitando, portanto, de aproximações. Assim posto, obtem-se a energia do estado fundamental a partir da equação 1.27 , quando $n(\mathbf{r})=\rho(\mathbf{r})$.

Resolve-se o segundo problema aplicando o princípio variacional na equação 1.27, considerando a condição,

$$
\int \delta n(\mathbf{r}) d \mathbf{r}=0
$$

Sabendo-se que o número total de partículas é dado por, $N=\int n(\mathbf{r}) d \mathbf{r}$, temos que a condição de mínimo é obtida de,

$$
\delta\left\{E\left[n_{\uparrow}, n_{\downarrow},\left\{\Psi_{s}\right\}, V_{e x t}\right]-\epsilon N\right\}=0,
$$

onde $\epsilon$ é um multiplicador de Lagrange. Dessa forma, a condição variacional resulta em,

$$
\int d \mathbf{r}\left\{V_{e x t}(\mathbf{r})+\int \frac{n\left(\mathbf{r}^{\prime}\right)}{\left|\mathbf{r}-\mathbf{r}^{\prime}\right|} d \mathbf{r}^{\prime}+\frac{\delta T_{n i}}{\delta n}+\frac{\delta E_{x c}}{\delta n}-\epsilon\right\} \delta n(\mathbf{r})=0 .
$$

Como a variação em $\delta n(\mathbf{r})$ é arbitrária, a expressão entre parênteses na equação 1.31 acima anula-se, levando a,

$$
V_{e x t}(\mathbf{r})+\int \frac{n\left(\mathbf{r}^{\prime}\right)}{\left|\mathbf{r}-\mathbf{r}^{\prime}\right|} d \mathbf{r}^{\prime}+\frac{\delta T_{n i}}{\delta n}+\frac{\delta E_{x c}}{\delta n}-\epsilon=0 .
$$

Para se obter as equações de Kohn-Sham deve-se, neste ponto, usar a densidade eletrônica do sistema em termos de um conjunto de funções ortonormais, os orbitais $\left\{\Psi_{s}(\mathbf{r})\right\}$, conforme a equação 1.26 e substituir em 1.32 para se efetuar a derivada funcional de $T_{n i}\left[\left\{\Psi_{s}\right\}\right]$. Feito isso, a variação deste funcional é dada por,

$$
\delta T_{n i}[n(\mathbf{r})]=-\int \delta \Psi_{s}^{*}(\mathbf{r}) \nabla^{2} \Psi_{s}(\mathbf{r}) d \mathbf{r}
$$


onde, na obtenção de 1.33 acima, uma integral de superfície se anulou devido à condições periódicas de contorno. Usando a definição de derivação funcional, tem-se que,

$$
\frac{\delta T_{n i}[n]}{\delta n}=-\frac{\nabla^{2} \Psi_{s}(\mathbf{r})}{\Psi_{s}(\mathbf{r})}
$$

Assim, substituindo a equação 1.34 em 1.32, chegamos às equações de KohnSham (KS) (em unidades atômicas):

$$
\left\{-\nabla^{2}+V_{K S}(\mathbf{r})\right\} \Psi_{s}(\mathbf{r})=\epsilon_{s} \Psi_{s}(\mathbf{r}),
$$

onde o potencial efetivo, $V_{K S}(\mathbf{r})$, é dado por,

$$
V_{K S}(\mathbf{r})=V_{e x t}(\mathbf{r})+\int \frac{n\left(\mathbf{r}^{\prime}\right)}{\left|\mathbf{r}-\mathbf{r}^{\prime}\right|} d \mathbf{r}^{\prime}+\frac{\delta E_{x c}}{\delta n} .
$$

Na equação 1.36, o primeiro termo é o potencial externo, o segundo é a energia potencial de Hartree e o último representa a energia de troca e correlação. As equações 1.29 e 1.31 são exatamente as mesmas obtidas por Hohenberg e Kohn para um sistema de elétrons não interagentes sujeitos ao potencial efetivo $V_{K S}(\mathbf{r})$. Portanto, a DFT relaciona um sistema de muitas partículas interagentes com um de elétrons não interagentes (partícula única) que possua a mesma densidade $n(\mathbf{r})$ no estado fundamental, ambos os sistemas sujeitos ao mesmo potencial externo $V_{\text {ext }}(\mathbf{r})$. Estas equações são semelhantes às de Hartree, porém, contém o termo $V_{x c}=\frac{\delta E_{x c}}{\delta n}$, que representa o potencial de troca mais o de correlação. Por sua vez, este termo abrange todos os efeitos de muitos corpos ausentes na teoria de Hartree, e, desse modo, as equações de Kohn-Sham (KS) são exatas.

A solução da equação 1.35 fornece um conjunto de funções de onda do estado fundamental $\left\{\Psi_{1}^{0}(\mathbf{r}) \ldots \Psi_{s}^{0}(\mathbf{r})\right\}$, permitindo a obtenção da densidade eletrônica do estado fundamental $\rho(\mathbf{r})$ por meio da equação 1.26. Das equações de Kohn-Sham 1.35, do funcional energia 1.27, e conhecendo-se a densidade acima, a energia total é calculada através da equação,

$$
E[\rho(\mathbf{r})]=\sum_{s=i, \sigma} \epsilon_{s}-\frac{1}{2} \int \frac{n(\mathbf{r}) n\left(\mathbf{r}^{\prime}\right)}{\left|\mathbf{r}-\mathbf{r}^{\prime}\right|} d \mathbf{r} d \mathbf{r}^{\prime}+\int \rho(\mathbf{r})\left[\epsilon_{x c}-V_{x c}\right] d \mathbf{r}
$$

que é a energia total escrita em função dos autovalores de Kohn-Sham $\epsilon_{s}$. Nesta equação, $\epsilon_{x c}$ é a densidade de energia de troca e correlação. Vemos que $E[\rho(\mathbf{r})]$ não é simplesmente a soma dos autovalores.

As equaçoes de Kohn-Sham 1.35 são resolvidas de modo auto-consistente. Isso ocorre porque o potencial efetivo $V_{K S}(\mathbf{r})$ depende da densidade $n(\mathbf{r})$, a qual, 
por sua vez, depende dos orbitais $\Psi_{s}$, que são obtidos conhecendo-se $V_{K S}(\mathbf{r})$. O ciclo de auto-consistência possui as seguintes etapas:

- partindo de um conjunto inicial de funções de onda constrói-se uma densidade de carga $n(\mathbf{r})$ e calcula-se o potencial $V_{K S}(\mathbf{r})$ usando a equação 1.36 ;

- com o potencial obtido antes, resolve-se às equações de Kohn-Sham 1.35 obtendo-se um conjunto de funções de onda;

- partindo destas funções de onda, calcula-se outra densidade pela equação 1.26 ;

- com essa densidade, calcula-se o potencial de Hartree comparando-o com aquele obtido da densidade inicial. Esses potenciais são obtidos resolvendose a equação de Poisson,

$$
\nabla^{2} V_{\text {Hartree }}=n(\mathbf{r})
$$

- se a diferença entre os potenciais for maior do que a precisão estabelecida, reinicia-se o ciclo de auto-consistência com a nova densidade. Repete-se esse processo até que a diferença entre os potenciais seja menor do que a precisão requerida.

Obtida a autoconsistência, a densidade resultante é a do estado fundamental $\rho(\mathbf{r})$ para o potencial externo considerado.

\subsubsection{A energia de Troca e Correlação}

No esquema de Kohn-Sham, mostrado anteriormente, a única aproximação efetuada, foi a de Born-Oppenheimer. Há, porém, outro aspecto a ressaltar, qual seja, o fato que não se conhece a forma exata para o funcional energia de troca e correlação. Para sua implementação, duas aproximações são amplamente utilizadas: a Aproximação da Densidade Local (LDA) e a Aproximação do Gradiente Generalizado (GGA).

A aproximação LDA foi proposta por Kohn-Sham [41] sendo uma das mais simples aproximações e bastante utilizada na DFT. A ideia principal da aproximação LDA é a de se considerar que em um volume infinitesimal do sistema, o funcional $E_{x c}$ nesse volume seja trocado pela energia de troca e correlação de um gás de elétrons homogêneo com a mesma densidade local do sistema original, ou seja, a densidade varia lentamente; em seguida, soma-se as contribuições de cada elemento de volume do seguinte modo, 


$$
E_{x c}^{L D A}[n \uparrow, n \downarrow]=\int \epsilon_{x c}[n \uparrow, n \downarrow] n(\mathbf{r}) d \mathbf{r},
$$

onde $\epsilon_{x c}[n \uparrow, n \downarrow]$ é a energia de troca e correlação por elétron. Dessa forma, o potencial de troca e correlação $V_{x c}$ é dado por,

$$
V_{x c}[n \uparrow, n \downarrow]=\frac{\partial\left(\epsilon_{x c}[n \uparrow, n \downarrow] n(\mathbf{r})\right)}{\partial n}=\epsilon_{x c}[n \uparrow, n \downarrow]+n(\mathbf{r}) \frac{\partial\left(\epsilon_{x c}[n \uparrow, n \downarrow]\right.}{\partial n} .
$$

Como se disse antes, na aproximação LDA, a energia de troca e correlação por elétron $\epsilon_{x c}$ em um ponto $r$ é considerada igual à energia de um gás de elétrons uniforme com a densidade do sistema naquele ponto,

$$
\epsilon_{x c}^{L D A}=\epsilon_{x c}^{u n i f},
$$

e o termos de troca e correlação são tratados de modo separado,

$$
\epsilon_{x c}=\epsilon_{x}+\epsilon_{c}
$$

A energia de troca por elétron $\epsilon_{x}$ de um gás de elétrons uniforme é dada pela expressão analítica [40],

$$
\epsilon_{x}=-\frac{3}{4}\left(\frac{3}{\pi}\right)^{\frac{1}{3}}(n(\mathbf{r}))^{\frac{1}{3}}
$$

De 1.43 e 1.39, temos,

$$
E_{x}^{L D A}=-\frac{3}{4}\left(\frac{3}{\pi}\right)^{\frac{1}{3}} \int(n(\mathbf{r}))^{\frac{4}{3}} d \mathbf{r}=\frac{-0.4582}{r_{s}(\mathbf{r})},
$$

onde a densidade $n(\mathbf{r})$ está escrita em função do raio de Wigner-Seitz, $r_{s}(\mathbf{r})$,

$$
n(\mathbf{r})=\left[\frac{4 \pi}{3} r_{s}^{3}(\mathbf{r})\right]^{-1}
$$

Por sua vez, a energia de correlação $\epsilon_{c}$ do gás de elétrons uniforme somente possui expressão analítica nas regiões com $r_{s}(\mathbf{r})<1$ ou $r_{s}(\mathbf{r})>2$. Porém, no intervalo onde ocorre a descontiuidade, $1<r_{s}(\mathbf{r})<2$, faz-se uma interpolação numérica, o que torna a energia por elétron $\epsilon_{c}$ contínua em toda a extensão de $r_{s}(\mathbf{r})$. Uma das expressões mais utilizadas para esta energia de correlação é a proprosta por Ceperley e Alder [43] e parametrizada por Perdew e Zunger [42]. Os pontos para a interpolação desta expressão são obtidos por meio de cálculos de Monte Carlo quântico para um gás de elétrons uniforme e interagente. 
A aproximação LDA, apesar dos bons resultados para sistemas onde a densidade apresenta grande uniformidade, não descreve adequadamente sistemas com densidades não homogêneas ou altamente localizadas. Com o propósito de contornar estas dificuldades, incorporou-se, nos funcionais de troca e correlação $E_{x c}$, os efeitos oriundos da não homogeneidade, resultando na Aproximação do Gradiente Generalizado (GGA).

As diferentes formas da aproximação GGA são variantes de uma mesma expressão que depende localmente da densidade eletrônica $n(\mathbf{r})$ e do seu gradiente,

$$
E_{x c}^{G G A}=\int f(n \uparrow, n \downarrow, \nabla n \uparrow, \nabla n \downarrow) d \mathbf{r},
$$

onde $f$ é uma função analitica parametrizada. As diferenças entre as várias aproximações encontradas na literatura estão na forma da parametrização. Neste trabalho, utilizamos a elaborada por Perdew e Wang [44, 45].

Na aproximação de Perdew e Wang (PW91), a energia de troca e correlação $E_{x c}$ é obtida da combinação de gradientes na expansão do termo de troca e correlação de um gás de elétrons uniforme. Essas energias são escritas separadamente como,

$$
E_{x c}=E_{x}+E_{c} .
$$

O termo de troca, que não depende do spin, é dado por,

$$
E_{x}^{P W 91}[n]=\int \epsilon_{x}^{u n i f}(n) F_{x}(s) n(\mathbf{r}) d \mathbf{r}
$$

onde, em unidades atômicas, Fermi.

$\epsilon_{x}^{u n i f}(n)=-\frac{3 k_{F}}{4 \pi}, k_{F}=\left(3 \pi^{2} n(\mathbf{r})\right)^{\frac{1}{3}}$ e $s=\frac{|\nabla n(\mathbf{r})|}{2 k_{F} n(\mathbf{r})}$ com $k_{F}$ sendo o momento de

Por outro lado, o termo de correlação dependente da polarização de spin sendo dado por,

$$
E_{c}^{P W 91}[n \uparrow, n \downarrow]=\int\left[\epsilon_{c}^{u n i f}\left(r_{s}, \xi\right)+H\left(r_{s}, \xi, t\right)\right] n(\mathbf{r}) d \mathbf{r},
$$

onde, $t=\frac{|\nabla n(\mathbf{r})|}{2 k_{F} \phi n(\mathbf{r})}, k_{s}=\sqrt{\frac{4 k_{F}}{\pi a_{0}}}, \xi=\frac{n \uparrow(\mathbf{r})-n \downarrow(\mathbf{r})}{n(\mathbf{r})}$ e $\phi=\frac{1}{2}\left((1+\xi)^{\frac{2}{3}}+(1-\xi)^{\frac{2}{3}}\right)$. As funções $F_{x}(s)$ e $H\left(r_{s}, \xi, t\right)$ estão descritas no apêndice A.

\subsection{Interações entre núcleos e elétrons}

A interação entre núcleos e elétrons é determinada pelo potencial de Coulomb e depende da configuração nuclear. Como vimos antes, mantem-se fixo um dado ar- 
ranjo nuclear definindo um ambiente no qual os elétrons se rearranjam de acordo com os seus estados eletrônicos.

No ambiente de um átomo isolado, o potencial sentido pelos elétrons deve-se a um único núcleo com carga $Z$ cuja solução fornece os estados eletrônicos do átomo. Quando se transfere este átomo para outros ambientes, tais como moléculas, cristais ou superfícies, os estados atômicos são perturbados na formação de ligações químicas. Aqueles elétrons cujos estados atômicos são fortemente pertubados quando transferidos de ambiente por participarem efetivamente de ligações químicas, são chamados de elétrons da valência. Os elétrons mais fortemente ligados ao núcleo e que possuem um papel menor nas ligações químicas e, portanto, tem seus estados pouco perturbados, são denominados de elétrons de caroço.

Como os estados de caroço não são significativamente perturbados pelo rearranjo elêtronico da valência nos diferentes ambientes, eles podem, de modo aproximado, serem considerados como congelados. Nesta aproximação, o átomo, composto por todos os elétrons e núcleo, pode ser substituído por um pseudoátomo, formado pelos elétrons de valência e um caroço iônico, este último constituído pelo núcleo e por elétrons do caroço mantidos em seus estados atômicos. As propriedades dos materiais relacionam-se com as ligações químicas e, dessa forma, espera-se que o congelamento dos estados do caroço não interfira nas propriedades obtidas usando essa aproximação [46].

Para a valência, o caroço iônico equivale a um núcleo com carga elétrica efetiva de $Z_{v}=Z-Z_{\text {ef }}$, sendo $Z_{\text {ef }}$ a carga efetiva dos elétrons do caroço. Desse modo, os elétrons da valência ficam sujeitos a um potencial efetivo resultante do potencial atrativo do núcleo que é parcialmente cancelado pelo potencial repulsivo dos elétrons do caroço. Este potencial resultante é denominado pseudopotencial. O pseudopotencial simplifica os cálculos de estruturas elêtronicas substituindo um problema de todos os elétrons por outro mais simples envolvendo apenas os estados de valência, como representado na figura 1.1

O átomo de prata, por exemplo, possui 47 elétrons distribuídos nos estados $1 s^{2} 2 s^{2} 2 p^{6} 3 s^{2} 3 p^{6} 3 d^{10} 4 s^{2} 4 p^{6} 4 d^{10} 5 s^{1}$, onde os estados $4 d^{10} 5 s^{1}$ são os mais perturbados e correspondem, efetivamente, à valência. Assim, um sistema composto por $N$ átomos de prata e $47 N$ elétrons, é substituído por um problema que envolve $11 N$ elétrons, reduzindo em aproximadamente 4 vezes o número de elétrons a tratar.

\subsubsection{Teoria do Pseudopotencial}

O surgimento da Teoria do Pseudopotencial está relacionada com a escolha da descrição da função de onda eletrônica $\Psi(\mathbf{r})$ em uma base de ondas planas (PW"plane waves") 


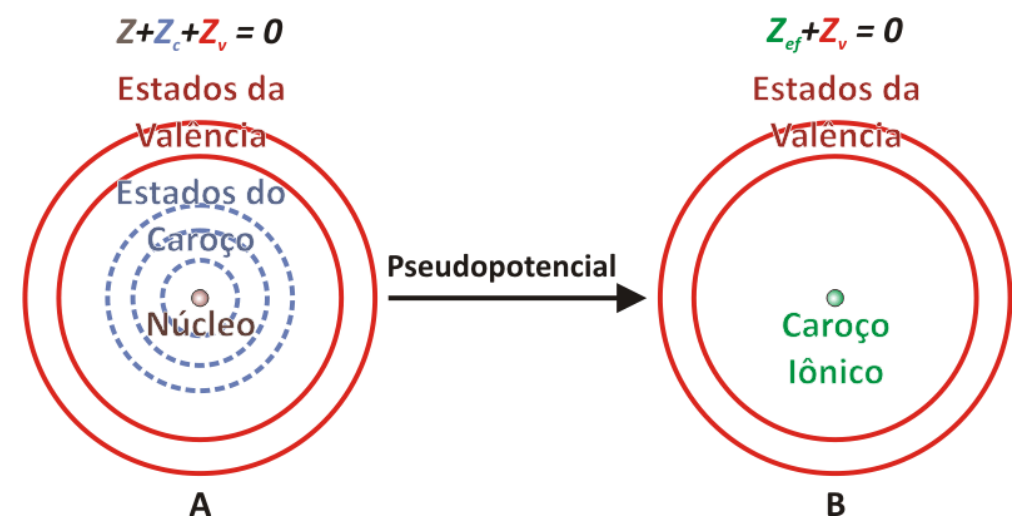

Figura 1.1: Representação das subdivisões do átomo em núcleo(marrom), estados do caroço(azul) e estados da valência(vermelho) e a correspondente simplificação realizada pelo método do pseudopotencial. A região do núcleo mais os elétrons do caroço é substituída por um caroço iônico com uma carga efetiva equivalente $\mathrm{Z}_{\text {ef }}$ (verde). As cargas do núcleo, do caroço e da valência são representadas respectivamente por $\mathrm{Z}, \mathrm{Z}_{c}$ e $\mathrm{Z}_{v}$. Reprodução autorizada por [1].

$$
\Psi(\mathbf{r})=\sum_{k} c_{k} e^{i \vec{k} \cdot \vec{r}}
$$

A adoção da expansão em ondas planas deve-se ao fato de que, em princípio, pode-se descrever qualquer função por meio de uma expansão de Fourier e porque simplifica o tratamento de sistemas periódicos. No entanto, devido a intensa interação com o núcleo e a ortogonalidade entre os estados, as funções de onda dos elétrons são localizadas e apresentam oscilações na região próxima ao núcleo, sendo necessário um número muito grande de ondas planas para uma boa descrição. Para resolver isto, Herring [47] propôs que as funções de onda dos estados de valência $\Psi_{v}$ fossem descritas como uma combinação linear de uma função de onda suave e sem nós, $\Phi_{v}$, expandida em ondas planas, com uma função de onda dos estados ligados de caroço $\Psi_{c}$,

$$
\left|\Psi_{v}\right\rangle=\left|\Phi_{v}\right\rangle+\sum_{c} b_{c v}\left|\Psi_{c}\right\rangle
$$

Os estados de caroço são ortogonais, $\left\langle\Psi_{c} \mid \Psi_{c^{\prime}}\right\rangle=\delta_{c, c^{\prime}}$, e os coeficientes $b_{c v}$, são determinados impondo-se a ortogonalidade entre os funções de onda de caroço $\Psi_{c}$ e de valência $\Psi_{v},\left\langle\Psi_{v} \mid \Psi_{c^{\prime}}\right\rangle=0$ e $b_{c v}=-\left\langle\Phi_{v} \mid \Psi_{c^{\prime}}\right\rangle$ Desse modo, trata-se a região oscilatória com funções de ondas atômicas(caroço) enquanto a região suave é descrita por ondas planas, necessitando de um menor número delas. Essa proposta, conhecida por ondas planas ortogonalizadas ("OPW-Orthogonalized Plane Waves"), deu origem ao método do pseudopotencial. 
Inspirados no método OPW, Philips e Kleinman [48] estudaram as propriedades de cancelamento entre os potenciais do núcleo e o dos elétrons do caroço e mostraram que a parte suave da função de onda da valência satisfaz a equação de Schrödinger modificada,

$$
\left(\hat{H}+\sum_{c}\left(\epsilon_{v}-\epsilon_{c}\right)\left|\Psi_{c}\right\rangle\left\langle\Psi_{c}\right|\right)\left|\Phi_{v}\right\rangle=\epsilon_{v}\left|\Phi_{v}\right\rangle,
$$

onde $\epsilon_{v}$ e $\epsilon_{c}$ são, respectivamente, os autovalores dos estados de valência e do caroço do Hamiltoniano atômico $\hat{H}=\hat{T}+\hat{V}$,

$$
\begin{aligned}
& \hat{H}\left|\Psi_{v}\right\rangle=\epsilon_{v}\left|\Psi_{v}\right\rangle=\epsilon_{v}\left|\Psi_{v}\right\rangle, \\
& \hat{H}\left|\Psi_{c}\right\rangle=\epsilon_{c}\left|\Psi_{c}\right\rangle=\epsilon_{c}\left|\Psi_{c}\right\rangle .
\end{aligned}
$$

Isso siginifica que podemos escrever uma pseudo-Hamiltoniana que fornece os mesmos autovalores para a valência da hamiltoniana original, no entanto, utilizando a pseudofunção de onda de valência $\Phi_{v}$, a qual é uma função suave e sem nós,

$$
\hat{H}_{p s}=\hat{H}+\sum_{c}\left(\epsilon_{v}-\epsilon_{c}\right)\left|\Psi_{c}\right\rangle\left\langle\Psi_{c}\right| .
$$

Como os autovalores $\epsilon_{c}$ são sempre menores que os autovalores $\epsilon_{v}$, o segundo termo do lado direito de 1.55 equivale a um potencial repulsivo $\hat{V}_{R}$,

$$
\hat{V}_{R}=\sum_{c}\left(\epsilon_{v}-\epsilon_{c}\right)\left|\Psi_{c}\right\rangle\left\langle\Psi_{c}\right|
$$

Assim, a pseudo-hamiltoniana é escrita como,

$$
\hat{H}_{p s}=\hat{T}+\hat{V}+\hat{V}_{R}
$$

onde o potencial resultante,

$$
\hat{V}_{p s}=\hat{V}+\hat{V}_{R}
$$

representa um potencial atrativo mais suave, consequência do cancelamento entre o termos atrativo $\hat{V}$ e o repulsivo $\hat{V}_{R}$. Este potencial resultante $\hat{V}_{p s}$ é denominado pseudopotencial. Cohen e Heine [49] mostraram que dentro da região do caroço o cancelamento entre $\hat{V}$ e $\hat{V}_{R}$ é quase completo. Isso resultou na total exclusão dos estados do caroço no tratamento do sistema, sendo realizado explicitamente apenas sobre os estados de valência. 


\subsubsection{Pseudopotenciais de primeiros princípios}

Os pseudopotenciais do tipo ab initio são gerados a partir de cálculos atômicos com todos os elétrons, usando a teoria do funcional da densidade e resolvendo-se a equação radial de Kohn-Sham,

$$
\left(-\frac{1}{2} \frac{\partial^{2}}{\partial r^{2}}+\frac{l(l+1)}{2 r^{2}}+\hat{V}_{K S}[n]\right) r R_{l}^{t e}(r)=\epsilon_{l} r R_{l}^{t e}(r),
$$

onde a função de onda atômica de todos os elétrons $\Phi_{l m}^{t e}(r, \theta, \phi)$ é dada pelo produto das componentes radial $R_{l}^{t e}(r)$ e harmônica esférica $Y_{l m}(\theta, \phi)$,

$$
\Phi_{l m}^{t e}(r, \theta, \phi)=R_{l}^{t e}(r) Y_{l m}(\theta, \phi) .
$$

O potencial de Kohn-Sham, $\hat{V}_{K S}[n]$, é dado pela equação 1.36, e o potencial externo é devido ao núcleo com número atômico $Z$, e, portanto, tem-se,

$$
\hat{V}_{K S}=-\frac{Z}{r} \hat{I}+\hat{V}_{\text {Hartree }}+\hat{V}_{x c}
$$

onde, $\hat{I}$, é o operador identidade. Partindo dos resultados das autofunções e autovalores obtidos para todos os elétrons, constrói-se as pseudofunções de onda $R_{l}^{p s}(r)$. Obtêm-se o pseudopotencial atômico a partir da inversão da equação radial de Kohn-Sham 1.59,

$$
v_{l}^{p s-a t o m}(r)=\epsilon_{l}-\frac{l(l+1)}{2 r^{2}}+\frac{1}{2 r R_{l}^{p s}(r)} \frac{\partial^{2}}{\partial r^{2}}\left[r R_{l}^{p s}(r)\right] .
$$

Para evitar a singularidade do pseudopotencial, impõe-se que as pseudofunções de onda não apresentem nós e se comportem como $r^{l}$ quando se aproximam da origem e, para garantir a continuidade do pseudopotencial, que possuam derivadas contínuas até a segunda ordem.

Na figura 1.2, comparamos a função de onda de todos os elétrons sujeita ao potencial de Coulomb e a correspondente pseudofunção de onda sujeita ao pseudopotencial. A partir do raio de corte $r_{c}$, a função de onda e o potencial de todos os elétrons coincidem com a pseudofunção de onda e o pseudopotencial, respectivamente.

E, por fim, produz-se o pseudopotencial representando apenas a região do caroço iônico, possibilitando a sua transferência para ambientes diferentes do atômico, retira-se do pseudopotencial atômico as interações de Hartree e de troca e correlação dos elétrons da valência,

$$
v_{l}^{p s}(r)=v_{l}^{p s-a t o m}(r)-\int \frac{\rho_{v}(r)}{\left|r-r^{\prime}\right|} d \mathbf{r}^{\prime}-v_{x c}\left[\rho_{v}(r)\right],
$$

onde $\rho_{v}(r)$, corresponde, apenas, a densidade dos elétrons da valência. 


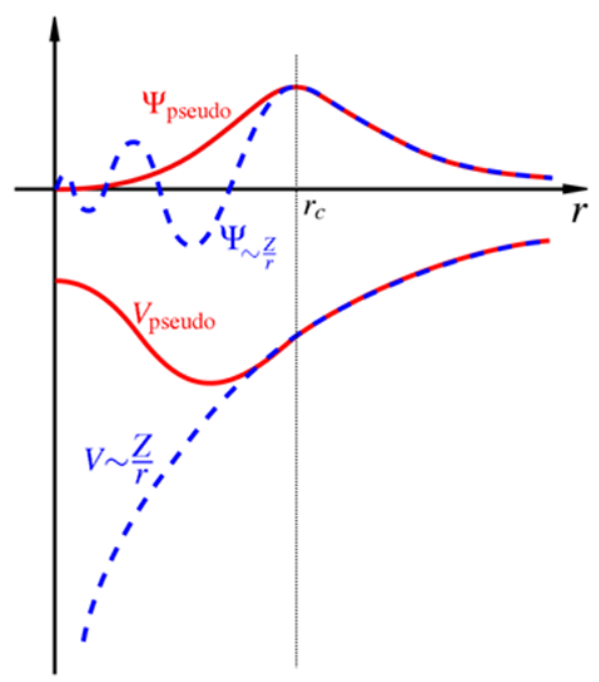

Figura 1.2: Comparação entre a função de onda de todos os elétrons sujeita ao potencial coulombiano(tracejado azul) e a pseudofunção de onda sujeita ao correspondente pseudopotencial(linha vermelha). Reprodução autorizada por [1].

\subsubsection{Pseudopotencial de norma conservada}

O pseudopotencial deve ser construído de forma que reproduza adequadamente os efeitos do potencial de todos os elétrons na região além do caroço. Desse forma, Hamman, Schlüter e Chiang [50] (HSC), propuseram quatro propriedades básicas:

1. os autovalores da valência do cálculo com todos os elétrons devem coincidir com os pseudoautovalores,

$$
\epsilon_{v}^{t e}=\epsilon_{v}^{p s}
$$

2. a pseudofunção de onda $\Phi_{v}$, deve ser idêntica a função de onda de todos os elétrons $\Psi_{v}$ a partir de um raio de corte $r_{c}$, escolhido após a região de grandes oscilações, e deve ser suave e sem nós na região dentro do raio de corte,

$$
R_{l}^{p s}(r)=R_{l}^{t e}(r), r \geq r_{c}
$$

3. a integral da densidade de carga do cálculo de todos os elétrons e da pseudodensidade devem ser iguais dentro da esfera de raio $r_{c}$,

$$
\int_{0}^{r_{c}}\left|R_{l}^{p s}(r)\right|^{2} r^{2} d r=\int_{0}^{r_{c}}\left|R_{l}^{t e}(r)\right|^{2} r^{2} d r
$$


4. a derivada logarítmica e a primeira derivada com relação a energia da função de onda do cálculo de todos os elétrons e da pseudofunção de onda devem ser iguais para $r \geq r_{c}$;

Os dois últimos itens relacionam-se pela identidade da regra de soma de Friedel,

$$
\left.\frac{1}{2}\left[\left(r R_{l}\right)^{2} \frac{\partial}{\partial \epsilon} \frac{\partial}{\partial r} \ln \left(R_{l}\right)\right]\right|_{r=r_{c}, \epsilon=\epsilon_{l}}=\int_{0}^{r_{c}} R_{l}^{2} r^{2} d r .
$$

Os pseudopotenciais que obedecem a estas quatro propriedades são ditos serem de primeiros princípios de norma conservada. Há, na literarura, várias formas para estes pseudopotenciais os quais se diferenciam, principalmente, pela forma da pseudofunção de onda.

\subsubsection{Pseudopotencial separável}

O pseudopotencial não é local por construção, atuando de modo diferente para cada momento angular $l$, escrevendo-se como,

$$
\hat{V}^{p s}=\sum_{l}^{\infty} \sum_{m=-l}^{+l}|l m\rangle v_{l}^{p s}(r)\langle l m|,
$$

onde $\langle\mathbf{r} \mid l m\rangle=Y_{l m}(\theta, \phi)$ são os harmômicos esféricos e $v_{l}^{p s}(r)$ são os pseudopotenciais para cada componente $l$ do momento angular obtidos da equação 1.63. Porém, como os termos $v_{l}^{p s}(r)$ convergem rapidamente com o aumento de $l$, o caroço é percebido da mesma forma por todas as componentes $l>l_{\max }$, e, sendo assim, pode-se reescrever o pseudopotencial separando-se as partes local e não local,

$$
\begin{aligned}
\hat{V}^{p s} & =\sum_{l}^{\infty} \sum_{m=-l}^{+l}|l m\rangle v_{l o c}^{p s}(r)\left\langle l m\left|+\sum_{l}^{l_{\max }} \sum_{m=-l}^{+l}\right| l m\right\rangle\left(v_{l}^{p s}(r)-v_{l o c}^{p s}(r)\right)\langle l m| \\
& =v_{l o c}^{p s}(r) \hat{I}+\sum_{l}^{l_{\max }} \sum_{m=-l}^{+l}|l m\rangle \Delta v_{l}^{p s}(r)\langle l m|,
\end{aligned}
$$

onde $\hat{I}$ representa a matriz identidade e o último termo, a parte não local do pseudopotencial,

$$
\Delta \hat{V}_{l}^{p s}=\sum_{m=-l}^{+l}|l m\rangle \Delta v_{l}^{p s}(r)\langle l m|
$$


De acordo com o proposto por Kleynman e Bylamder [51], a parte não local do pseudopotencial, de um modo geral, se escreve como,

$$
|l m\rangle \Delta v_{l}^{p s}(r)\langle l m|=\sum_{m=-l}^{+l} \frac{\left|\chi^{l m}\right\rangle\left\langle\chi^{l m}\right|}{\left\langle\chi^{l m} \mid \Phi_{l m}^{p s}\right\rangle},
$$

o que corresponde a um operador de projeção, onde, as funções projetoras, as quais dependem da escolha do potencial local, são dadas por,

$$
\left|\chi^{l m}\right\rangle=\Delta V_{l}^{p s}\left|\Phi_{l m}^{p s}\right\rangle=\left(\epsilon_{l}-\hat{T}-v_{l o c}^{p s} \hat{I}\right)\left|\Phi_{l m}^{p s}\right\rangle,
$$

tal que a pseudofunção de onda é autoestado da pseudo-Hamiltoniana com autovalores $\epsilon_{l}$,

$$
\left(\hat{T}+\hat{V}^{p s}\right)\left|\Phi_{l m}^{p s}\right\rangle=\left(\hat{T}+\hat{V}_{l o c}^{p s}+\Delta V_{l}^{p s}\right)\left|\Phi_{l m}^{p s}\right\rangle=\epsilon_{l}\left|\Phi_{l m}^{p s}\right\rangle,
$$

$\operatorname{com} \hat{V}_{l o c}^{p s}=v_{l o c}^{p s}(r) \hat{I}$.

A separação entre as partes local e não local do pseudopotencial reduzem o custo computacional pois a obtenção da parte não local é a operação com o maior custo entre os diferentes termos da Hamiltoniana.

\subsubsection{Pseudopotencial Ultrassuave-USPP}

Nos pseudopotenciais de norma conservada a função de onda de todos os elétrons é substituída, dentro de um raio de corte, por uma pseudofunção de onda suave, sem nós e com a mesma norma, ou seja, contendo a mesma carga nessa região. Após o raio de corte, ambas as funções são idênticas. Para garantir essas condições e uma boa transferibilidade do potencial, que reproduza a distribuição de carga e o momento, é necessário que o raio de corte fique próximo ao máximo mais extremo da função de onda de todos os elétrons. No entanto, elementos com orbitais muito localizados produzem pseudopotenciais profundos que ainda necessitam de um conjunto grande de ondas planas para uma boa descrição. Exemplos de tais elementos com orbitais localizados são aqueles da primeira coluna da tabel periódica, as terras raras e os que incluem os orbitais do tipo $d$. O aumento do raio de corte suaviza ainda mais o pseudopotencial, entretanto, compromete a sua transferibilidade, exigindo testes adicionais para assegurar a qualidade do pseudopotencial nos novos ambientes. Na regra da soma de Friedel, equação 1.67, relacionada com a transferibilidade, a troca de fase depende da norma da função de onda, e, por isso, a conservação da norma foi imposta na construção dos pseudopotenciais. No entanto, excetuando-se essa condição, a norma não é estritamente necessária para a solução da equação de autoconsistência. Vanderbilt $[23,24,30]$ demonstrou que removendo a condição de conservação 
da norma é possível escolher um raio de corte maior, independente do máximo da função de onda, e construir pseudofunções muito mais suaves do que nos métodos tradicionais. Isso possibilitou a criação de pseudopotenciais igualmente transferíveis, no entanto, muito mais suaves conhecidos como Pseudopotenciais Ultrassuaves-(USPP-"Ultra-Soft- Pseudopotential").

A figura 1.3 ilustra como a pseudofunção de onda para o orbital $2 p$ do oxigênio construída dentro do método HSC, que conserva a norma, é tão localizada quanto a função de todos os elétrons e, por outro lado, como a pseudofunção de onda construída com o método USPP é bem mais suave. De um modo geral, o raio de corte para o método USPP é maior em um fator de 1,5, relativamente àquele necessário usando um método com conservação da norma, permitindo a construção de pseudofunções de onda muito mais suaves.

A conservação da norma exige que a diferença entre a densidade de carga da função de onda atômica de todos os elétrons $\Phi_{i l m}^{t e}$ e a pseudofunção de onda atômica $\Phi_{i l m}^{p s}$ seja nula, $Q_{i l m}^{l}=0$, onde,

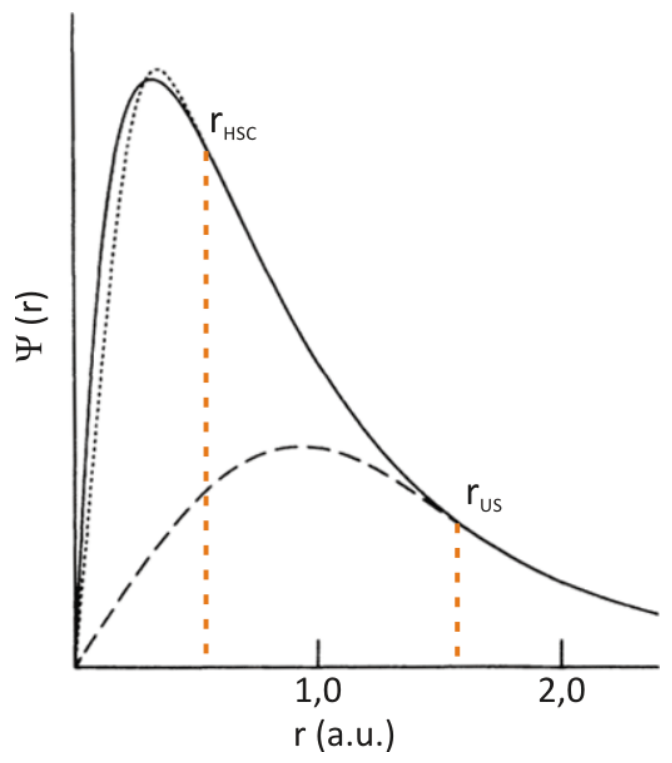

Figura 1.3: Função de onda radial do orbital $2 p$ do oxigênio(linha sólida) e as correspondentes pseudofunções de onda geradas com os pseudopotenciais de norma conservada HSC (linha pontilhada) e Ultrassuave (linha tracejada) e seus respectivos raios de corte $\mathrm{r}_{H S C}$ e $\mathrm{r}_{U S}$. Figura adaptada do trabalho de Vanderbilt (1990)[30] e reproduzida com autorização de [1].

$$
Q_{i l m}^{l}=\left\langle\Phi_{i l m}^{t e} \mid \Phi_{j l m}^{t e}\right\rangle_{r_{c}}-\left\langle\Phi_{i l m}^{p s} \mid \Phi_{j l m}^{p s}\right\rangle_{r_{c}} .
$$

Vanderbilt demonstrou que a condição $Q_{i l m}^{l}=0$ não é necessária se for adotado 
o seguinte operador de sobreposição não local,

$$
\hat{S}=\hat{I}+\sum_{i, j} \sum_{l} \sum_{m=-l}^{+l} Q_{i j}^{l}\left|\beta_{i}^{l m}\right\rangle\left\langle\beta_{j}^{l m}\right|,
$$

e redefinindo o operador potencial não local como,

$$
\Delta V_{l}^{U S}=\sum_{i, j} D_{i j}^{l-i o n} \sum_{m=-l}^{+l}\left|\beta_{i}^{l m}\right\rangle\left\langle\beta_{j}^{l m}\right|,
$$

onde $\left|\beta_{i}^{l m}\right\rangle$ são funções locais definidas por,

$$
\left|\beta_{i}^{l m}\right\rangle=\sum_{j}\left(B^{-1}\right)_{i j}^{l}\left|\chi_{j}^{l m}\right\rangle
$$

$\operatorname{com} B_{i j}^{l}=\left\langle\Phi_{i l m}^{p s} \mid \chi_{j}^{l m}\right\rangle$. Os termos $D_{i j}^{l-i o n}$ são dados por,

$$
D_{i j}^{l-i o n}=B_{i j}^{l}+\epsilon_{i l} Q_{i l m}^{l},
$$

onde $\epsilon_{i l}$ são os autovalores das pseudofunções de onda atômicas,

$$
\left(\hat{T}+\hat{V}^{p s}\right)\left|\Phi_{i l m}^{p s}\right\rangle=\left(\hat{T}+\hat{V}_{l o c}^{p s}+\Delta V_{l}^{p s}\right)\left|\Phi_{i l m}^{p s}\right\rangle=\epsilon_{l}\left|\Phi_{i l m}^{p s}\right\rangle .
$$

Com essa definição é possível restabelecer a conservação da norma,

$$
\left\langle\Phi_{i l m}^{t e} \mid \Phi_{j l m}^{t e}\right\rangle_{r_{c}}=\left\langle\Phi_{i l m}^{p s}|\hat{S}| \Phi_{j l m}^{p s}\right\rangle_{r_{c}},
$$

onde o conjunto de pseudofunções de onda atômicas $\left|\Phi_{i l m}^{p s}\right\rangle$ são soluções do problema generalizado de autovalores,

$$
\hat{H}\left|\Phi_{i l m}^{p s}\right\rangle=\epsilon_{i l} \hat{S}\left|\Phi_{i l m}^{p s}\right\rangle .
$$

Para os cálculos de estrutura eletrônica que utilizam o método do pseudopotencial ultrassuave, a densidade de carga, calculada apenas com as pseudofunções, é menor do que a densidade de carga total do sistema. Isso acontece por causa da carga deficitária em cada caroço, consequência da não conservação da norma nessa região. Essa diferença na densidade de carga tem que ser corrigida para que os termos da Hamiltoniana de Kohn-Sham, os quais dependem da densidade, sejam descritos corretamente. Efetua-se essa correção ao final de cada ciclo de autoconsistência e a densidade de carga corrigida possui a forma seguinte,

$$
\rho_{\nu}(\mathbf{r})=\sum_{n} f_{n}\left[\phi_{n}(\mathbf{r}) \phi_{n}^{*}(\mathbf{r})+\sum_{l} \sum_{m=-l}^{+l} \sum_{i, j}\left\langle\phi_{n} \mid \beta_{i}^{l m}\right\rangle Q_{i j}^{l}(\mathbf{r})\left\langle\beta_{j}^{l m} \mid \phi_{n}\right\rangle\right]
$$


onde o segundo termo dentro dos colchetes representa toda a correção na densidade de carga devido a não conservação da norma com,

$$
Q_{i, j}^{l}(\mathbf{r})=\phi_{i l m}^{t e *}(\mathbf{r}) \phi_{j l m}^{t e}(\mathbf{r})-\phi_{i l m}^{p s *}(\mathbf{r}) \phi_{j l m}^{p s}(\mathbf{r}),
$$

integrando a densidade, $\rho_{\nu}(\mathbf{r})$, sobre a condição de normalização $\left\langle\phi_{n}|\hat{S}| \phi_{m}\right\rangle=$ $\delta_{n, m}$, obtemos o número de elétrons, $N$, do sistema,

$$
\begin{aligned}
N=\int \rho_{\nu}(\mathbf{r}) d \mathbf{r} & =\sum_{n}\left[\left\langle\phi_{n} \mid \phi_{n}\right\rangle+\sum_{l} \sum_{m=-l}^{+l} \sum_{i, j}\left\langle\phi_{n} \mid \beta_{i}^{l m}\right\rangle Q_{i j}^{l}(\mathbf{r})\left\langle\beta_{j}^{l m} \mid \phi_{n}\right\rangle\right] \\
& =\sum_{n}\left\langle\phi _ { n } \left|\left(\hat{I}+\sum_{l} \sum_{m=-l}^{+l} \sum_{i, j}\left|\beta_{i}^{l m}\right\rangle Q_{i j}^{l}(\mathbf{r})\left\langle\beta_{j}^{l m}\right)\left|\phi_{n}\right\rangle\right.\right.\right. \\
& =\sum_{n}\left\langle\phi_{n}|\hat{S}| \phi_{n}\right\rangle
\end{aligned}
$$

A equação secular autoconsistente mantém a mesma forma da equação 1.81,

$$
\hat{H}\left|\Phi_{n}^{p s}\right\rangle=\epsilon_{n} \hat{S}\left|\Phi_{n}^{p s}\right\rangle,
$$

entretanto, agora o potencial local inclui as contribuições de Hartree e de troca e correlação das interações entre os elétrons,

$$
v_{l o c}=v_{l o c}^{p s}+v_{\text {Hartree }}\left[\rho_{\nu}\right]+v_{x c}\left[\rho_{\nu}\right] .
$$

Devido a não localidade do operador de projeção $\hat{S}$, o potencial local $v_{l o c}$, passa a contribuir na parte não local do pseudopotencial, modificando os termos de matriz $D_{i j}^{l-i o n}$ para,

$$
D_{i j}^{l}=D_{i j}^{l-i o n}+\int v_{l o c} Q_{i, j}^{l}(\mathbf{r}) d \mathbf{r}
$$

$\mathrm{e}$

$$
\Delta \hat{V}^{p s-U S}=\sum_{l} \sum_{i, j} D_{i j}^{l}\left|\beta_{i}^{l m}\right\rangle\left\langle\beta_{j}^{l m}\right| .
$$

A energia total eletrônica no esquema do pseudopotencial ultrassuave tem a seguinte forma,

$$
E_{e l}^{U S}=\sum_{s}\left\langle\phi_{s}\left|-\vec{\nabla}^{2}+\Delta \hat{V}^{p s-U S}\right| \phi_{s}\right\rangle+\int v_{l o c} n(\mathbf{r}) d \mathbf{r} .
$$

Assim, o pseudopotencial ultrassuave descreve de modo adequado a energia total eletrônica mantendo as condições de transferibilidade, porém, necessitando de um conjunto bem menor de ondas planas. 


\subsection{Energia total e relaxação estrutural}

Para obter a energia total do sistema somam-se a energia eletrônica $E_{e l}^{U S}$, equação 1.89 , e a de interação entre os núcleos $E_{n}$,

$$
E_{t o t}^{U S}=E_{e l}^{U S}+E_{n}
$$

onde a energia dos núcleos deve-se apenas as interações de Coulomb,

$$
E_{n}=\frac{1}{2} \sum_{\mu} \sum_{\nu \neq \mu} \frac{Z_{\mu} Z_{\nu}}{\left|\mathbf{R}_{\mu}-\mathbf{R}_{\nu}\right|}
$$

com $\mathbf{R}$ e $Z$, sendo, respectivamente, as posições dos íons e seus números atômicos. Assim, tem-se,

$$
E_{t o t}^{U S}=\sum_{s}\left\langle\phi_{s}\left|-\vec{\nabla}^{2}+\Delta \hat{V}^{p s-U S}\right| \phi_{s}\right\rangle+\int v_{l o c} n(\mathbf{r}) d \mathbf{r}+\frac{1}{2} \sum_{\mu} \sum_{\nu \neq \mu} \frac{Z_{\mu} Z_{\nu}}{\left|\mathbf{R}_{\mu}-\mathbf{R}_{\nu}\right|}
$$

onde, $v_{l o c}$ e $\Delta V^{p s-U S}$ são dadas pelas equações 1.86 e 1.88 .

Com o formalismo desenvolvido obtêm-se a energia total do sistema para uma configuração congelada de núcleos. Entretanto, é necessário um método para relaxar esses núcleos na busca do mínimo global da energia total, equação 1.92 .

Uma alternativa para obter este mínimo é a busca da configuração que cancele as forças atuantes sobre estes núcleos. Para tanto, resolve-se autoconsistentemente a equação de Kohn-Sham para a configuração fixa de núcleos e calcula-se as forças que agem sobre cada núcleo. Tendo essas forças, movimenta-se os núcleos com o objetivo de reduzí-las. Repete-se o processo para cada nova configuração de núcleos até que as forças sejam menores do que a precisão estabelecida. Ao fim de cada ciclo, obtêm-se a configuração de equilíbrio que leva ao mínimo da energia. Porém, este procedimento garante apenas a obtenção do mínimo de energia local não o global da configuração inicial dos núcleos. Na prática, nenhum mecanismo garante que se atingirá o mínimo global do sistema. O que se faz é o teste de diferentes configurações e adota-se aquela que possuir o menor mínimo local.

\subsubsection{Forças sobre os íons}

As forças sobre os íons do sistema são importantes na obtenção da estrutura de equilíbrio. Obtem-se as mesmas derivando a energia em relação às coordenadas nucleares, 


$$
\mathbf{F}_{\mu}=-\frac{\partial E_{t o t}}{\partial \mathbf{R}_{\mu}}
$$

Porém, efetua-se a derivação sobre um funcional mais geral da energia, o qual inclui a ortonormalidade das funções de onda através da introdução dos multiplicadores de Lagrange $\Lambda_{i j}$,

$$
\Xi=E_{t o t}+\sum_{i j} \Lambda_{i j}\left(\left\langle\psi_{i} \mid \psi_{j}\right\rangle-\delta_{i j}\right)
$$

que toma a forma seguinte quando utiliza-se as pseudofunções de onda ultrassuaves $\phi$,

$$
\Xi^{U S}=E_{t o t}^{U S}+\sum_{i j} \Lambda_{i j}\left(\left\langle\phi_{i}|\hat{S}| \phi_{j}\right\rangle-\delta_{i j}\right)
$$

No contexto da formulação de Hellmann-Feynman [52, 53], escreve-se a força sobre os íons do modo seguinte,

$$
\mathbf{F}_{\mu}^{U S}=-\frac{\partial E_{t o t}^{U S}}{\partial \mathbf{R}_{\mu}}+\sum_{i j} \Lambda_{i j}\left\langle\phi_{i}\left|\frac{\partial \hat{S}}{\partial \mathbf{R}_{\mu}}\right| \phi_{j}\right\rangle .
$$

O cálculo da força no método do pseudopotencial ultrassuave apresenta termos extras quando comparado com os métodos de norma conservada devido a dependência da posição dos núcleos na carga de compensação $Q_{i j}^{l}$ e no operador de projeção $\hat{S}[32,54,55]$.

A partir das forças que agem nos núcleos, adota-se um método para movimentálos no sentido de minimizar aquelas forças dentro da precisão estabelecida.

Diferente de algoritmos baseados nos formalismos de Car e Parrinello(CP) [56], com o estabelecimento de uma pseudodinâmica baseada nos formalismos lagrangeano para movimentar os graus de liberdade eletrônicos e nucleares na busca de valores de mínimos eletrônicos e estruturais, utilizamos para tal objetivo o método do Gradiente Conjugado(CG) [57].

Com a separação das etapas de cálculo da estrutura eletrônica(passos eletrônicos) e de movimentação dos íons(passos iônicos), a relaxação iterativa do sistema depende de diagonalizações de matrizes com alto custo computacional, necessitando-se, desse modo, de algoritmos que tornem eficiente a convergência à configurações vantajosas sob o aspecto energético, o que é conseguido com a busca direcionada implementada pelo CG. Esta abordagem evita elementos potencialmente prejudiciais à eficiência na convergência como as flutuações características do método CP [54, 58]. Além disso, com o aperfeiçoamento das técnicas de paralelização, as operações de diagonalização de matrizes são menos custosas e, 
assim, métodos com essa perspectiva tornam-se mais vantajosos em relação ao seu desempenho.

Nas etapas do CG (i) avalia-se inicialmente os valores das forças e energias; sendo, então, (ii) as posições dos íons e dos parâmetros de rede variados na direção das forças calculadas e do tensor de stress (como realizado nos algoritmos de Steepest Decent [57]), recalculando-se as forças e energias; a partir destes dois valores de força e energia (iii) uma interpolação quadrática nesta superfície de energia potencial (PES-"Potential Energy Surface"), de 3N dimensões, possibilita que com a informação proveniente desta amostragem corrija-se a direção de variação das posições atômicas e dos parâmetros de rede[57]. Passos adicionais para melhorar a eficiência do procedimento são incorporados como variações do algoritmo de Brent[59].

\subsubsection{Interações de van der Waals e a energia total}

As interações de van der Waals (vdW) (ou forças de dispersão) são estudadas há bastante tempo. Apesar desse problema ser de origem puramente quântica, seu estudo se iniciou muito antes do nascimento da mecânica quântica e dura até hoje. Em 1910, o físico holandês Johannes Diderik van der Waals, ganhou o prêmio Nobel de Física por seu trabalho sobre "A equação de estado para gases e líquidos". A equação de estado de vdW,

$$
\left(p+\frac{a}{v^{2}}\right)(v-b)=R_{g a s} T,
$$

diz que as moléculas individuais do gás não tem acesso ao volume total $v$ mas a um volume efetivo $(v-b)$. O termo de correção $\frac{a}{v^{2}}$ na pressão implica que a energia cinética com a qual as moléculas atingem os contornos do volume é mais baixa do que seu valor no interior devido às forças atrativas das outras moléculas. Sendo $R$ a separação média das moléculas do gás, essa correção é proporcional a $\frac{1}{R^{6}}[35]$. Historicamente, muitos outros pesquisadores forneceram contribuições importantes para o estudo desse tipo de interação. Uma atenção particular deve ser dada a Willem Hendrik Keesom, que produziu a primeira descrição matemática das interações entre dipolos permanentes, a Peter Debye, que estudou a interação entre dipolos permanentes e dipolos induzidos; e, por fim, a Fritz London, que, utilizando a Mecânica Quântica com perturbação, mostrou que existe uma força geral de atração entre duas moléculas mesmo que nenhuma possua um momento de dipolo permanente. As forças de Keesom, Debye e London também são proporcionais a $\frac{1}{R^{6}}$. No caso das forças de Keesom, a energia de interação é proporcional à $-\frac{p_{1}^{2} p_{2}^{2}}{3 K_{B} T R^{6}}$, onde $p_{1}$ e $p_{2}$ são os momentos de dipolo elétrico das moléculas. Esse efeito de interação entre dipolos permanentes não pode fornecer uma explicação geral das forças de vdW por dois motivos. 
Primeiro, muitas moléculas que não possuem momento de dipolo exibem forças atrativas, e o efeito orientacional dos momentos de dipolo se tornam pequenos em temperaturas altas, mas as forças de vdW persistem. O segundo motivo foi salientado por Debye, que chamou atenção para o fato que as moléculas não são estruturas rígidas, mas distribuições deformáveis de carga, que, se colocadas em um campo externo, tornam-se polarizadas, de modo que sempre existem as forças de atração. Essa interpretação chamou atenção para o caráter universal das forças de vdW e para sua persistência em altas temperaturas[35]. A interação de Debye, onde dipolos permanentes interagem com dipolos induzidos, é dada por $-\frac{p_{1}^{2} \alpha_{2}^{2} p_{2}^{2} \alpha_{1}^{2}}{R^{6}}$, onde $\alpha$ é a polarizabilidade[60]. Essas considerações dão conta de parte da explicação do efeito atrativo das interações de vdW. As forças de Keesom são capazes de explicar as forças de (vdW) para moléculas com dipolo permanente a baixas temperaturas, e as forças de Debye introduzem uma atração adicional que persiste em altas temperaturas. Contudo, a força atrativa entre átomos neutros sem dipolos permanentes ainda não foi explicada. Foi London, em 1930, que reconheceu o significado amplo dessas forças, e derivou fórmulas para esse caso, apontando uma conexão entre sua natureza e os processos de dispersão ótica (por isso o nome forças de dispersão). A energia de interação derivada por London é dada por $-\frac{C_{6}}{R^{6}}$, onde $C_{6}$ é uma constante que depende da polarizabilidade e dos potenciais de ionização do átomo ou molécula. Mais uma vez, a interação de dispersão é uma explícita manisfestação do efeito de correlação eletrônica, não local, e é fundamental na interação entre sistemas apolares. Todos os seus termos estão contidos na equação de Schrödinger e, assim, em toda solução exata dessa equação. A necessidade de se adotar aproximações no problema de muitos corpos dificulta a obtenção exata da interação de van der Waals. A solução exata da teoria do funcional da densidade certamente contém esta interação.

\subsubsection{Correção na energia total}

As interações de van der Waals são computadas usando a correção empírica de Grimme [34, 61]. Neste método (DFT-D2)[62], a energia total do sistema

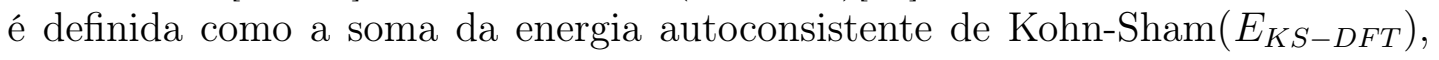
obtida de acordo com o funcional da densidade escolhido, e a correção empírica $\left(E_{\text {disp }}\right)$,

$$
E_{D F T-D 2}=E_{K S-D F T}+E_{d i s p},
$$

e a energia de dispersão é dada por,

$$
E_{\text {disp }}=-s_{6} \sum_{i=1}^{N_{a t}-1} \sum_{j=i+1}^{N_{a t}} \frac{C_{6}^{i j}}{R_{i j}^{6}} f_{d a m p}\left(R_{i j}\right),
$$


onde, $N_{a t}$ é o número de átomos do sistema, $C_{6}^{i j}$ é o coeficiente de dispersão para o par de átomos $i j, s_{6}$ é um fator de escala global que depende somente do funcional da densidade escolhido, e $R_{i j}$ é a distância interatômica. Para evitar singularidades quando $R$ se torna pequeno, usa-se uma função de amortecimento,

$$
f_{\text {damp }}\left(R_{i j}\right)=\frac{1}{1+e^{-d\left(\frac{R_{i j}}{R_{r}}-1\right)}},
$$

onde $R_{r}$ é a soma dos raios de (vdW) atômicos, $d$ é um parâmetro de distância que confere maiores correções em distâncias intermediárias (parâmetro de amortecimento)[34, 61].

Os valores de $R_{0}$ e $C_{6}$ para os elementos $\mathrm{Ag}$ e $\mathrm{Au}$, utilizados neste trabalho [61], estão na tabela 1.1. O valor do parâmetro de amortecimento $d$ usado foi de $20 \AA$, que é o default do programa de simulação utilizado [62]. Já o valor do fator de escala usado foi de $0,75 \AA$, que é o indicado para o funcional da densidade utilizado(GGA-PW91). Este valor também é o default do programa VASP[62]. Há ainda, um outro parâmetro usado nos cálculos[62], a saber, que é o raio de corte do par de interações. O valor usado nos cálculos, que é o default do programa foi de $30 \AA$.

As interações de dispersão tem despertado grande interesse em estudos de adsorção em superfície [63, 64, 65]. A adsorção física ou fisissorção, é melhor descrita quando se inclui a interação de (vdW)[66]. Como nas adsorções em superfícies a fisissorção é importante, a inclusão desta interação deve melhorar os resultados nos processos de adsorção [34, 38, 61, 63, 65].

Tabela 1.1: Parâmetros $C_{6}\left(\mathrm{em} J n m^{6} \mathrm{~mol}^{-1}\right)$ e raio de van der Waals $\left(R_{0}\right)$ (em A) da prata $(A g)$ e do ouro $(A u)$.

\begin{tabular}{ccc}
\hline Elemento & $\mathrm{R}_{0}$ & $\mathrm{C}_{6}$ \\
\hline $\mathrm{Ag}$ & 1,639 & 24,67 \\
$\mathrm{Au}$ & 1,772 & 40,62
\end{tabular}

\subsubsection{Esquema de supercélula}

O formalismo apresentado até aqui descreve sistemas periódicos. Entretanto, estruturas como nanopartículas, superfícies, moléculas e nanofios, que não apresentam periodicidade em uma, duas ou até mesmo em três direções, são tratadas com o esquema de supercélulas.

Nesse esquema, substituí-se a célula convencional por uma caixa contendo a estrutura de interesse com uma região de vácuo na direção, ou direções, em que 
a periodicidade foi quebrada. A imagem da supercélula é, então, reproduzida periodicamente por todo o espaço.

A função do vácuo é separar as imagens adjacentes para que as mesmas não interajam e, por isso, devem ser suficientemente grandes. Com isso, a periodicidade não é estabelecida na direção que o vácuo separa, reproduzindo os efeitos dos sistemas não periódicos.

Como uma nanopartícula não possui periodicidade em nenhuma direção, constrói-se sua supercélula com vácuo em todas as direções, conforme se nota na figura 1.4. Com uma região de vácuo suficientemente grande, despreza-se as interações da nanopartícula com suas imagens considerando-a isolada. Em nossos cálculos, modelamos as nanopartículas em supercélulas com regiões de vácuo com pelo menos $10 \AA$.
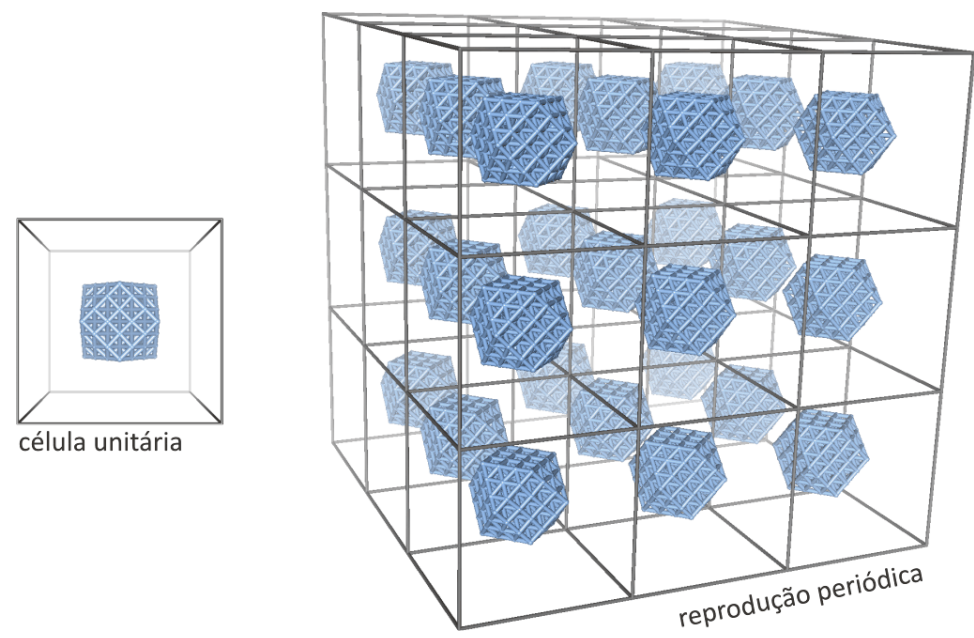

Figura 1.4: Esquema da supercélula para uma nanopartícula com vácuo por todo o entorno. À esquerda, a supercélula que é reproduzida periodicamente e à direita a reprodução de todas as imagens adjacentes à supercélula no centro. Reprodução autorizada por [1].

\subsubsection{Pacote de simulação Vienna Ab-initio -VASP}

O formalismo apresentado está implementado no pacote de simulação Vienna Ab-initio (VASP-"Vienna Ab-initio Simulation Package") [54, 62], desenvolvido para realizar simulações de dinâmica molecular quântica de primeiros princípios utilizando a teoria do funcional da densidade. Neste trabalho utilizamos a versão 5.3 .2 . 


\section{Capítulo 2}

\section{Construção das nanopartículas}

Apresentaremos, neste capítulo, as nanopartículas de prata e ouro estudadas, bem como as suas core-shell em suas formas não relaxadas estruturalmente e os processos de construção. Na literatura, as nanopartículas metálicas se apresentam em diferentes formatos e tamanhos. Podem ser tridimensionais, semelhantes a esferas, cubos, octaedros, dodecaedros entre outros poliedros [67, 68, 69], ou bidimensionais, semelhantes a triângulos, quadrados e outros polígonos [70, 71]. Apesar de muitos estudos sugerirem qual seria a estrutura mais estável para determinado número de átomos $[72,73,74,75,76]$, outros trabalhos observam que tanto o formato como o empacotamento podem ser induzidos pelo método de crescimento utilizado em sua síntese [67, 77, 78, 79, 80, 81]. Em decorrência da ligação metálica, os átomos têm liberdade para se arranjarem em um empilhamento compacto, apresentando um grande número de primeiros vizinhos e alta densidade. Por isso, os metais geralmente se cristalizam na estrutura cúbica de face centrada $(\mathrm{CFC})$ ou hexagonal compacta $(\mathrm{HCP})$, conforme figura 2.1, apresentando um fator de empacotamento de 0,74 com 12 primeiros vizinhos [82]. Nos cristais de prata e de ouro, os átomos se arranjam na configuração CFC, sendo esperado que os mesmos, nas nanopartículas maiores, se aproximem desta configuração. Por outro lado, para os pequenos aglomerados, não existe a restrição da periodicidade cristalina, possibilitando outras formas de agrupamentos. Estes agrupamentos podem ser simétricos, como nas estruturas icosaédricas, correspondendo a sólidos regulares, ou não apresentar simetria bem definida [83]. Os aglomerados sem simetria definida ocorrem pela agregação dos átomos em estruturas sem ordenamento claro, ou ainda, pela formação de estruturas com uma variedade de simetrias locais distintas na mesma nanopartícula.

Neste trabalho, estudamos apenas as estruturas simétricas cubo-octaédricas (c-oct) derivadas de cortes da estrutura cristalina CFC não relaxada, considerando os resultados experimentais indicando a maior probabilidade de formação dessas estruturas $[84,85,86]$. Utilizaremos o termo nanopartícula de modo ge- 

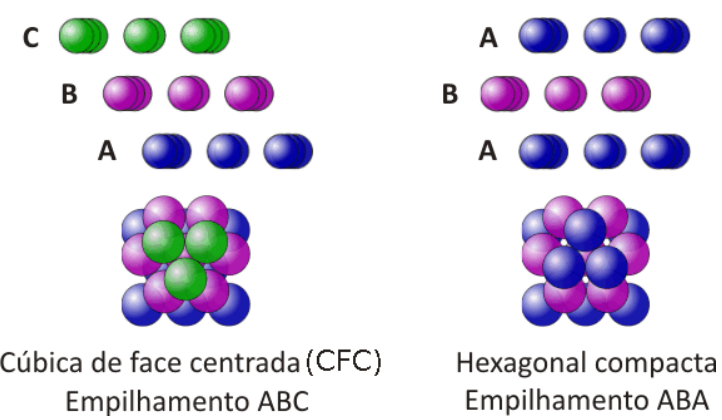

Figura 2.1: Representação do empilhamento dos átomos das estruturas cristalinas CFC e HCP. Figura repruduzida de Christopher Dang Ngoc Chan (http://e.wikipedia.org/wiki/File:Empilementcompact.svg).

nérico para representar qualquer uma das estruturas cubo-octaédricas, independente do tamanho. Os sólidos poliédricos regulares estão representados na figura 2.2 .

(a)

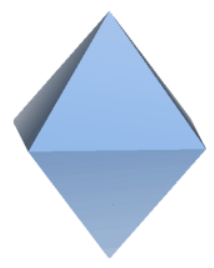

(b)

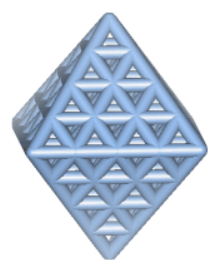

oct
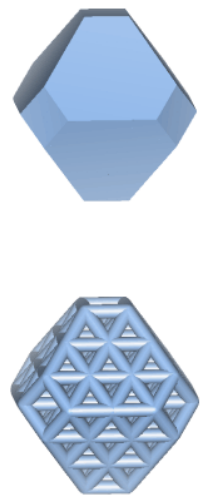

t-oct
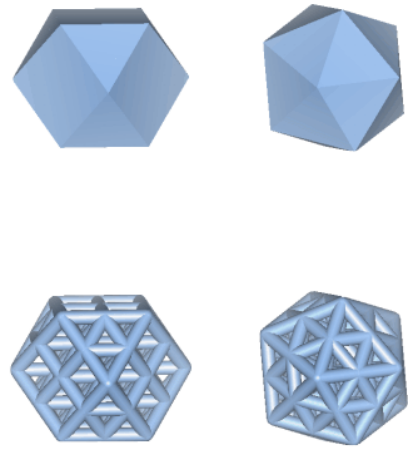

c-oct

ico

Figura 2.2: Representação dos sólidos regulares (a): octaedro(oct), octaedro truncado(t-oct), cubo-octaedro(c-oct) e icosaedro(ico); b) Exemplos de arranjos atômicos em nanopartículas com as simetrias correspondentes. Reprodução autorizada por [1].

Na figura 2.3 identifica-se a nanopartícula cubo-octaédrica com 309 átomos, uma das estudadas neste trabalho. Tal é compatível com a imagem de uma nanopartícula de prata obtida por microscopia eletrônica de alta resolução (HREM "High Resolution Electron Microscopy") [87], justificando, dessa maneira, a escolha do método de construção empregado. A nanopartícula apresenta claramente a família de planos [110] da rede cristalina CFC. Os átomos de prata e de ouro, na estrutura cristalina CFC, apresentam 12 primeiros vizinhos, ou seja, número 
de coordenação 12. Nas superfícies das nanopartículas (c-oct) os átomos podem apresentar sítios não equivalentes com coordenação entre 5 e 9 , devido aos cortes que reduzem a primeira vizinhança dos átomos da superfície. Consideramos como átomos de superfície aqueles que não apresentam a coordenação 12 do cristal. Por simplicidade, um sítio de coordenação 5, por exemplo, será identificado como "sítio $c 5$ " ou apenas $c 5$. A figura 2.4 apresenta os sítios não equivalentes presentes nas superfícies das nanopartículas (c-oct) estudadas e, também, os presentes em outros formatos poliédricos, visando a comparação.

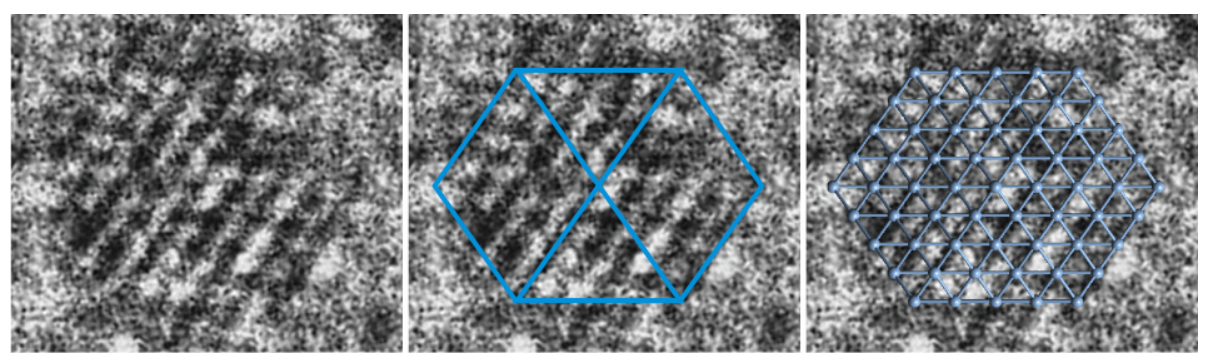

Figura 2.3: Comparação entre a nanopartícula cubo-octaédrica com 309 átomos estudada e uma imagem obtida por HREM [87]. As linhas azuis, sobrepostas à imagem na nanopartícula no centro, representam as silhuetas da nanopartícula 309. Estas silhuetas correspondem às arestas que separam os planos [111] e [001] presentes na superfícies desta nanopartícula. Na figura à direita, tem-se s representação dos átomos e ligações desta nanopartícula 309 sobreposta à mesma imagem HREM.

\subsection{Nanopartículas poliédricas}

Uma propriedade das nanopartículas poliédricas é a baixa rugosidade de suas superfícies, compostas por planos de átomos semelhantes às superfícies [001] e [111]. As superfícies das nanopartículas poliédricas não apresentam degraus ou vales e são caracterizadas por possuírem 3 ou 4 sítios distintos decorrentes dos vértices, arestas e planos presentes nas mesmas. Os átomos nos vértices das nanopartículas poliédricas apresentam coordenação $c 4$ para as nanopartículas octaédricas oct, $c 5$ para as c-oct ou $c 6$ para as octaédricas truncadas-(t-oct) e icosaédricas (ico). Os átomos das arestas apresentam coordenação $c 7$ para as nanopartículas oct, c-oct e t-oct, ou $c 8$ para as ico. Os átomos das superfícies podem apresentar coordenação $c 8$ para as nanopartículas oct, c-oct e t-oct, que é semelhante à coordenação presente no corte da superfície [001] dos cristais de prata e ouro, e $c 9$ para todas as nanopartículas poliédricas, que, por sua vez, é semelhante ao sítio 


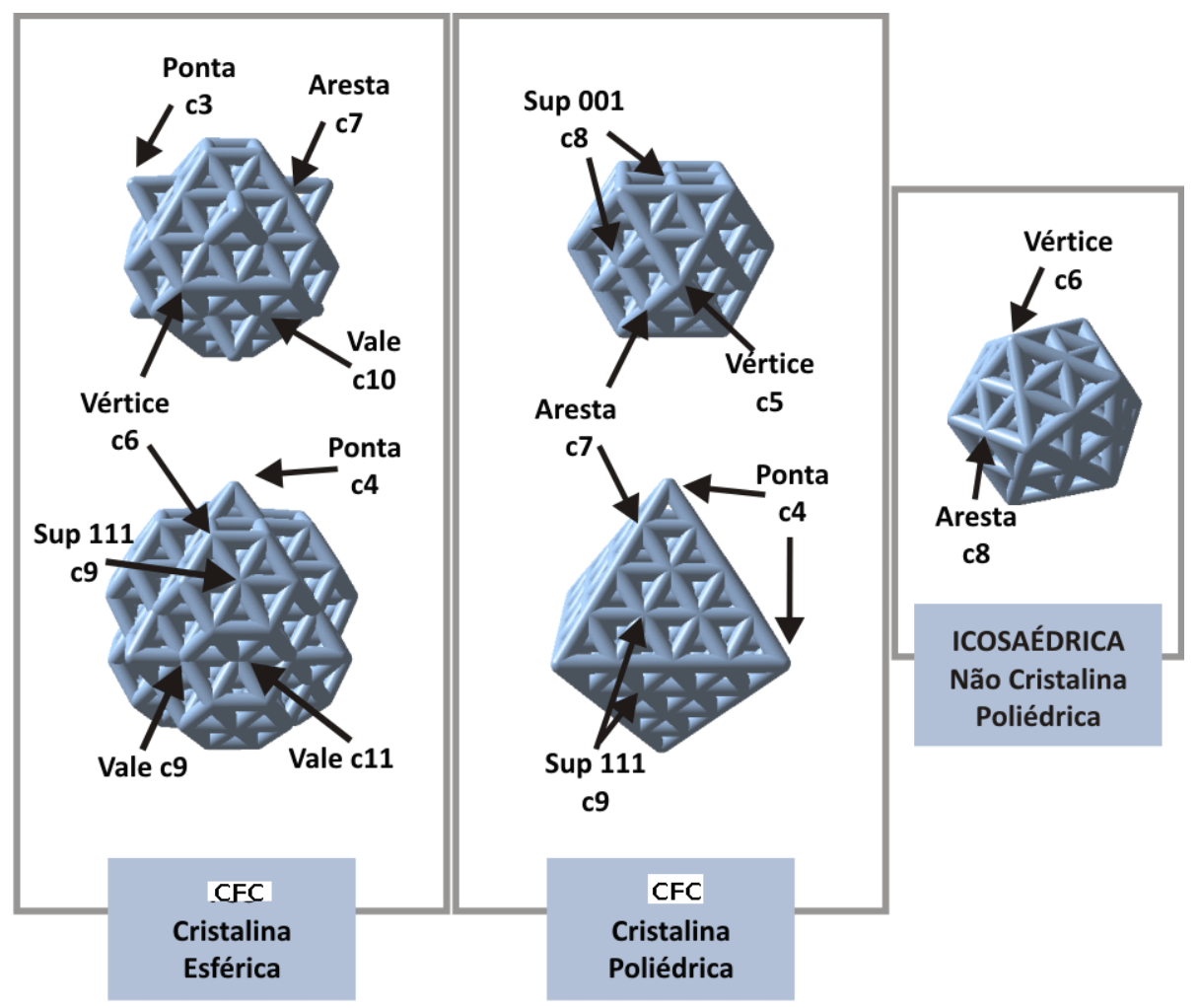

Figura 2.4: Representação dos diferentes sítios presentes nas nanopartículas baseadas nas estrutras CFC e icosaédrica. Reprodução autorizada por [1].

presente na superfície [111] da prata e do ouro. Todos estes sítios estão representados na figura 2.4. Os sítios $c 6$ e $c 7$ da nanopartícula octaédrica truncada são equivalentes àqueles indicados nas nanopartículas CFC esféricas da figura $2.4 \mathrm{Os}$ sítios $c 8$ e c9 são equivalentes àqueles indicados nas nanopartículas CFC poliédricas na mesma figura 2.4. Os sítios $c 4$ possuem todos os seus primeiros vizinhos na superfície da nanopartícula, enquanto que os sítios $c 5$ e $c 6$ apresentam um vizinho no interior e os demais vizinhos na superfície. Os sítios $c 7$ estão presentes nas arestas da junção das duas superfícies [001] e [111]. Podem se formar do encontro de duas superfícies [111], apresentando um sítio vizinho no interior e os outros seis vizinhos na superfície, ou podem se formar do encontro da superfície [111] com a superfície [001], apresentando dois vizinhos no interior e os outros cinco na superfície. Os sítios $c 8$ presentes nas arestas das nanopartículas icosaédricas apresentam dois vizinhos no interior e seis na superfície. Já os sítios $c 8$ presentes nas superfícies [001] das nanopartículas derivadas da estrutura CFC apresentam quatro vizinhos no interior da nanopartícula e os outros quatro na superfície. Os sítios $c 9$, por sua vez, possuem três vizinhos no interior da nanopartícula 
e os outros seis na superfície. Como as nanopartículas poliédricas crescem por camadas, cobrindo por completo com uma camada de átomos a nanopartícula anterior de mesmo formato, também podem ser identificadas pelo número de camadas utilizadas na construção. Como as menores nanopartículas, com apenas uma ou duas camadas de átomos utilizadas na construção, não apresentam todos os átomos distintos característicos do seu formato nas nanopartículas maiores, infere-se que estas nanopartículas não representam estruturalmente as nanopartículas maiores. Entretanto, incluíndo mais uma ou duas camadas, as superfícies dessas nanopartículas já apresentam todos os sítios distintos característicos do seu formato. Desse modo, com poucas camadas, se aproximam estruturalmente das nanopartículas maiores com o mesmo formato.

\subsubsection{Nanopartículas cubo-octaédricas}

As nanopartículas cubo-octaédricas (c-oct) são construídas ao redor de um átomo central da rede cristalina $\mathrm{CFC}$ da prata ou do ouro, e apresentam, na superfície, 12 vértices, 24 arestas, 06 superfícies quadradas tipo [001] e 8 superfícies triangulares tipo [111], respectivamente com os sítios $c 5, c 7, c 8$ e $c 9$. De acordo com a evolução dos sítios, representada na figura 2.5, observamos que os sítios $c 8$ e $c 9$ são predominantes para as nanopartículas maiores, devido ao crescimento quadrático das superfícies [001] e [111], com maior presença do sítio c8. A partir da terceira camada de átomos utilizada na construção, a superfície já apresenta todos os sítios característicos das nanopartículas c-oct.

As nanopartículas c-oct estudadas foram construídas considerando até a sexta camada de átomos e estão representadas na figura 2.8.

\subsubsection{Comparação entre as nanopartículas poliédricas}

Uma propriedade relevante das nanopartículas é a fração significativa de átomos na superfície em relação ao total de átomos. Na figura 2.6 apresentamos a evolução da fração de átomos na superfície para as nanopartículas nos formatos octaédricos com total de átomos ímpares e pares(oct-(i e p)), t-oct, c-oct e ico relativamente ao diâmetro das nanopartículas. Para diâmetros até $2,5 \mathrm{~nm}$, a superfície corresponde a mais que $70 \%$ do total de átomos. Ao redor de 5,0 nm essa fração ainda é representativa correspondendo a cerca de $30 \%$ à $40 \%$ do total de átomos. Próximo de um diâmetro de $25 \mathrm{~nm}$ a superfície já é bem menos representativa correspondendo a menos que $10 \%$ do total. Para as nanopartículas com aproximadamente $100 \mathrm{~nm}$, correspondente à transição entre as escalas nanométrica e micrométrica, os átomos da superfície correspondem à $2 \%$ do total. Como se pode observar para as nanopartículas octaédricas, a fração de átomos na superfície em relação ao total é levemente superior comparado com as demais. Por 


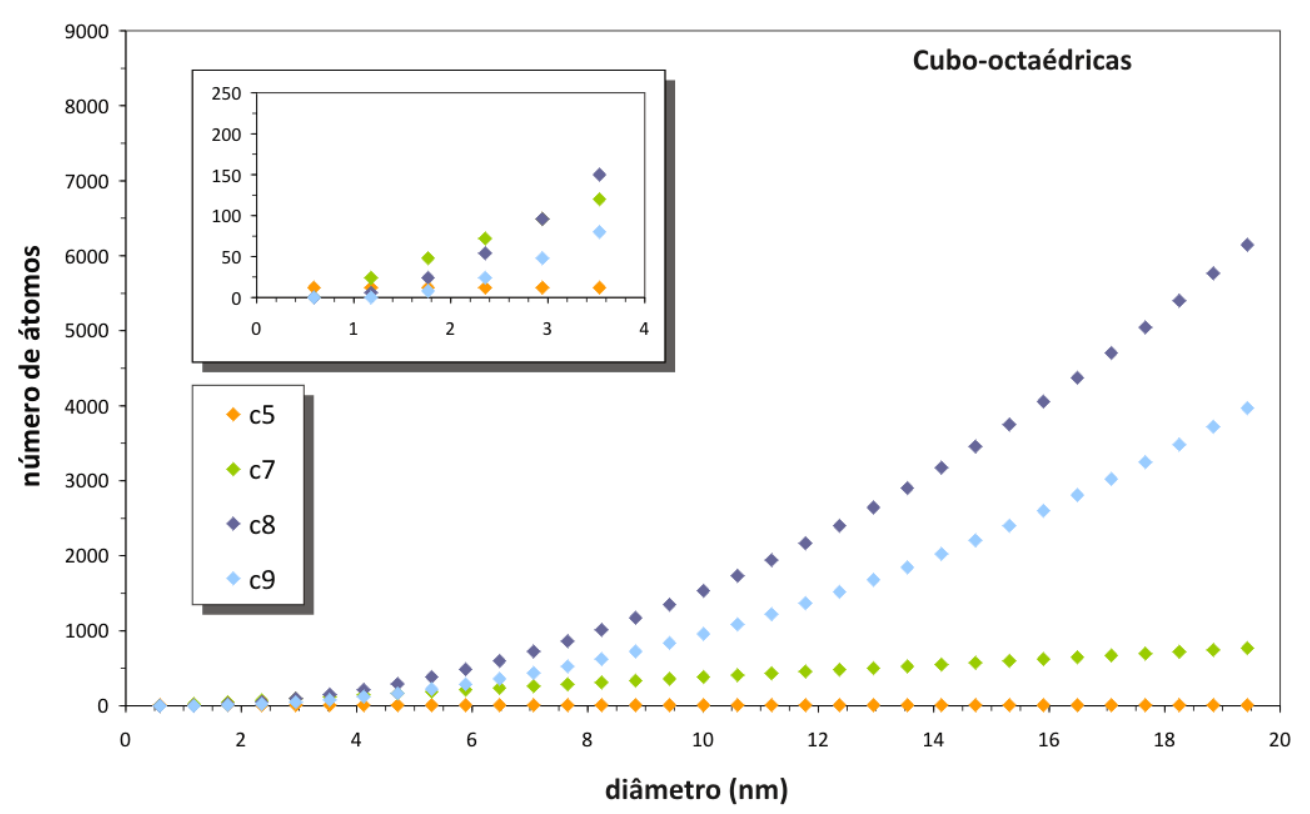

Figura 2.5: Evolução dos diferentes sítios presentes na superfície das nanopartículas cubo-octaédricas. Reprodução autorizada por [1].

outro lado, como pode ser observado na figura 2.7, a superfície total das nanopartículas octaédricas é menor em relação aos outros formatos de nanopartículas com o mesmo diâmetro. Resumindo, podemos observar, pelas figuras 2.6 e 2.7, a equivalência estrutural entre as nanopartículas-oct-i e nanopartículas-oct-p, bem como a proximidade estrutural entre as nanopartículas c-oct e t-oct.

\subsection{Nanopartículas puras e core-shell de prata e de ouro}

Das nanopartículas poliédricas existentes, estudamos aquelas com formato cubooctaédrico, constituídas pelos metais prata e ouro e também por combinações bimetálicas destes metais, formando nanoestruturas conhecidas por Core-Shell.

As nanopartículas puras são assim designadas quando as mesmas são constituídas somente de um dos metais, ouro ou prata, para os variados tamanhos construídos. Ainda, é possível dizer que estas são as nanopartículas puras de ouro ou de prata. As dimensões das nanopartículas construídas abrangem os diâmetros de 1,76 à 3,52 nm para a prata e 1,75 à 3,49 nm para o ouro incluíndo a interação de van der Waals, e 1,77 à 3,53 nm para a prata e 1,78 à 3,55 nm para o ouro não incluíndo a interação de dispersão. Considerando estes intervalos, 


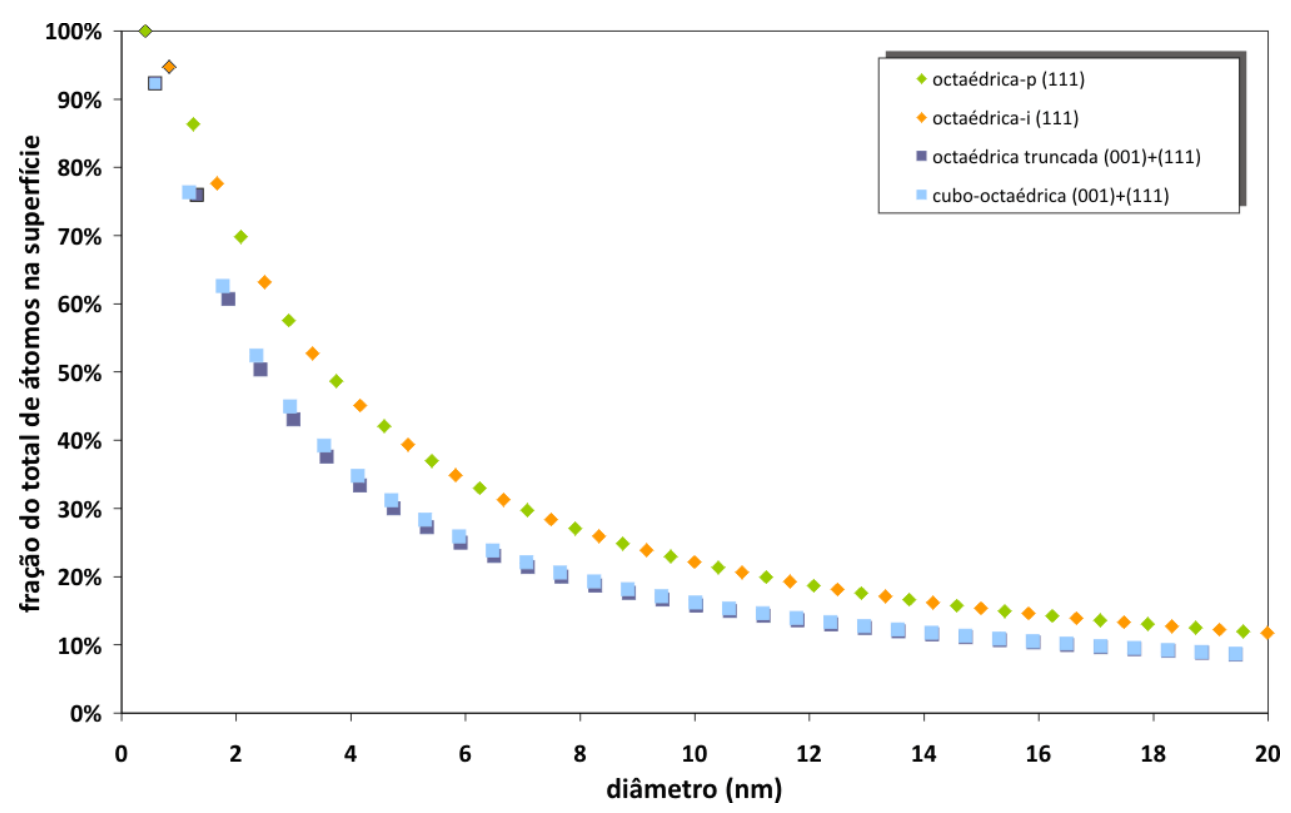

Figura 2.6: Evolução da fração de átomos na superfície em relação ao total para as nanopartículas oct (i e p), que apresentam apenas as superfícies [111], e para as nanopartículas oct e c-oct, que apresentam as superfícies [001] e [111]. Reprodução autorizada por [1].

construímos as nanopartículas contendo as seguintes quantidades de átomos de prata ou de ouro, conforme o caso, 147, 309, 561 e 923. De acordo com [2], as nanopartículas metálicas com cerca 150 átomos apresentam um regime de transição entre as características molecular e cristalina, e, nas maiores, acentua-se o caráter cristalino na nanoestrutura. Assim, as nanopartículas maiores são obtidas da estrutura com 147 átomos, pelo acréscimo de uma, duas e três camadas, obtendo, respectivamente, as nanoestruturas com 309, 561 e 923 átomos. Nesse sentido, a nanopartícula com 147 átomos possui 3 camadas de átomos, com um átomo central e mais 12 envolvendo-o, e, assim, formando a primeira camada; a segunda camada de átomos possui 42 átomos envolvendo os 13 da primeira resultando em 55 átomos e, adicionando mais 92 átomos, envolvendo os da segunda, tem-se a terceira. Seguindo esse processo, a nanopartícula com 309 átomos possui 4 camadas de átomos, a 561 tem 5 camadas e, finalmente, a nanopartícula 923, com 6 camadas de átomos, conforme a figura 2.8 .

Considerando as nanopartículas bimetálicas constituídas por prata e ouro, as core-shell, figuras 2.9 e 2.10, o processo de construção delas é similar ao das nanopartículas puras, com exceção das composições das camadas. Seja $k$ o número total de camadas da core-shell, se $n$ for a quantidade de camadas de um tipo de átomos e m quantidade do outro tipo, teremos $k=n+m$. A quantidade de 


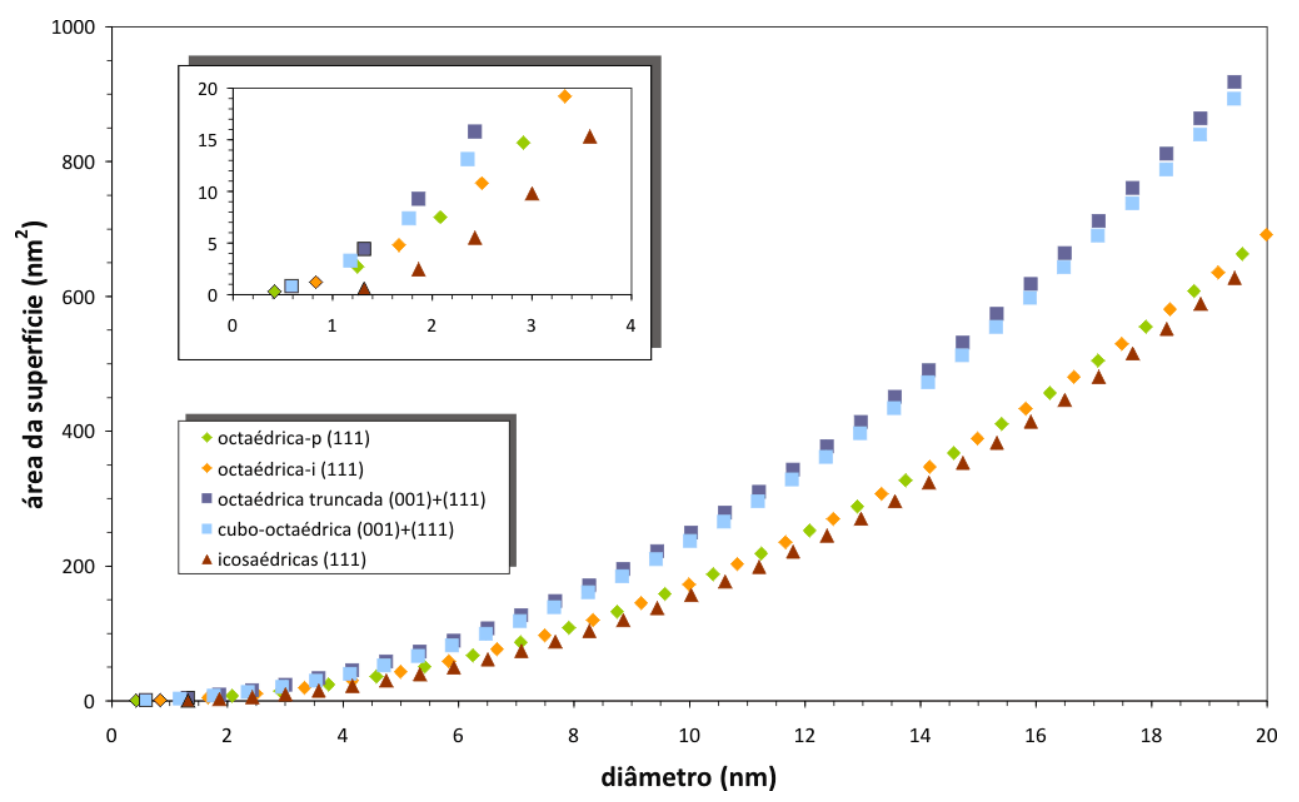

Figura 2.7: Evolução da área total da superfície para as nanopartículas oct (i e p), que apresenta apenas as superf[icies [111], e para as nanopartículas t-oct e c-oct, que apresentam as superfícies [001] e [111]. Reprodução autorizada por [1].

camada(s) mais interna(s) é (são) o core e as externas em relação a anterior é (são) o shell. Evidentemente, as camadas do core contém o átomo central e as camadas de shell contém a superfície da nanopartícula. Em nosso trabalho, os possíveis valores de $k$ são $3,4,5$ e 6 . Assim, excluíndo os valores $n=0$ e $m=0$, pois correspondem as nanopartículas puras, os possíveis valores das quantidades de camadas, internas e externas, respectivamente, para, por exemplo, $k=3$, são $n=2$ ou $n=1$ paras as camadas internas, e $m=1$ e $m=2$ para as camadas externas. Para o caso $m=2$ e $n=1$, tem-se uma core-shell com 2 camadas de core de um elemento e 1 camada de shell do outro tipo de átomo, tem-se, por exemplo, 2 camadas internas (core) de prata (ouro)e 1 camada externa (shell) de ouro (prata). Na convenção, usa-se a seguinte notação shell@core. Assim, no caso exemplificado, tem-se, 1Ag@2Au ou 1Au@2Ag para os casos entre parênteses.

Na figura 2.10, está representada, em corte, uma nanopartícula c-oct coreshell, com o total de 561 átomos, sendo duas camadas internas, o core, com 55 átomos de ouro $(\mathrm{Au})$ e três camadas externas, o shell, com 506 átomos de prata (Ag). Na representação shell@core, tem-se 3Ag@2Au. 


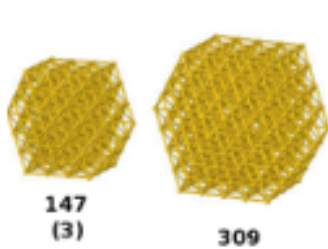

(4)

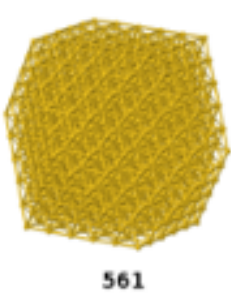

(5)

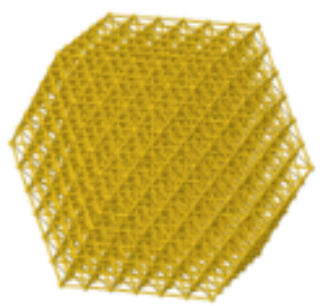

923
$(6)$

Figura 2.8: Representação de algumas das nanopartículas cubo-octaédricas puras de ouro estudadas, com o número total de átomos e, entre parênteses, o número de camadas utilizadas na construção.
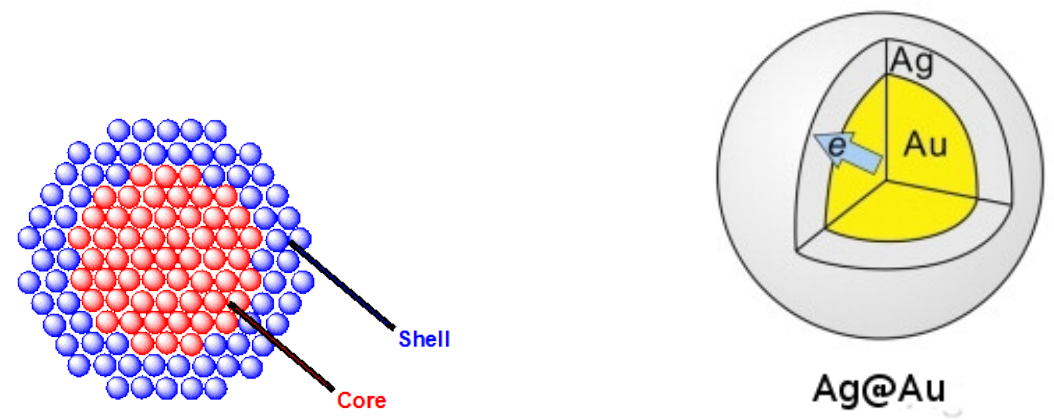

Figura 2.9: Representação genérica de uma nanopartícula discriminando caroço e shell.
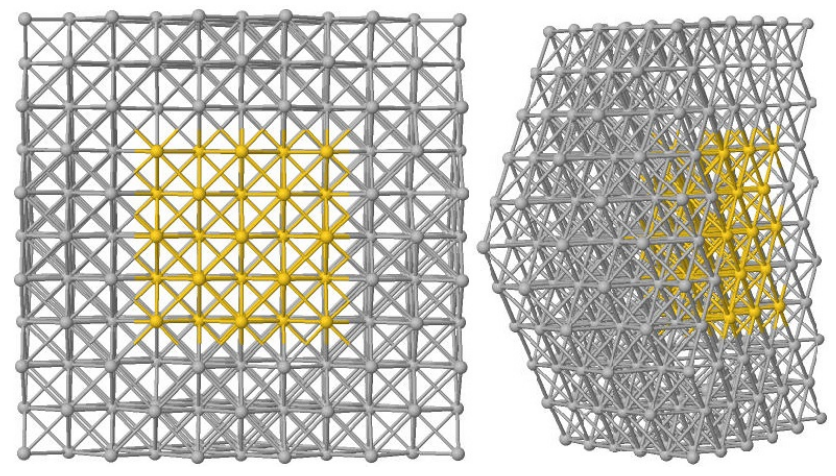

Figura 2.10: Representação em corte de uma nanopartícula c-oct core-shell com 561 átomos com 2 camadas internas (caroço) de átomos de ouro (Au) e 3 camadas externas (shell) de átomos de prata $(\mathrm{Ag})$. 


\section{Capítulo 3}

\section{Resultados e Discussão das nanopartículas puras e core-shell}

Estudamos as nanopartículas, puras de ouro e prata bem como as core-shell, a fim de analisar os efeitos decorrentes do recobrimento de camadas de ouro sobre as de prata e as de prata sobre as de ouro [11, 88, 89, 90]. O ouro é um catalisador melhor do que a prata [11, 90, 91, 92], enquanto a prata possui propriedades satisfatórias como agente bactericida, por um lado, mas, por outro, possui alta toxicidade mesmo em pequenas quantidades [93, 94, 95, 96]. Em trabalho anterior, Kiss [1] abordou as principais propriedades das nanopartículas puras de prata, em variados formatos, com até 561 átomos. Aqui estudamos as nanopartículas livres e core-shell de prata e de ouro com até 923 átomos, analisando as propriedades estruturais, energéticas e eletrônicas, das core-shell em comparação com a evolução das dimensões destas estruturas [92, 97, 98]. Adicionalmente, analisaremos os efeitos da interação de van der Waals nestas estruturas.

As nanopartículas estudadas foram construídas no formato cubo-octaédrico, pois este é observado experimentalmente [84, 85, 86], conforme descrito no capítulo 2, com número total de átomos variando de 147 à 923. As simulações, tanto das nanopartículas puras quanto das core-shell, foram realizadas dentro do formalismo apresentado no capítulo 1, com o intuíto de se obter a estrutura mais estável em cada umas das situações. Cada sistema foi relaxado até que a diferença na energia total entre dois ciclos autoconsistentes fosse menor do que 0,001 $\mathrm{eV}$ e até que as forças entre os íons fossem menores do que $0,01 \mathrm{eV} / \AA$. A energia de corte utilizada para os coeficientes da expansão das ondas planas foi de 290 $\mathrm{eV}$. Estas nanopartículas foram relaxadas fixando o átomo central somente.

No apêndice B há vários resultados preliminares de estruturas de prata e de ouro obtidos por meio do formalismo do funcional da densidade e dinâmica molecular quântica no programa VASP, apresentando as propriedades dos cristais 
e das superfícies livres [001] e [111] da prata e do ouro, ambos na estrutura CFC. Os resultados das superfícies são importantes porque as nanopartículas c-oct apresentam em suas superfícies os planos [001] e [111].

\subsection{Propriedades estruturais das nanopartículas puras e core-shell}

Para efetuar a análise das mudanças estruturais das nanopartículas puras e das core-shell, examinaremos o que acontece com o sítio de coordenação c5, com os planos [001] e [111] e as arestas que estão na junção desses planos. Estas estruturas contém todos os sítios de coordenação das superfícies das nanopartículas citadas.

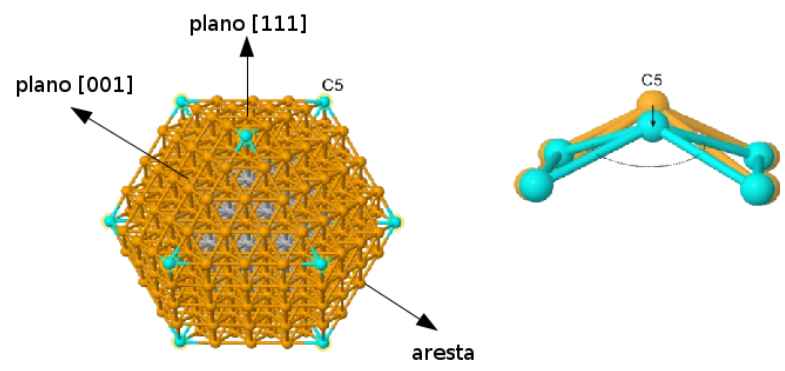

Figura 3.1: Representação do sítio de coordenação c5, dos planos [001] e [111] e da aresta entre eles, presentes nas nanopartículas e do ângulo total entre as ligações do sítio c5 e seus vizinhos.

O sítio de coordenação c5 possui 4 (quatro) íons vizinhos na superfície da nanopartícula. Suas ligações com eles formam ângulos que, na estrutura não relaxada (ideal), somados tem $300^{\circ}$. Analisaremos como este ângulo evolui com o aumento das nanopartículas bem como a distância do sítio c5 ao átomo central, que permanece fixo durante a relaxação estrutural, definindo um caráter mais ou menos esférico da nanopartícula, na condição de equilíbrio. A figura 3.1 representa a variação que ocorre com o sítio c5 e sua vizinhança. Na mesma figura, tem-se a representação de uma nanopartícula, indicando-se os planos [001] e [111] e a aresta entre estes planos. As tabelas 3.1, 3.2, 3.3 e 3.4 apresentam os valores 
Tabela 3.1: Valores médios dos deslocamentos, em Angstrons, A, dos átomos no sítio c5, dos átomos dos planos [001] e [111], dos átomos da aresta entre estes planos, do ângulo total das ligações do sítio c5 em graus, ’, das superfícies das nanopartículas puras e core-shell com 147 átomos.

\begin{tabular}{|c|c|c|c|c|c|c|c|c|c|c|}
\hline \multirow{2}{*}{$\begin{array}{c}147 \\
\text { shell@core }\end{array}$} & \multicolumn{2}{|c|}{$\hat{\text { Angulos }}\left({ }^{\circ}\right)$} & \multicolumn{2}{|c|}{$\mathrm{c} 5(\AA)$} & \multicolumn{2}{|c|}{$[001](\AA)$} & \multicolumn{2}{|c|}{$[111](\AA)$} & \multicolumn{2}{|c|}{ Aresta $(\AA)$} \\
\hline & cvdW & svdW & cvdW & svdW & cvdW & svdW & cvdW & svdW & cvdW & svdW \\
\hline \multirow[t]{2}{*}{$3 \mathrm{Ag}$} & 305,5 & 304,8 & $-0,21$ & $-0,02$ & $+0,09$ & $+0,09$ & $+0,03$ & $+0,09$ & $-0,03$ & $-0,02$ \\
\hline & $+1,8 \%$ & $+1,6 \%$ & $-2,4 \%$ & $-0,2 \%$ & $+1,4 \%$ & $+1,4 \%$ & $+0,4 \%$ & $+1,3 \%$ & $-0,4 \%$ & $-0,3 \%$ \\
\hline \multirow[t]{2}{*}{$1 \mathrm{Au} @ 2 \mathrm{Ag}$} & 312,6 & 310,6 & $-0,21$ & $-0,05$ & $+0,07$ & $+0,09$ & 0,00 & $+0,09$ & $-0,19$ & $-0,12$ \\
\hline & $+4,2 \%$ & $+3,5 \%$ & $-2,4 \%$ & $-0,6 \%$ & $+1,1 \%$ & $+1,4 \%$ & $0,0 \%$ & $+1,3 \%$ & $-2,5 \%$ & $-1,6 \%$ \\
\hline \multirow[t]{2}{*}{$2 \mathrm{Au} @ 1 \mathrm{Ag}$} & 309,7 & 305,0 & $-0,23$ & $-0,06$ & $+0,06$ & $+0,05$ & $+0,04$ & $+0,10$ & $-0,19$ & $-0,12$ \\
\hline & $+3,2 \%$ & $+1,7 \%$ & $-2,6 \%$ & $-0,7 \%$ & $+1,0 \%$ & $+0,8 \%$ & $+0,6 \%$ & $+1,4 \%$ & $-2,5 \%$ & $-1,6 \%$ \\
\hline \multirow[t]{2}{*}{$3 \mathrm{Au}$} & 309,7 & 309,9 & $-0,07$ & $-0,05$ & $+0,26$ & 0,00 & $+0,03$ & $-0,06$ & $-0,14$ & $-0,13$ \\
\hline & $+3,2 \%$ & $+3,3 \%$ & $-0,8 \%$ & $-0,6 \%$ & $+3,9 \%$ & $0,0 \%$ & $+0,4 \%$ & $-0,8 \%$ & $-1,8 \%$ & $-1,7 \%$ \\
\hline \multirow[t]{2}{*}{$1 \mathrm{Ag} @ 2 \mathrm{Au}$} & 303,2 & 303,9 & $-0,05$ & $-0,13$ & $+0,19$ & $+0,08$ & $-0,05$ & $-0,14$ & $-0,10$ & $-0,23$ \\
\hline & $+1,1 \%$ & $+1,3 \%$ & $-0,6 \%$ & $-1,5 \%$ & $+2,9 \%$ & $+1,2 \%$ & $-0,7 \%$ & $-1,9 \%$ & $-1,3 \%$ & $-2,9 \%$ \\
\hline \multirow[t]{2}{*}{$2 \mathrm{Ag} @ 1 \mathrm{Au}$} & 305,8 & 305,0 & $-0,16$ & $-0,26$ & $+0,25$ & $+0,09$ & $+0,02$ & $-0,07$ & $-0,08$ & $-0,20$ \\
\hline & $+1,9 \%$ & $+1,7 \%$ & $-1,8 \%$ & $-2,9 \%$ & $+3,8 \%$ & $+1,4 \%$ & $+0,3 \%$ & $-1,0 \%$ & $-1,0 \%$ & $-2,6 \%$ \\
\hline \multirow[t]{2}{*}{$3 \mathrm{Ag}$} & 305,5 & 304,8 & $-0,21$ & $-0,02$ & $+0,09$ & $+0,09$ & $+0,03$ & $+0,09$ & $-0,03$ & $-0,02$ \\
\hline & $+1,8 \%$ & $+1,6 \%$ & $-2,4 \%$ & $-0,2 \%$ & $+1,4 \%$ & $+1,4 \%$ & $+0,4 \%$ & $-1,3 \%$ & $-0,4 \%$ & $-0,3 \%$ \\
\hline
\end{tabular}

médios dos valores obtidos para os ângulos entre o sítio c5 e seus vizinhos, a distância do sítio c5 ao átomo central, os valores médios das variações das distâncias dos átomos dos planos [001] e [111] ao átomo central e também valores médios das distâncias dos átomos pertencentes a aresta entre os planos citados e o mesmo átomo central. Os valores são apresentados com e sem interação de van der Waals. Nessas tabelas, os números que aparecem nas shell@core (nomenclatura das core-shell) representam o número de camadas, assim, em 3Au@2Ag teremos uma core-shell com 3 camadas de shell de Au e 2 camadas de caroço de Ag.

Analisando os dados dessas tabelas, notamos que as maiores contrações ocorrem com o sítio de coordenação c5 e seguem o mesmo padrão de contração aumentando com o tamanho da nanopartícula, tanto considerando nos cálculos a interação de van der Waals quanto sem considerá-la. Esse padrão é praticamente o mesmo nas nanopartículas puras quanto nas core-shell. As maiores contrações do sítio c5 nas core-shell acontecem naquelas formadas com shell de Au e caroço (core) de Ag, sendo maior nas nanopartículas maiores (561 e 923 átomos no total). Esse comportamento é o mesmo com ou sem a interação de van der Waals. As contrações do sítio c5 nas core-shell com shell de Au são maiores do que as 
Tabela 3.2: Valores médios dos deslocamentos, em Angstrons, A, dos átomos no sítio c5, dos átomos dos planos [001] e [111], dos átomos da aresta entre estes planos, do ângulo total das ligações do sítio c5 em graus, ’, das superfícies das nanopartículas puras e core-shell com 309 átomos.

\begin{tabular}{|c|c|c|c|c|c|c|c|c|c|c|}
\hline \multirow{2}{*}{$\begin{array}{c}309 \\
\text { shell@core }\end{array}$} & \multicolumn{2}{|c|}{ Ângulos $\left({ }^{\circ}\right)$} & \multicolumn{2}{|c|}{$\mathrm{c} 5(\AA)$} & \multicolumn{2}{|c|}{$[001](\AA)$} & \multicolumn{2}{|c|}{$[111](\AA)$} & \multicolumn{2}{|c|}{ Aresta $(\AA)$} \\
\hline & cvdW & svdW & cvdW & svdW & cvdW & svdW & cvdW & svdW & cvdW & svdW \\
\hline \multirow[t]{2}{*}{$4 \mathrm{Ag}$} & 306,3 & 305,4 & $-0,25$ & $-0,23$ & $-0,05$ & $-0,03$ & $-0,12$ & $-0,03$ & $-0,24$ & $-0,13$ \\
\hline & $+2,1 \%$ & $+1,8 \%$ & $-2,1 \%$ & $-2,0 \%$ & $-0,6 \%$ & $-0,3 \%$ & $-1,2 \%$ & $-0,3 \%$ & $-2,3 \%$ & $-1,2 \%$ \\
\hline \multirow[t]{2}{*}{ 1Au@3Ag } & 312,7 & 312,4 & $-0,25$ & $-0,02$ & $-0,12$ & 0,00 & $-0,15$ & $+0,01$ & $-0,31$ & $-0,11$ \\
\hline & $+4,2 \%$ & $+4,1 \%$ & $-2,3 \%$ & $-0,2 \%$ & $-1,4 \%$ & $0,0 \%$ & $-1,5 \%$ & $+0,1 \%$ & $-3,0 \%$ & $-1,0 \%$ \\
\hline \multirow[t]{2}{*}{$2 \mathrm{Au} @ 2 \mathrm{Ag}$} & 312,5 & 312,2 & $-0,30$ & $-0,11$ & $-0,12$ & 0,00 & $-0,13$ & $+0,01$ & $-0,32$ & $-0,13$ \\
\hline & $+4,2 \%$ & $+4,1 \%$ & $-2,6 \%$ & $-0,9 \%$ & $-1,4 \%$ & $0,0 \%$ & $-1,4 \%$ & $+0,1 \%$ & $-3,1 \%$ & $-1,2 \%$ \\
\hline \multirow[t]{2}{*}{$3 \mathrm{Au} @ 1 \mathrm{Ag}$} & 311,5 & 311,7 & $-0,34$ & $-0,07$ & $-0,13$ & 0,00 & $-0,13$ & $+0,03$ & $-0,33$ & $-0,11$ \\
\hline & $+3,8 \%$ & $+3,9 \%$ & $-2,9 \%$ & $-0,6 \%$ & $-1,5 \%$ & $0,0 \%$ & $-1,4 \%$ & $+0,3 \%$ & $-3,1 \%$ & $-1,1 \%$ \\
\hline \multirow[t]{2}{*}{$4 \mathrm{Au}$} & 311,0 & 312,2 & $-0,32$ & $-0,25$ & $-0,06$ & $-0,04$ & $-0,07$ & $-0,04$ & $-0,22$ & $-0,11$ \\
\hline & $+3,7 \%$ & $+4,1 \%$ & $-2,8 \%$ & $-2,1 \%$ & $-0,7 \%$ & $-0,4 \%$ & $-0,7 \%$ & $-0,4 \%$ & $-2,2 \%$ & $-1,0 \%$ \\
\hline \multirow[t]{2}{*}{$1 \mathrm{Ag} @ 3 \mathrm{Au}$} & 304,1 & 304,6 & $-0,18$ & $-0,25$ & $+0,02$ & $-0,06$ & $-0,04$ & $-0,07$ & $-0,16$ & $-0,15$ \\
\hline & $+1,4 \%$ & $+1,5 \%$ & $-1,6 \%$ & $-2,1 \%$ & $+0,2 \%$ & $-0,7 \%$ & $-0,4 \%$ & $-0,7 \%$ & $-1,6 \%$ & $-1,4 \%$ \\
\hline \multirow[t]{2}{*}{$2 \mathrm{Ag} @ 2 \mathrm{Au}$} & 305,4 & 304,8 & $-0,18$ & $-0,29$ & $+0,02$ & $-0,06$ & $-0,04$ & $-0,09$ & $-0,17$ & $-0,13$ \\
\hline & $+1,8 \%$ & $+1,6 \%$ & $-1,6 \%$ & $-2,5 \%$ & $+0,2 \%$ & $-0,7 \%$ & $-0,4 \%$ & $-0,9 \%$ & $-1,6 \%$ & $-1,2 \%$ \\
\hline \multirow[t]{2}{*}{ 3Ag@1Au } & 306,1 & 305,2 & $-0,17$ & $-0,30$ & $+0,02$ & $-0,06$ & $+0,05$ & $-0,08$ & $-0,07$ & $-0,13$ \\
\hline & $+2,0 \%$ & $+1,7 \%$ & $-1,5 \%$ & $-2,5 \%$ & $+0,2 \%$ & $-0,7 \%$ & $+0,5 \%$ & $-0,8 \%$ & $-0,7 \%$ & $-1,2 \%$ \\
\hline \multirow[t]{2}{*}{$4 \mathrm{Ag}$} & 306,3 & 305,4 & $-0,25$ & $-0,23$ & $-0,05$ & $-0,03$ & $-0,12$ & $-0,03$ & $-0,24$ & $-0,13$ \\
\hline & $+2,1 \%$ & $+1,8 \%$ & $-2,1 \%$ & $-2,0 \%$ & $-0,6 \%$ & $-0,3 \%$ & $-1,2 \%$ & $-0,3 \%$ & $-2,3 \%$ & $-1,2 \%$ \\
\hline
\end{tabular}


Tabela 3.3: Valores médios dos deslocamentos, em Angstrons, A, dos átomos no sítio c5, dos átomos dos planos [001] e [111], dos átomos da aresta entre estes planos, do ângulo total das ligações do sítio c5 em graus, ’, das superfícies das nanopartículas puras e core-shell com 561 átomos.

\begin{tabular}{|c|c|c|c|c|c|c|c|c|c|c|}
\hline \multirow{2}{*}{$\begin{array}{c}561 \\
\text { shell@core }\end{array}$} & \multicolumn{2}{|c|}{$\hat{A} \operatorname{ngulos}\left({ }^{\circ}\right)$} & \multicolumn{2}{|c|}{$\mathrm{c} 5(\AA)$} & \multicolumn{2}{|c|}{$[001](\AA)$} & \multicolumn{2}{|c|}{$[111](\AA)$} & \multicolumn{2}{|c|}{ Aresta $(\AA)$} \\
\hline & cvdW & svdW & cvdW & svdW & cvdW & svdW & cvdW & svdW & cvdW & svdW \\
\hline \multirow[t]{2}{*}{$5 \mathrm{Ag}$} & 305,9 & 306,6 & $-0,32$ & $-0,29$ & $-0,03$ & $-0,02$ & $-0,04$ & $-0,03$ & $-0,20$ & $-0,15$ \\
\hline & $+2,0 \%$ & $+2,2 \%$ & $-2,2 \%$ & $-2,0 \%$ & $-0,3 \%$ & $-0,2 \%$ & $-0,3 \%$ & $-0,3 \%$ & $-1,5 \%$ & $-1,2 \%$ \\
\hline \multirow[t]{2}{*}{$1 \mathrm{Au} @ 4 \mathrm{Ag}$} & 311,7 & 312,4 & $-0,43$ & $-0,08$ & $-0,16$ & $+0,03$ & $-0,15$ & $+0,05$ & $-0,36$ & $-0,18$ \\
\hline & $+3,9 \%$ & $+4,1 \%$ & $-2,9 \%$ & $-0,5 \%$ & $-1,4 \%$ & $+0,3 \%$ & $-1,2 \%$ & $+0,4 \%$ & $-2,7 \%$ & $-1,3 \%$ \\
\hline \multirow[t]{2}{*}{$2 \mathrm{Au} @ 3 \mathrm{Ag}$} & 312,7 & 312,5 & $-0,45$ & $-0,16$ & $-0,15$ & $+0,03$ & $-0,15$ & $+0,05$ & $-0,37$ & $-0,18$ \\
\hline & $+4,2 \%$ & $+4,2 \%$ & $-3,1 \%$ & $-1,1 \%$ & $-1,3 \%$ & $+0,3 \%$ & $-1,2 \%$ & $+0,4 \%$ & $-2,8 \%$ & $-1,3 \%$ \\
\hline \multirow[t]{2}{*}{$3 \mathrm{Au} @ 2 \mathrm{Ag}$} & 312,0 & 312,4 & $-0,33$ & $-0,07$ & $-0,15$ & $+0,03$ & $-0,16$ & $+0,04$ & $-0,38$ & $-0,19$ \\
\hline & $+4,0 \%$ & $+4,1 \%$ & $-2,3 \%$ & $-0,5 \%$ & $-1,3 \%$ & $+0,3 \%$ & $-1,3 \%$ & $+0,3 \%$ & $-2,9 \%$ & $-1,4 \%$ \\
\hline \multirow[t]{2}{*}{$4 \mathrm{Au} @ 1 \mathrm{Ag}$} & 312,5 & 312,8 & $-0,44$ & $-0,13$ & $-0,15$ & $+0,03$ & $-0,16$ & $+0,04$ & $-0,40$ & $-0,19$ \\
\hline & $+4,2 \%$ & $+4,3 \%$ & $-3,0 \%$ & $-0,9 \%$ & $-1,3 \%$ & $+0,3 \%$ & $-1,3 \%$ & $+0,3 \%$ & $-3,1 \%$ & $-1,4 \%$ \\
\hline \multirow[t]{2}{*}{$5 \mathrm{Au}$} & 312,3 & 313,8 & $-0,43$ & $-0,42$ & $-0,05$ & $-0,03$ & $-0,03$ & $-0,01$ & $-0,27$ & $-0,26$ \\
\hline & $+4,1 \%$ & $+4,6 \%$ & $-3,0 \%$ & $-2,8 \%$ & $-0,5 \%$ & $-0,3 \%$ & $-0,2 \%$ & $-0,1 \%$ & $-2,1 \%$ & $-2,0 \%$ \\
\hline \multirow[t]{2}{*}{$1 \mathrm{Ag} @ 4 \mathrm{Au}$} & 305,2 & 306,8 & $-0,25$ & $-0,33$ & $+0,08$ & $-0,09$ & $+0,08$ & $-0,10$ & $-0,06$ & $-0,20$ \\
\hline & $+1,7 \%$ & $+2,3 \%$ & $-1,7 \%$ & $-2,2 \%$ & $+0,7 \%$ & $-0,8 \%$ & $+0,6 \%$ & $-0,8 \%$ & $-0,5 \%$ & $-1,5 \%$ \\
\hline \multirow[t]{2}{*}{$2 \mathrm{Ag} @ 3 \mathrm{Au}$} & 305,5 & 307,0 & $-0,20$ & $-0,35$ & $+0,08$ & $-0,09$ & $+0,07$ & $-0,10$ & $-0,08$ & $-0,20$ \\
\hline & $+1,8 \%$ & $+2,3 \%$ & $-1,4 \%$ & $-2,4 \%$ & $+0,7 \%$ & $-0,8 \%$ & $+0,6 \%$ & $-0,8 \%$ & $-0,6 \%$ & $-1,5 \%$ \\
\hline \multirow[t]{2}{*}{$3 \mathrm{Ag} @ 2 \mathrm{Au}$} & 307,6 & 307,1 & $-0,21$ & $-0,37$ & $+0,08$ & $-0,09$ & $+0,07$ & $-0,10$ & $-0,08$ & $-0,21$ \\
\hline & $+2,5 \%$ & $+2,4 \%$ & $-1,4 \%$ & $-2,5 \%$ & $+0,7 \%$ & $-0,8 \%$ & $+0,6 \%$ & $-0,8 \%$ & $-0,6 \%$ & $-1,6 \%$ \\
\hline \multirow[t]{2}{*}{ 4Ag@1Au } & 306,4 & 307,2 & $-0,20$ & $-0,38$ & $+0,08$ & $-0,09$ & $+0,07$ & $-0,10$ & $-0,08$ & $-0,23$ \\
\hline & $+2,1 \%$ & $+2,4 \%$ & $-1,4 \%$ & $-2,6 \%$ & $+0,7 \%$ & $-0,8 \%$ & $+0,6 \%$ & $-0,8 \%$ & $-0,6 \%$ & $-1,7 \%$ \\
\hline \multirow[t]{2}{*}{$5 \mathrm{Ag}$} & 305,9 & 306,6 & $-0,32$ & $-0,29$ & $-0,03$ & $-0,02$ & $-0,04$ & $-0,03$ & $-0,20$ & $-0,15$ \\
\hline & $+2,0 \%$ & $+2,2 \%$ & $-2,2 \%$ & $-2,0 \%$ & $-0,3 \%$ & $-0,2 \%$ & $-0,3 \%$ & $-0,3 \%$ & $-1,5 \%$ & $-1,2 \%$ \\
\hline
\end{tabular}


Tabela 3.4: Valores médios dos deslocamentos, em Angstrons, A, dos átomos no sítio c5, dos átomos dos planos [001] e [111], dos átomos da aresta entre estes planos, do ângulo total das ligações do sítio c5 em graus, ’, das superfícies das nanopartículas puras e core-shell com 923 átomos.

\begin{tabular}{|c|c|c|c|c|c|c|c|c|c|c|}
\hline \multirow{2}{*}{$\begin{array}{c}923 \\
\text { shell@core }\end{array}$} & \multicolumn{2}{|c|}{ Ângulos $\left(^{\circ}\right)$} & \multicolumn{2}{|c|}{$\mathrm{c} 5(\AA)$} & \multicolumn{2}{|c|}{$[001](\AA)$} & \multicolumn{2}{|c|}{$[111](\AA)$} & \multicolumn{2}{|c|}{ Aresta $(\AA)$} \\
\hline & cvdW & svdW & cvdW & svdW & cvdW & svdW & cvdW & svdW & cvdW & svdW \\
\hline \multirow[t]{2}{*}{$6 \mathrm{Ag}$} & 306,8 & 307,3 & $-0,31$ & $-0,27$ & $-0,07$ & $-0,03$ & $-0,20$ & $-0,01$ & $-0,26$ & $-0,12$ \\
\hline & $+2,3 \%$ & $+2,4 \%$ & $-1,8 \%$ & $-1,8 \%$ & $-0,5 \%$ & $-0,2 \%$ & $-1,4 \%$ & $-0,1 \%$ & $-1,7 \%$ & $-0,7 \%$ \\
\hline \multirow[t]{2}{*}{$1 \mathrm{Au} @ 5 \mathrm{Ag}$} & 313,5 & 313,6 & $-0,39$ & $-0,35$ & $-0,23$ & $-0,01$ & $-0,21$ & $-0,05$ & $-0,55$ & $-0,24$ \\
\hline & $+4,5 \%$ & $+4,5 \%$ & $-2,2 \%$ & $-2,0 \%$ & $-1,7 \%$ & $-0,1 \%$ & $-1,4 \%$ & $-0,3 \%$ & $-3,5 \%$ & $-1,5 \%$ \\
\hline \multirow[t]{2}{*}{$2 \mathrm{Au} @ 4 \mathrm{Ag}$} & 312,7 & 312,9 & $-0,35$ & $-0,31$ & $-0,23$ & $+0,02$ & $-0,20$ & $+0,02$ & $-0,53$ & $-0,22$ \\
\hline & $+4,2 \%$ & $+4,3 \%$ & $-2,0 \%$ & $-1,8 \%$ & $-1,7 \%$ & $+0,1 \%$ & $-1,4 \%$ & $+0,1 \%$ & $-3,4 \%$ & $-1,4 \%$ \\
\hline \multirow[t]{2}{*}{$3 \mathrm{Au} @ 3 \mathrm{Ag}$} & 313,0 & 312,6 & $-0,35$ & $-0,33$ & $-0,23$ & 0,00 & $-0,23$ & $-0,01$ & $-0,52$ & $-0,22$ \\
\hline & $+4,3 \%$ & $+4,2 \%$ & $-2,0 \%$ & $-1,9 \%$ & $-1,7 \%$ & $0,0 \%$ & $-1,5 \%$ & $-0,1 \%$ & $-3,3 \%$ & $-1,4 \%$ \\
\hline \multirow[t]{2}{*}{$4 \mathrm{Au} @ 2 \mathrm{Ag}$} & 313,0 & 312,4 & $-0,33$ & $-0,29$ & $-0,23$ & $+0,01$ & $-0,23$ & $-0,02$ & $-0,52$ & $-0,22$ \\
\hline & $+4,3 \%$ & $+4,1 \%$ & $-1,9 \%$ & $-1,6 \%$ & $-1,7 \%$ & $+0,1 \%$ & $-1,5 \%$ & $-0,1 \%$ & $-3,3 \%$ & $-1,4 \%$ \\
\hline \multirow[t]{2}{*}{$5 \mathrm{Au} @ 1 \mathrm{Ag}$} & 312,6 & 312,5 & $-0,35$ & $-0,31$ & $-0,23$ & $+0,01$ & $-0,23$ & $+0,01$ & $-0,51$ & $-0,26$ \\
\hline & $+4,2 \%$ & $+4,2 \%$ & $-2,0 \%$ & $-1,8 \%$ & $-1,7 \%$ & $+0,1 \%$ & $-1,5 \%$ & $+0,1 \%$ & $-3,3 \%$ & $-1,6 \%$ \\
\hline \multirow[t]{2}{*}{$6 \mathrm{Au}$} & 313,6 & 313,0 & $-0,57$ & $-0,61$ & $-0,09$ & $-0,09$ & $-0,05$ & $-0,09$ & $-0,35$ & $-0,34$ \\
\hline & $+4,5 \%$ & $+4,3 \%$ & $-3,3 \%$ & $-3,4 \%$ & $-0,7 \%$ & $-0,6 \%$ & $-0,4 \%$ & $-0,6 \%$ & $-2,2 \%$ & $-2,1 \%$ \\
\hline \multirow[t]{2}{*}{$1 \mathrm{Ag} @ 5 \mathrm{Au}$} & 305,8 & 305,6 & $-0,24$ & $-0,35$ & $+0,06$ & $-0,09$ & $-0,09$ & $-0,12$ & $-0,10$ & $-0,19$ \\
\hline & $+1,9 \%$ & $+1,9 \%$ & $-1,4 \%$ & $-2,0 \%$ & $+0,4 \%$ & $-0,6 \%$ & $-0,6 \%$ & $-0,8 \%$ & $-0,7 \%$ & $-1,2 \%$ \\
\hline \multirow[t]{2}{*}{$2 \mathrm{Ag} @ 4 \mathrm{Au}$} & 306,4 & 306,5 & $-0,18$ & $-0,37$ & $+0,07$ & $-0,09$ & $-0,07$ & $-0,15$ & $-0,13$ & $-0,21$ \\
\hline & $+2,1 \%$ & $+2,2 \%$ & $-1,0 \%$ & $-2,1 \%$ & $+0,5 \%$ & $-0,6 \%$ & $-0,4 \%$ & $-1,0 \%$ & $-0,8 \%$ & $-1,3 \%$ \\
\hline \multirow[t]{2}{*}{ 3Ag@3Au } & 306,6 & 307,4 & $-0,18$ & $-0,36$ & $+0,07$ & $-0,10$ & $-0,09$ & $-0,09$ & $-0,12$ & $-0,19$ \\
\hline & $+2,2 \%$ & $+2,5 \%$ & $-1,0 \%$ & $-2,0 \%$ & $+0,5 \%$ & $-0,7 \%$ & $-0,6 \%$ & $-0,6 \%$ & $-0,8 \%$ & $-1,2 \%$ \\
\hline \multirow[t]{2}{*}{$4 \mathrm{Ag} @ 2 \mathrm{Au}$} & 306,4 & 307,2 & $-0,13$ & $-0,36$ & $+0,08$ & $-0,09$ & $-0,06$ & $-0,09$ & $-0,09$ & $-0,19$ \\
\hline & $+2,1 \%$ & $+2,4 \%$ & $-0,7 \%$ & $-2,0 \%$ & $+0,6 \%$ & $-0,6 \%$ & $-0,4 \%$ & $-0,6 \%$ & $-0,6 \%$ & $-1,2 \%$ \\
\hline \multirow[t]{2}{*}{$5 \mathrm{Ag} @ 1 \mathrm{Au}$} & 305,8 & 307,4 & $-0,14$ & $-0,36$ & $+0,08$ & $-0,10$ & $-0,06$ & $-0,09$ & $-0,11$ & $-0,20$ \\
\hline & $+1,9 \%$ & $+2,5 \%$ & $-0,8 \%$ & $-2,0 \%$ & $+0,6 \%$ & $-0,7 \%$ & $-0,4 \%$ & $-0,6 \%$ & $-0,7 \%$ & $-1,3 \%$ \\
\hline \multirow[t]{2}{*}{$6 \mathrm{Ag}$} & 306,8 & 307,3 & $-0,31$ & $-0,27$ & $-0,07$ & $-0,03$ & $-0,20$ & $-0,01$ & $-0,26$ & $-0,12$ \\
\hline & $+2,3 \%$ & $+2,4 \%$ & $-1,8 \%$ & $-1,5 \%$ & $-0,5 \%$ & $-0,2 \%$ & $-1,4 \%$ & $-0,1 \%$ & $-1,7 \%$ & $-0,7 \%$ \\
\hline
\end{tabular}


com shell de Ag.

Especificamente, nas nanopartículas puras de Ag, as contrações do sítio c5, variam de $0,21 \AA$ à $0,31 \AA$ entre as nanopartículas de 147 à 923 átomos considerando a interação de van der Waals e de $0,02 \AA$ à $0,27 \AA$ sem a interação. Nas nanopartículas puras de $\mathrm{Au}$, as contrações do sítio c5 variam de $0,07 \AA$ à $0,57 \AA$ com a interação de van der Waals e de $0,05 \AA$ à $0,61 \AA$ sem a interação.

As contrações do sítio c5 nas core-shell com 147 átomos variam com o aumento de camadas de shell de Au de -0,21 $\AA$ à $-0,23 \AA$ A considerando a interação de van

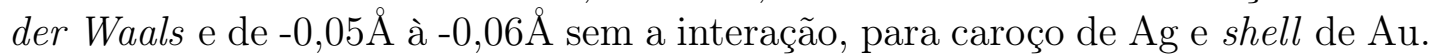

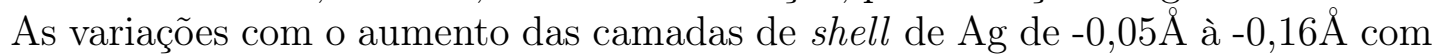
interação de van der Waals e de $-0,13 \AA$ à $-0,26 \AA$ sem a interação, para caroço de $\mathrm{Au}$ e shell de Ag.

Para as core-shell de 309 átomos temos variações com o aumento das camadas de shell de $\mathrm{Au}$ de $-0,25 \AA$ à $-0,34 \AA$ com van der Waals e de $-0,02 \AA$ à $-0,07 \AA$ sem a interação, para caroço de Ag e shell de Au. Para caroço de Au e shell de Ag, as variações com o aumento das camadas de shell de $\mathrm{Ag}$ vão de $-0,17 \AA$ à $-0,18 \AA$ com interação de van der Waals e de $-0,25 \AA$ à $-0,30 \AA$ sem a interação.

Para as core-shell de 561 átomos temos variações de $-0,33 \AA$ à $-0,45 \AA$ com van der Waals e de $-0,07 \AA$ à - $0,16 \AA$ sem interação, para caroço de Ag e shell de Au. Para caroço de $\mathrm{Au}$ e shell de $\mathrm{Ag}$, temos variações entre $-0,20 \AA$ à $-0,25 \AA$ com van der Waals e de $-0,33 \AA$ à $-0,38 \AA$ sem interação.

Por fim, nas core-shell com 923 átomos temos deslocamentos de -0,33 $\AA$ à

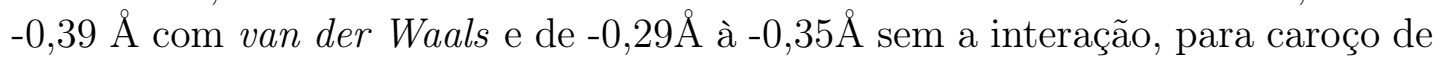
$\mathrm{Ag}$ e shell de $\mathrm{Au}$, e, variações entre $-0,13 \AA$ à $-0,24 \AA$ com interação de van der Waals e de $-0,35 \AA$ à $-0,36 \AA$ sem a interação, para caroço de Au e shell de Ag.

O ângulo total formado entre as ligações do sítio c5 com seus quatro primeiros vizinhos (detalhes na figura 3.1), aumenta com o aumento do tamanho da nanopartícula, padrão que se observa com ou sem a interação de van der Waals. Nas core-shell, os ângulos são definidos praticamente pela camada da superfície shell, ou seja, uma única camada de shell de prata $(\mathrm{Ag})$ ou de ouro $(\mathrm{Au})$ já define o ângulo que vai na direção da nanopartícula pura de Ag ou de $\mathrm{Au}$, respectivamente. As core-shell com caroço de Ag e shell de Au tem ângulo maior em cerca de $6^{\circ}$ do que as com caroço de Au e shell de Ag.

Na estrutura não relaxada, o ângulo do c5 com os seus quatro primeiros vizinhos é de $300^{\circ}$. Ele aumenta de $305,5^{\circ}$ para $306,8^{\circ}$ nas nanopartículas puras de $\mathrm{Ag}$, indo da nanoestrutura com 147 para a com 923 átomos com van der Waals, e de $304,8^{\circ}$ para $307,3^{\circ}$ no caso sem van der Waals. Nas nanopartículas puras de Au ele varia de $309,7^{\circ}$ à $313,6^{\circ}$, indo da estrutura com 147 para a com 923 átomos, no caso com van der Waals e de 309,9 à $313,0^{\circ}$ no caso sem van der Waals. 
Nas core-shell, os ângulos nas estruturas com 147 átomos variam de 309, $7^{\circ}$ à $312,6^{\circ}$ com van der Waals e de $305,0^{\circ}$ à $310,6^{\circ}$ sem van der Waals para caroço de Ag e shell de $\mathrm{Au}$, e, variações de $303,2^{\circ}$ à $305,8^{\circ}$ com van der Waals e de $303,9^{\circ}$ à $305,0^{\circ}$ sem van der Waals para caroço de Au e shell de Ag.

Já para as core-shell com 309 átomos os ângulos variam de $311,5^{\circ}$ à $312,7^{\circ}$ com van der Waals e de $311,7^{\circ}$ à $312,4^{\circ}$ sem van der Waals para caroço de $\mathrm{Ag}$ e shell de $\mathrm{Au}$, e, variações de $304,1^{\circ}$ à $306,1^{\circ}$ com van der Waals e de $304,6^{\circ}$ à $305,2^{\circ}$ sem van der Waals para caroço de Au e shell de Ag.

Nas core-shell com 561 átomos, as variações dos ângulos vão de $311,7^{\circ}$ para $312,5^{\circ}$ com van der Waals e de $312,4^{\circ}$ à $312,8^{\circ}$ sem van der Waals para caroço de Ag e shell de $\mathrm{Au}$, e, variações de $305,2^{\circ}$ à $307,6^{\circ}$ com van der Waals e de $306,8^{\circ}$ à $307,2^{\circ}$ sem van der Waals para caroço de Au e shell de Ag.

Finalmente, nas core-shell com 923 átomos temos ângulos que variam de $312,7^{\circ}$ à $313,5^{\circ}$ com van der Waals e de $312,4^{\circ}$ à $313,6^{\circ}$ sem van der Waals para caroço de $\mathrm{Ag}$ e shell de $\mathrm{Au}$, e variações de $305,8^{\circ}$ à $306,6^{\circ}$ com van der Waals e de $305,6^{\circ}$ à $307,4^{\circ}$ sem van der Waals para caroço de Au e shell de Ag.

Quanto aos átomos localizados no plano [001] na superfície das nanopartículas, os valores médios dos deslocamentos apresentam dilatação em todas as core-shell com caroço de Au e shell de Ag com van der Waals e contrações nas sem van der Waals, excetuando-se as nanopartículas com 147 átomos. Os maiores deslocamentos ocorrem nas nanopartículas maiores e são da ordem de $0,2 \AA$. As nanopartículas com 147 átomos com caroço de Ag e shell de Au também apresentam dilatação na superfície relacionada ao plano [001] com ou sem van der Waals. Todas as demais nanopartículas apresentam contrações nessa superfície, com van der Waals e alternam pequenas contrações e dilatações sem van der Waals.

O valor médio dos deslocamentos dos átomos do plano [111] das nanopartículas apresenta contração em todas as core-shell de caroço de Ag e de shell de Au com van der Waals e dilatações nas sem van der Waals, com excessão das com 923 átomos, que apresentam uma pequena contração. Novamente, os maiores deslocamentos ocorrem nas maiores nanopartículas e são da ordem de $0,2 \AA$. Todas as core-shell com caroço de Au e shell de Ag apresentam pequena contração na direção [111], exceto as core-shell com 561 átomos, com van der Waals enquanto acontecem contrações em todas sem van der Waals.

Fato significativo é que os deslocamentos dos átomos da superfície localizados nos planos [001] e [111] em todas as nanopartículas puras e core-shell é bem maior do que aquele observado nas superfícies livres de ouro e de prata conforme apresentado no Apêndide B.

Os átomos localizados nas arestas que unem os planos [001] e [111] na superfície das nanopartículas apresentam, em todos os casos, contrações e as maiores 
contrações se encontram nas maiores nanopartículas. Essas contrações são maiores nas core-shell com caroço de Ag e shell de Au do que nas com caroço de $\mathrm{Au}$ e shell de Ag. Essas contrações das arestas evidenciam que as nanopartículas se tornam menos "bicudas", mais achatadas, suavizando suas superfícies.

As contrações das arestas, juntamente com a redução das distâncias dos sítios c5 ao átomo central das nanopartículas e o aumento do ângulo das ligações desse sítio c5 com a sua vizinhança, mostram que as nanopartículas maiores tendem à uma superfície mais esférica, sendo essa esfericidade maior nas core-shell formadas de shell de Au e caroço de Ag. Esse resultado está em acordo com dados experimentais de imagens de TEM(Transmission electron microscopy-microscopia de transmissão eletrônica) obtidas por Shankar e colaboradores [99].

Resultado relevante encontrado nas core-shell é que tanto os ângulos do sítio c5 quanto os deslocamentos dos átomos da superfície, praticamente não sofrem alteração em função do número de camadas shell de ouro ou de prata, ou com suas respectivas concentrações, em cada core-shell com número definido de átomos.

Os resultados dos deslocamentos apresentados sem van der Waals evidenciam padrões um tanto diferentes daqueles com van der Waals porque o parâmetro de rede calculado sem van der Waals para o ouro é maior que o da prata, contrariamente ao resultado experimental e com o valor obtido no cálculo com van der Waals, o que pode provocar distorções nas acomodações das camadas. Nesse pormenor, acreditamos que os cálculos com van der Waals são mais realistas do que os sem van der Waals. Além disso, nos cálculos considerando a interação de van der Waals, encontramos praticamente o mesmo padrão de deslocamentos tanto nas nanopartículas puras quanto nas core-shell.

Convém salientar que todo esse padrão observado na superfície das nanopartículas é o que regula suas estruturas e propriedades, tendo em vista que todos os deslocamentos atômicos encontrados na camada inferior à superfície (sub-superfície), também de contração, são, entretanto, mais de uma ordem de grandeza menores do que os deslocamentos dos átomos da superfície. Especificamente, nas nanopartículas puras e core-shell de 147, 309 e 561 átomos, todos os deslocamentos da camada inferior(sub-superfície) são em média inferiores à $0,5 \%$. Somente as core-shell 0Au@3Ag, 1Au@2Ag e 2Au@1Ag tem deslocamentos que podem ir até $0,8 \%$. Nesses casos, temos uma maior acomodação da camada da sub-superfície. Mesmo assim bem menores que os deslocamentos da superfície. Nas maiores nanopartículas, com 923 átomos, esses deslocamentos são ainda menores e inferiores à $0,2 \%$. Praticamente não temos mais relaxação dos átomos localizados na sub-superfície. Esse fato segue o padrão encontrado na superfícies livres de ouro e de prata onde praticamente os deslocamentos dos átomos da sub-superfície são mínimos (Apêndice B). 


\subsection{Propriedades energéticas das nanopartículas puras e core-shell}

Analisamos nesse tópico a evolução das energias de formação das nanopartículas em relação à sua dimensão e composição (core-shell) a fim de verificarmos sua tendência à estabilidade e estruturas mais favoráveis energeticamente.

Na figura 3.2, estão representadas as energias total e de formação por átomo, em (eV), para diferentes nanopartículas puras de Au e Ag, superfícies [001], [111] e bulks, em função do número de coordenação médio. O número de coordenação médio $N$ é definido como a média ponderada da quantidade de sítios presentes nas nanopartículas estudadas e é calculado por meio de,

$$
N=\frac{\sum_{i} n_{i} c_{i}}{\sum_{i} n_{i}}
$$

onde $c_{i}$, com $i=5,7,8,9,12$, é cada um dos sítios de coordenação das nanopartículas e $n_{i}$ é a quantidade de cada um desses sítios. Por exemplo, as nanopartículas com 923 átomos possuem 12 átomos com coordenação c5, 120 com coordenação c7, 150 com coordenação c8, 80 átomos com coordenação c9 e 561 átomos com coordenação c12.

As nanopartículas com 147, 309, 561 e 923 átomos possuem, respectivamente, as coordenações médias de 8,98, 9,63, 10,05 e 10,35. Os cálculos da superfície livre foram realizados considerando uma célula com 8 camadas de átomos, com 6 camadas no interior com átomos de coordenação c12 e duas camadas de superfície, superior e inferior, com átomos de coordenação característica. Os sítios característicos da superfície [001] apresentam coordenação c8 e dessa forma sua coordenação média é $\bar{c}_{[001]}=\frac{(2 \cdot 8+6 \cdot 12)}{8}=11,00$. Os sítios característicos da superfície [111] apresentam coodenação c9 e sua coordenação média é $\bar{c}_{[111]}=\frac{(2 \cdot 9+6 \cdot 12)}{8}=11,25$. As coordenações dos bulks, de Au e Ag, são iguais a 12,00.

As energias de formação por átomo, $E_{f}$, das nanopartículas puras e core-shell são obtidas usando a expressão,

$$
E_{f}=\frac{E_{\text {sistema }}-\left(N_{A g} \mu_{A g}+N_{A u} \mu_{A u}\right)}{N_{t o t}}
$$

onde $E_{\text {sistema }}$, é a energia total de uma dada nanopartícula em $(\mathrm{eV}) . N_{A g}$ e $N_{A u}$ são o número de átomos de $\mathrm{Ag}$ e $\mathrm{Au}$, respectivamente, $\mu_{A g}$ e $\mu_{A g}$, são, respectivamente, os potenciais químicos da $\mathrm{Ag}$ e do $\mathrm{Au} . N_{t o t}=N_{A g}+N_{A u}$ é o número total de átomos do sistema. Já a energia total por átomo, $E_{a t}$, é dada por, 

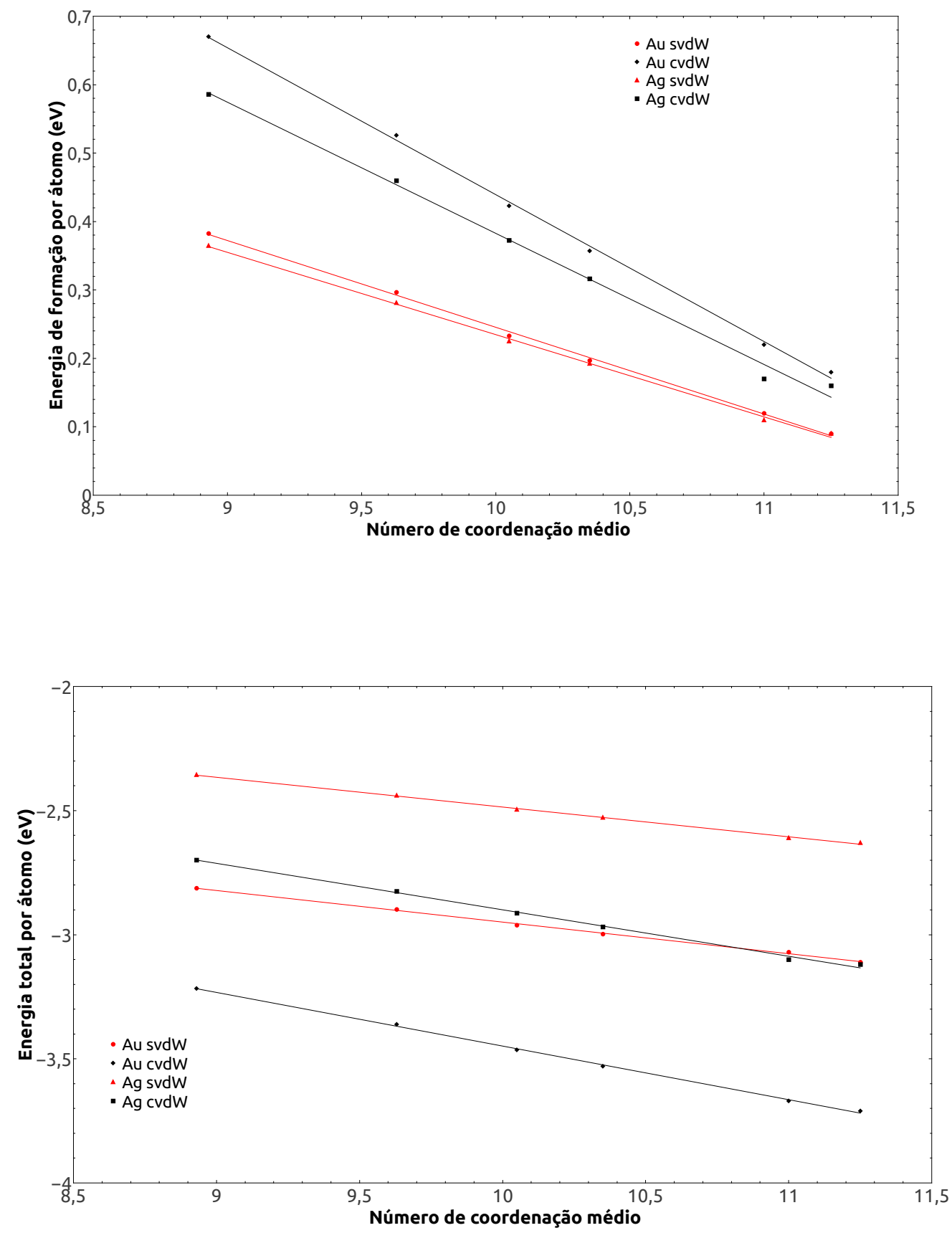

Figura 3.2: Energias total e de formação por átomo com e sem interação de $v d W$, em (eV), das nanopartículas puras, das superfícies [001] e [111] e dos bulks de Ag e Au. As nanopartículas puras com 147, 309, 561 e 923 átomos possuem números de coordenação médio de 8,98, 9,63, 10,05 e 10,35, respectivamente. Os números de coordenação médios das superfícies [001] de [111] são, respectivamente, 11,00 e 11,25. As linhas sólidas representam as retas da regressão linear. 

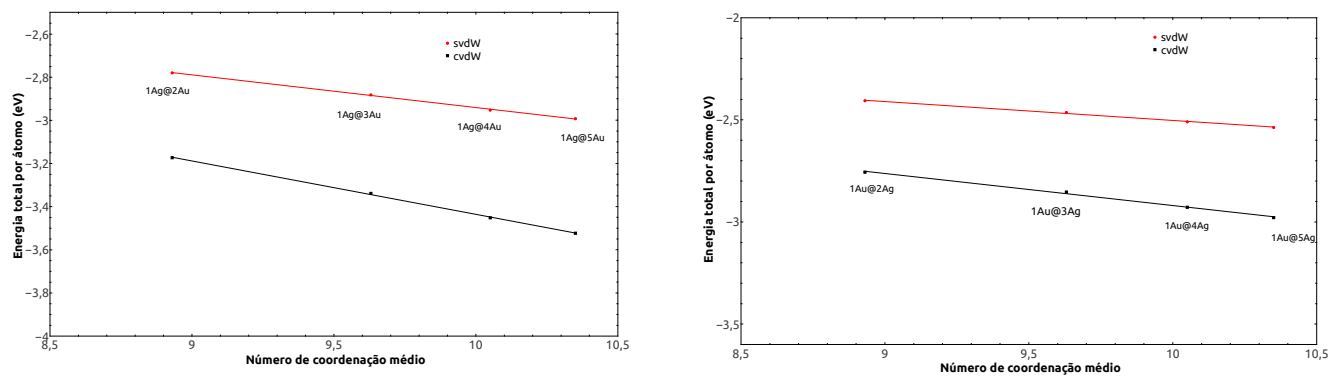

Figura 3.3: Energias total por átomo em $(\mathrm{eV})$, com e sem interação de $v d W$, das core-shell 147, 309, 561 e 923, com 1 camada de shell de Ag e 1 camada de shell de Au. Os números de coordenação médio são, respectivamente, 8,98, 9,63, 10,05 e 10,35. As linhas sólidas representam as retas da regressão linear.

$$
E_{a t}=\frac{E_{\text {sistema }}}{N_{\text {tot }}} .
$$

Notemos ainda, na figura 3.2, da energia de total por átomo, que tanto o $\mathrm{Au}$ quanto a $\mathrm{Ag}$ possuem coeficientes da regressão linear similares, -0,22 e -0,19, respectivamente, quando a interação de van der Waals é incluída, e é de -0,13, em ambos os casos (Au e Ag), quando não se inclui a interação de van der Waals. Ainda na mesma figura, para o gráfico da energia de formação por átomo, temos que os coeficientes da regressão linear do Au e da Ag são, respectivamente, - -0,22 e -0,19, incluíndo van der Waals e -0,13 para o $\mathrm{Au}$ e para a $\mathrm{Ag}$ sem incluir a interação. Novamente, esses coeficientes são similares. A tendência das curvas são as mesmas nos dois gráficos e a introdução da interação de van der Waals tornam as curvas mais acentuadas. O efeito da interação de van der Waals é dependente do tamanho da nanopartícula. De um modo geral, as variações nas energias por átomo são menores para as nanopartículas menores. Isto provavelmente relaciona-se com o fato de que as menores nanopartículas possuem números de coordenação médio menores. De outro modo, como essas menores nanopartículas possuem um percentual menor de sítios de coordenação ideal c12, as interações de van der Waals são mais relevantes na descrição dos sítios de coordenação menores. Isto concorda com observações anteriores de menores diferenças de energias para adsorções atômicas, por exemplo, de gases nobres [100], em sitios com diferentes números de coordenação de superfícies metálicas quando as interações de dispersão são incluídas. Essas curvas claramente indicam o limite de regime das macroestruturas das nanopartículas.

Considerando os gráficos das figuras 3.3 e 3.4, notamos, inicialmente, a se- 

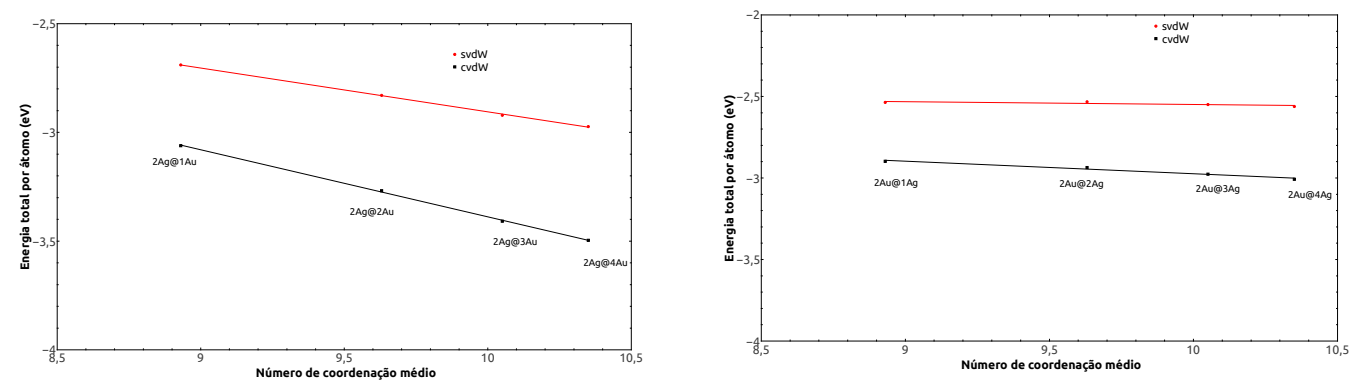

Figura 3.4: Energias total por átomo em $(\mathrm{eV})$, com e sem a interação de $v d W$, das core-shell 147, 309, 561 e 923, com 2 camadas de shell de Ag e 2 camadas de shell de Au. Os números de coordenação médio são, respectivamente, 8,98, 9,63, 10,05 e 10,35. As linhas sólidas representam as retas da regressão linear.
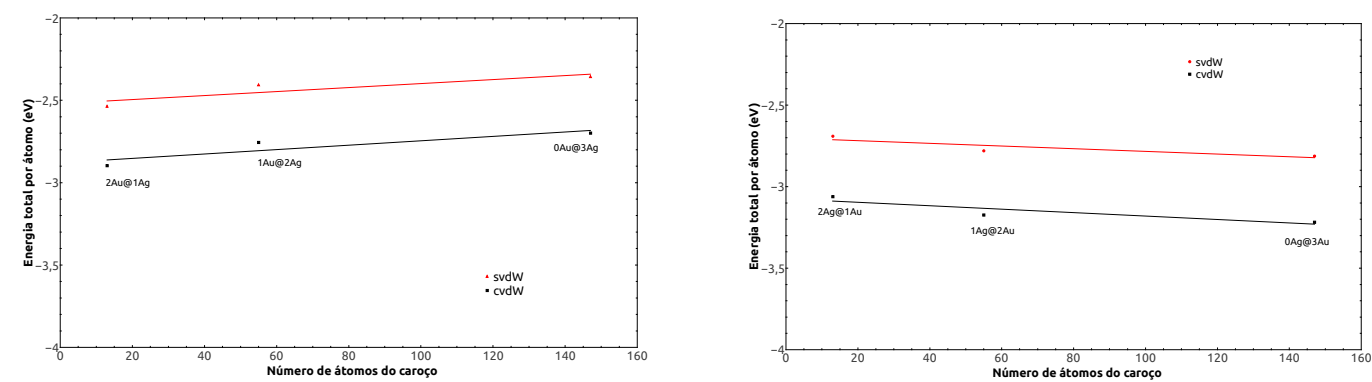

Figura 3.5: Energias total por átomo em (eV), com e sem a interação de $v d W$, das core-shell 147 com core de Au e Ag em função da quantidade de átomos do caroço. As linhas sólidas representam as retas da regressão linear. 

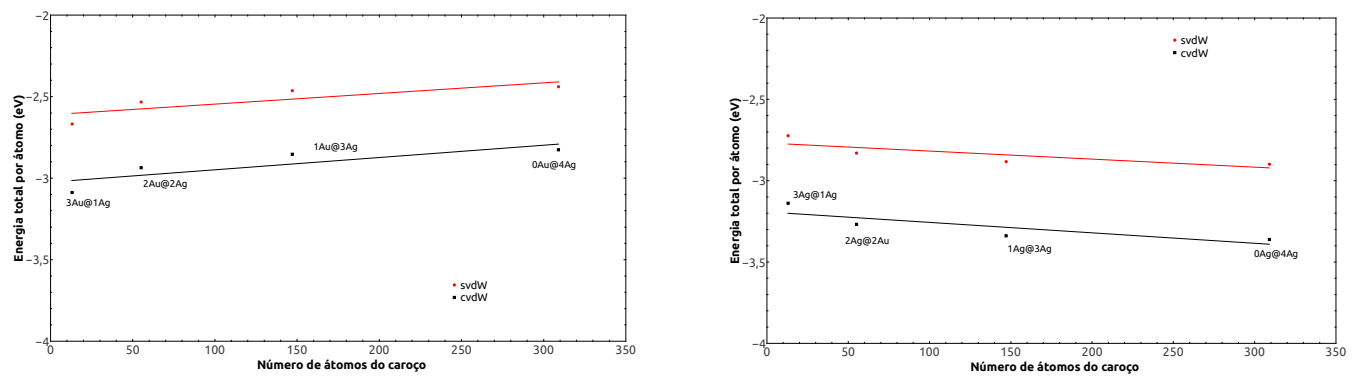

Figura 3.6: Energias total por átomo em $(\mathrm{eV})$, com e sem interação de $v d W$, das core-shell 309 com core de Au e Ag em função da quantidade de átomos do caroço. As linhas sólidas representam as retas da regressão linear.
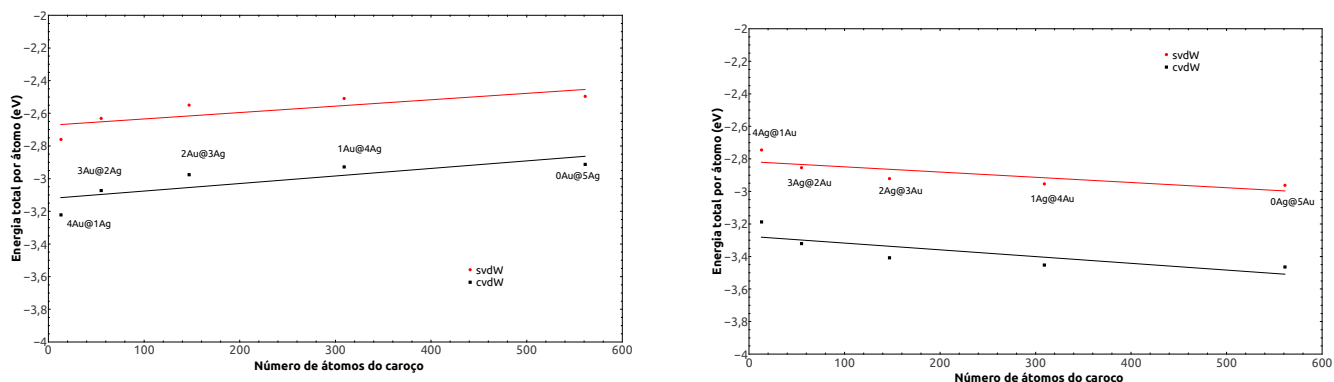

Figura 3.7: Energias total por átomo em $(\mathrm{eV})$, com e sem interação de $v d W$, das core-shell 561 com core de Au e Ag em função da quantidade de átomos do caroço. As linhas sólidas representam as retas da regressão linear.

melhança das curvas obtidas utilizando-se ou não no cálculo a interação de van der Waals. Uma única camada shell tanto de ouro quanto de prata já apresenta o comportamento energético das core-shell de sempre serem mais favoráveis aumentando-se o número de camadas do caroço fixando-se o número de camadas shell. Os coeficientes das retas de regressão linear são -0,12 (svdW) e -0,19 (cvdW) para uma única camada de shell de Au e -0,13 (svdW) e -0,22 (cvdW) para um única camada shell de Ag (fig.3.3) Valores esses muito próximos das coeficientes das regressões obtidos com duas camadas de shell de ouro ou prata (fig.3.4) que foram -0,12 (svdW) e -0,21 (cvdW) para duas camadas de shell de Au e -0,1 (svdW) e -0,17 (cvdW) para duas camadas de shell de Ag. Em ambos os casos as curvas mais acentuadas se dão para os cálculos considerando a interação de van der Waals. 

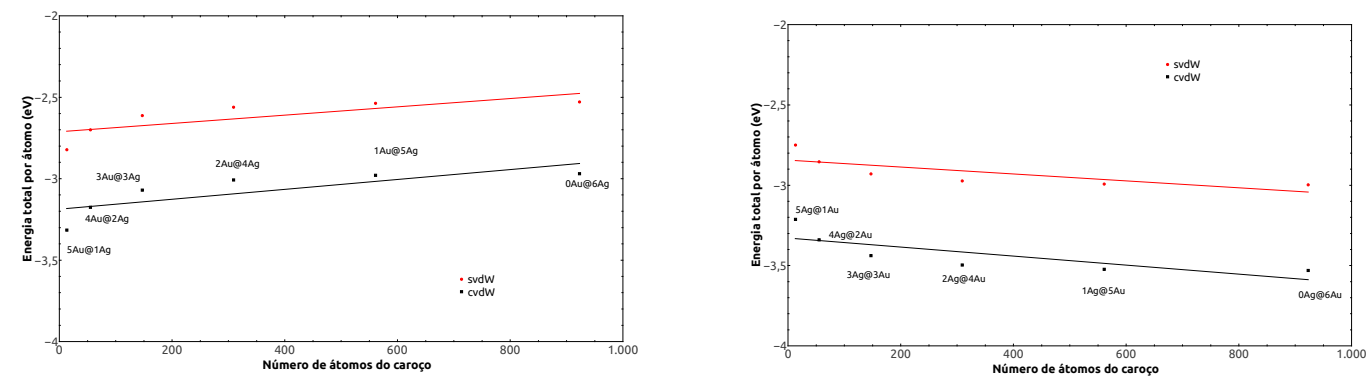

Figura 3.8: Energias total por átomo em $(\mathrm{eV})$, com e sem interação de $v d W$, das core-shell 923 com core de Au e Ag em função da quantidade de átomos do caroço. As linhas sólidas representam as retas da regressão linear.

Ainda, percebe-se que as energias de formação por átomo das core-shell tendem às energias das superfícies [001] e [111] e dos bulks (ver Âpêndice B), conforme aumenta o número de coordenação, da mesma forma que a figura 3.2. Este aumento corresponde a uma predominância de átomos da região interior com coordenação c12. Nas superfícies livres, predominam os sítios de coordenação c8, característicos do plano [001] e sítios com coordenação c9, típicos do plano [111]. Também, de acordo com a figura 3.2, as energias de formação por átomo das nanopartículas puras tendem às energias das superfícies [001], [111] e bulks. Observamos que as core-shell com 309, 561 e 923 átomos apresentam um caráter mais cristalino, que é próprio das nanopartículas maiores(>300 átomos) [1] enquanto as core-shell com 147 átomos apresentam características intermediárias entre os regimes molecular e cristalino [1]. Aqui, novamente, verificamos que poucas camadas de shell (uma ou duas) já definem o caráter da nanopartícula (core-shell) com propriedades energéticas praticamente definidas pelas camadas de shell da nanopartícula pura correspondente.

As figuras 3.5, 3.6, 3.7 e 3.8, apresentam individualmente a evolução energética das core-shell de ouro e prata para as nanopartículas com 147, 309, 561 e 923 átomos. Em todos os casos é sempre menos favorável energeticamente, diminuir as camadas de shell de Au e aumentar as camadas de caroço de Ag, com ou sem interação de van der Waals, enquanto que sempre é mais favorável aumentar-se o número de camadas de caroço de $\mathrm{Au}$ com respectiva diminuição do número de camadas de shell de Ag. Sendo assim, sempre é favorável encapsular mais camadas de shell de Au sobre camadas de caroço de Ag. O aumento das camadas de shell de Ag sobre núcleos de Au representam uma desestabilização das nanopartículas obtidas devido ao aumento da energia de formação por átomo. Em contrapartida, o aumento das camadas de shell de Au sobre núcleos de Ag 
representam uma maior estabilidade das core-shell resultantes.

Continuando a análise das energias das nanopartículas, calculamos as diferenças de energia por átomo de todas as estruturas, resultando nos diagramas seguintes a fim de detalharmos e verificarmos as possíveis transições. Também nesses diagramas, os números representam o número de camadas das core-shell, onde suprimimos o símbolo @. Dessa forma, $1 \mathrm{Ag} 4 \mathrm{Au}$ representa 1 camada de shell de Ag e 4 camadas de caroço (core) de Au.

Nos diagramas das figuras 3.9 e 3.10, as setas indicam o sentido entre uma estrutura de origem e a final. As diferenças de energias são obtidas das energias de formação por átomo, calculados por meio da equação 3.2, subtraindo o valor da estrutura final do referente à inicial (origem das setas).

Dos dois primeiros diagramas das figuras 3.9 e 3.10, ou aqueles sem setas diagonais, vemos que partindo do caroço de Ag, é mais favorável encapsular mais camadas de shell de Au do que adicionar mais uma camada de Ag. Sobrepor camadas de (shell) de Au sobre caroço de Ag é sempre mais favorável energeticamente. Partindo agora de um caroço de Au, sempre é menos favorável encapsular uma ou mais camadas de shell de Ag do que adicionar outra camada de Au.

Aqui, como no caso dos deslocamentos atômicos, acontecem algumas pequenas diferenças, entre os cálculos considerando a interação de van der Waals e os sem considerá-la. Mesmo assim os padrões acima mencionados se mantém. Novamente, podemos atribuir essas diferenças ao fato de o cálculo do parâmetro de rede sem a utlização das interações de van der Waals do Au ser maior do que o da $\mathrm{Ag}$ (contrariamente ao resultado experimental e com a aproximação vdW), podendo ocasionar algumas pequenas distorções nos casos de acomodação de uma camada de ouro sobre a prata ou principalmente da prata sobre o ouro, invertendo a ordem natural de acomodar camadas com maior (ou menor) parâmetro de rede sobre camadas com menor (maior) parâmetro de rede.

Em seguida, passamos a analisar os segundos diagramas das figuras 3.9 e 3.10, aqueles com setas diagonais. Nesses diagramas, os resultados decorrrentes dos cálculos com o uso das interações de van der Waals e aqueles sem o uso dessas interações apresentam o mesmo padrão. Partindo-se das core-shell 2Ag@1Au ou $2 \mathrm{Au} @ 1 \mathrm{Ag}$ com menor número de átomos(147), aumentar o número de camadas de shell para $3 \mathrm{Ag}, 4 \mathrm{Ag}, 5 \mathrm{Ag}$ ou $3 \mathrm{Au}, 4 \mathrm{Au}, 5 \mathrm{Au}$, mantendo somente uma camada de caroço de ouro ou de prata é sempre favorável, com ou sem van der Waals. Nesse caso, adicionar uma só camada de shell de Au é mais favorável do que adicionar uma camada de shell de Ag. Aumentar uma camada de caroço de Au com redução de uma camada de shell de Ag é favorável (trocas de camadas favorável), enquanto que aumentar uma camada de caroço de Ag reduzindo uma camada de shell de Au é desfavorável (trocas de camadas desfavoráveis).

O mesmo fato acontece partindo das nanopartículas puras 3Ag@0Au e 


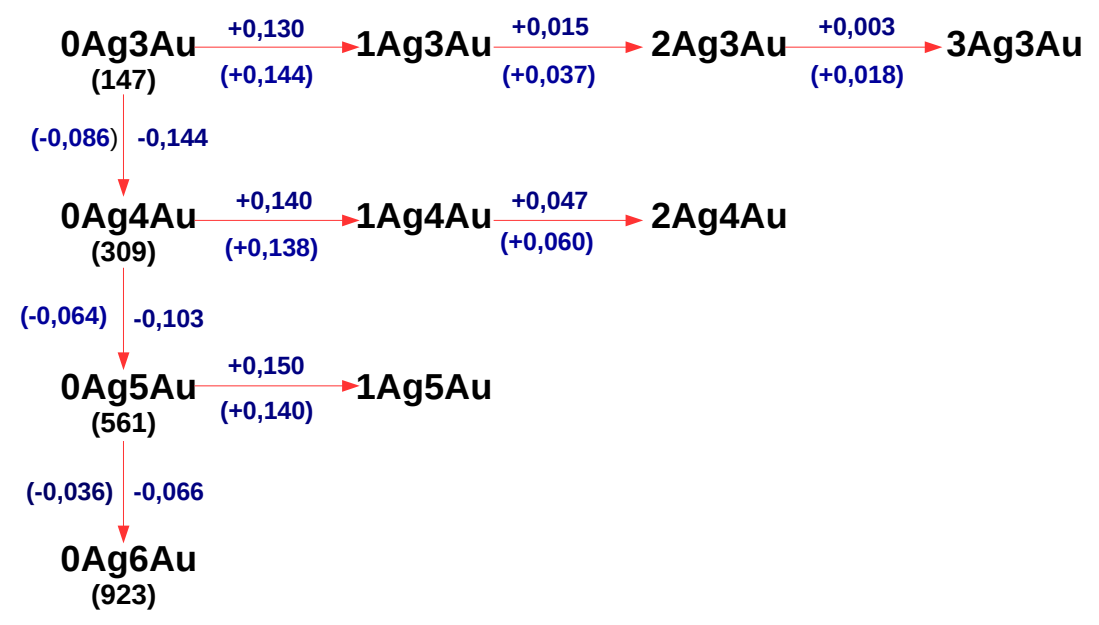

\section{Ag0Au}

$(-0,050)-0,057$

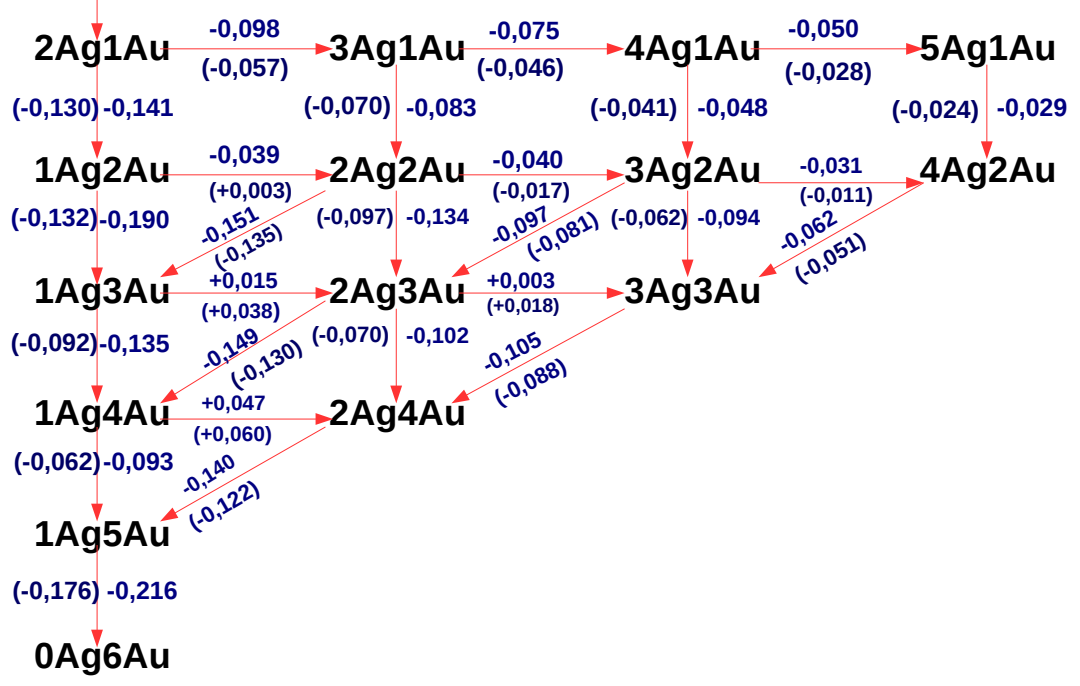

Figura 3.9: Diferenças de energia por átomo com e sem $v d W$, em $(\mathrm{eV})$, das nanopartículas puras e core-shell Ag@Au. Os valores entre parênteses referem-se a cálculos sem a inclusão das interações de van der Waals. 


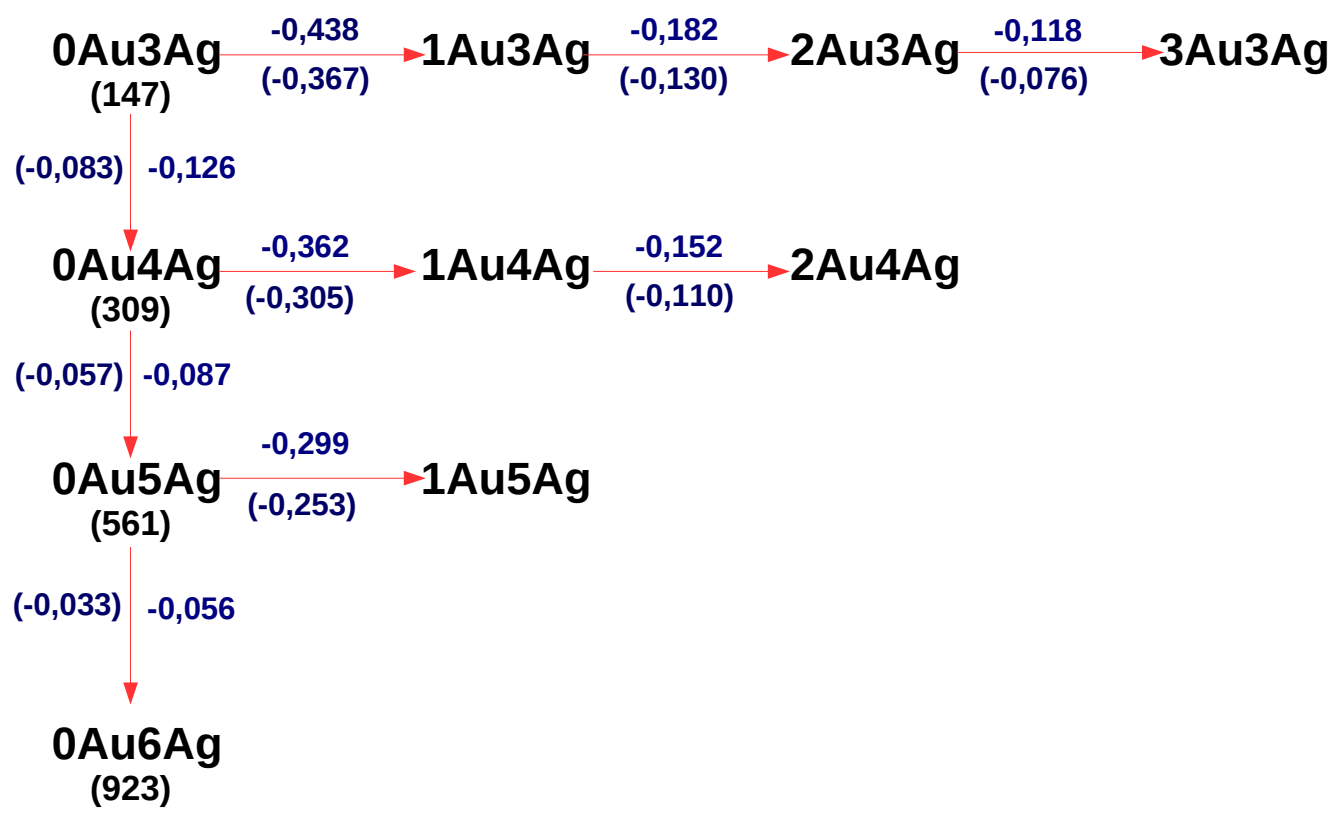

\section{Au0Ag}

$(+0,032)+0,044$

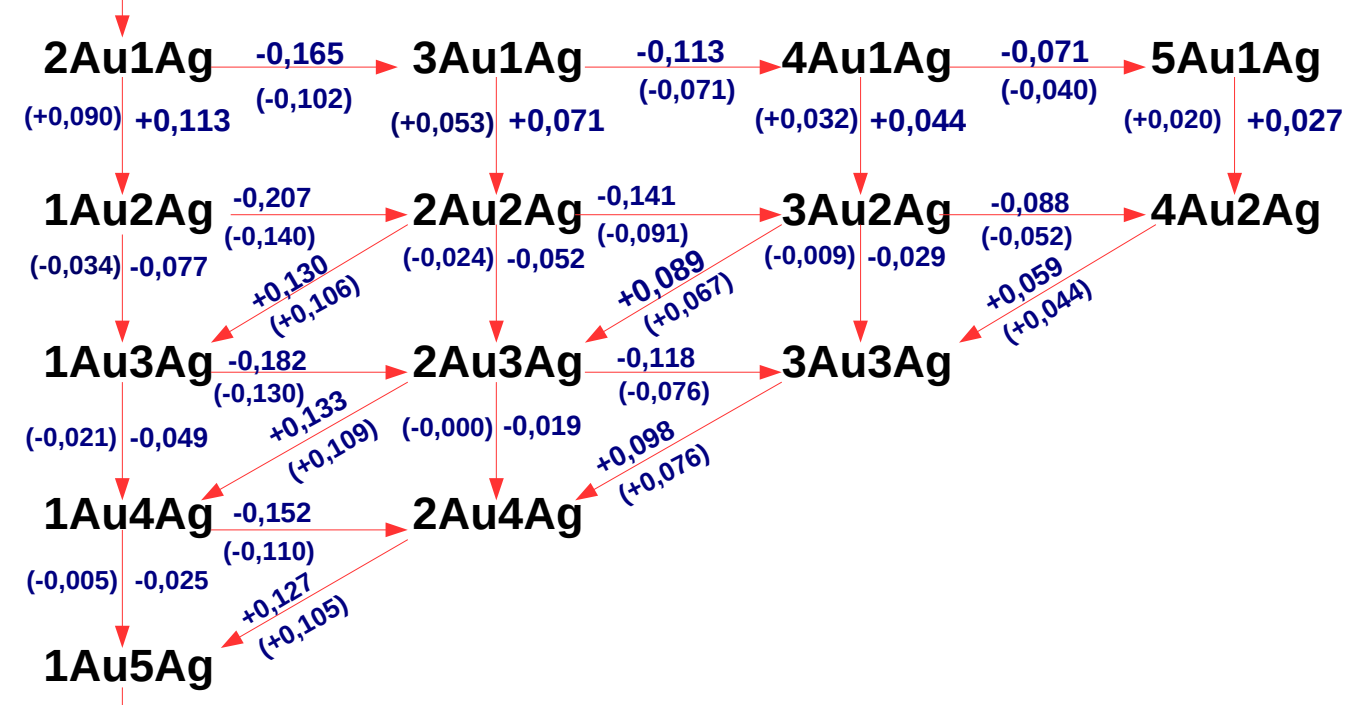

$(+0,221)+0,243$

\section{oAú6Ag}

Figura 3.10: Diferenças de energia por átomo com e sem $v d W$, em $(\mathrm{eV})$, das nanopartículas puras e core-shell Au@Ag. Os valores entre parênteses referem-se a cálculos sem a inclusão das interações de van der Waals. 
3Au@0Ag. Quando na nanopartícula pura de prata 3Ag@0Au ao trocarmos uma camada do caroço por Au com redução de uma camada de shell de Ag o sistema é favorável. Entretanto, ao considerarmos a nanopartícula pura de ouro 3Au@0Ag, ao trocarmos uma camada do caroço por Ag com redução de uma camada de shell de Au o sistema é desfavorável.

Partindo-se de um caroço de Ag com uma só camada de shell de Au, é sempre favorável adicionar-se mais camadas de shell de Au. Da mesma forma, partindose de um caroço de Au com uma só camada de shell de Ag, também é sempre favorável adicionar-se mais camadas de caroço de Ag. Em ambos os casos a diferença energética descrece com o aumento das camadas de shell. Aumentar o número de camadas de shell de Au sobre um caroço de Ag é sempre mais favorável do que adicionar camadas de shell de Ag sobre um caroço de Au, que é desfavorável à partir de $1 \mathrm{Ag} @ 3 \mathrm{Au}$.

Trocar uma camada shell de Au por uma camada de caroço de Ag (setas na diagonal), como, por exemplo, de $2 \mathrm{Au} @ 2 \mathrm{Ag}$ para $1 \mathrm{Au} @ 3 \mathrm{Ag}$, é sempre desfavorável. Entretanto, sempre é favorável nos casos de se trocar uma camada de shell de Ag por uma de caroço de Au, como, por exemplo, de 2Ag@2Au para 1Ag@3Au.

Manter o número de camadas de shell de Ag fixo e aumentar o número de camadas de caroço de $\mathrm{Au}$ (setas verticais para baixo à partir de $1 \mathrm{Ag} @ 2 \mathrm{Au}$ ) é sempre mais favorável energeticamente do que manter fixo o número de camadas de shell de Au e aumentar o número de camadas de caroço de Ag (à partir de $1 \mathrm{Au} @ 2 \mathrm{Ag})$.

Manter uma camada de shell de Au e aumentar o caroço de Ag, com ou sem interação de van der Waals, é sempre favorável até a formação de $1 \mathrm{Au} @ 5 \mathrm{Ag}$. Em geral, para as Au@Ag, novas camadas de shell são mais favoráveis do que novas camadas de caroço. Para as core-shell Ag@Au, novas camadas de caroço são mais favoráveis do que novas camadas de shell.

Partindo-se de uma core-shell Au@Ag é mais favorável adicionar-se uma nova camada de shell de Au do que uma camada de caroço de Ag com ou sem a interação de van der Waals. Complementarmente, iniciando-se com uma coreshell Ag@Au, é mais favorável adicionar-se uma nova camada de caroço de $\mathrm{Au}$ do que uma camada de shell de Ag com ou sem a interação de van der Waals, que é desfavorável à partir de $1 \mathrm{Ag} @ 3 \mathrm{Au}$. 


\subsection{Propriedades eletrônicas das nanopartículas puras e core-shell}

No estudo das propriedades eletrônicas analisamos a densidade de estados (DOS) em torno do nível de Fermi para diferentes tamanhos de nanopartículas. A análise das DOS das nanopartículas puras foi realizada em comparação com as DOS das superfícies [001], [111] e dos bulks de Ag e Au. Já as DOS das core-shells foi efetuada comparando-as com as das nanopartículas puras e dos bulks correspondentes. Os gráficos DOS estão normalizados pelo número de elétrons do sistema representado.

As figuras 3.11 e 3.12 representam a densidade de estados das nanopartículas puras de Ag e Au, respectivamente, em comparação com seus bulks e superfícies, considerando cálculos com e sem a interação de van der Waals. Nas figuras 3.13 e 3.14 apresentamos com mais detalhes a evolução da DOS referentes aos gráficos inferiores das figuras 3.11 e 3.12 .

Verifica-se claramente que para as nanopartículas menores (147 átomos) ainda há considerável característica molecular com presença de picos mais intensos e localizados, modulados tanto pela superfície como pelo bulk do cristal correspondente.

O aumento do número de átomos que compõe a nanopartícula reduz a característica molecular fazendo com que as DOS tenham características mistas de superfície e cristal, com predominância desta última nas maiores nanopartículas (923 átomos). Tal fato já havia sido observado para as nanopartículas puras de Ag por Kiss [2] em trabalho recente. A mesma característica padrão é observada tanto nos cálculos considerando a interação de van der Waals quanto nos cálculos sem a sua consideração. A redução da característica molecular com o aumento da nanopartícula é mais acentuada nas nanopartículas puras de Ag indicando que nas nanopartículas puras de Au a característica molecular da DOS só é bem atenuada nas nanopartículas maiores, enquanto nas fases intermediárias as modulações de superfícies e cristalinas se sobrepõem. Dessa forma, esse misto de modulação é verificado em nanopartículas maiores de Au com até 561 átomos enquanto nas nanopartículas de $\mathrm{Ag}$ ele vai até as nanopartículas com 309 átomos conforme já observado por Kiss [2]. Comparativamente, podemos então estabelecer que: a) o regime molecular, com forte influência da superfície e poucas propriedades cristalinas acontece nas nanopartículas menores, com cerca de 150 átomos ( 2,0 nm); b) regime misto, com características de cristal, superfície e molécula e estão no limite da transição do regime molecular para o regime cristalino, as nanopartículas de Ag possuem entre 150 e 300 átomos ( 2,0 a 2,5 nm) enquanto as nanopartículas de Au entre 150 e 560 átomos ( 2,0 a $3,0 \mathrm{~nm}$ ); c) o regime cristalino, onde as características cristalinas e de superfície 


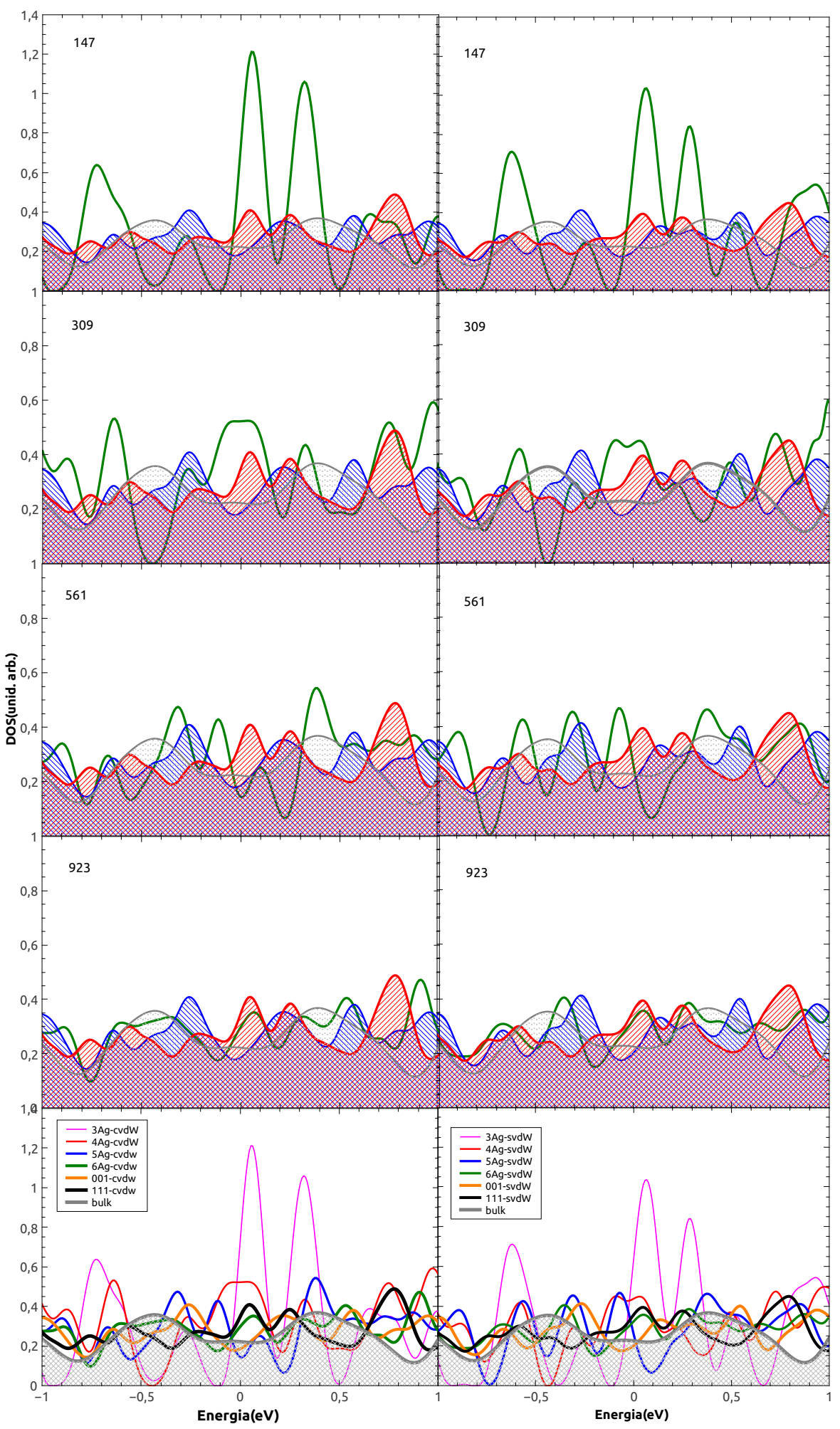

Figura 3.11: Densidade de estados das nanopartículas puras, superfícies [001] e [111] e bulk de Ag com e sem a interação de van der Waals. Nos oito primeiros gráficos, de cima para baixo, o esquema de cores é o seguinte: as nanopartículas puras estão representadas por linhas verdes, o cristal pela região sombreada em cinza, a superfície [001] pela região hachurada em azul e a [111] pela região hachurada em vermelho. Gráficos da esquerda, incluíndo a interação de van der Waals e os da direita não incluem esta interação. 


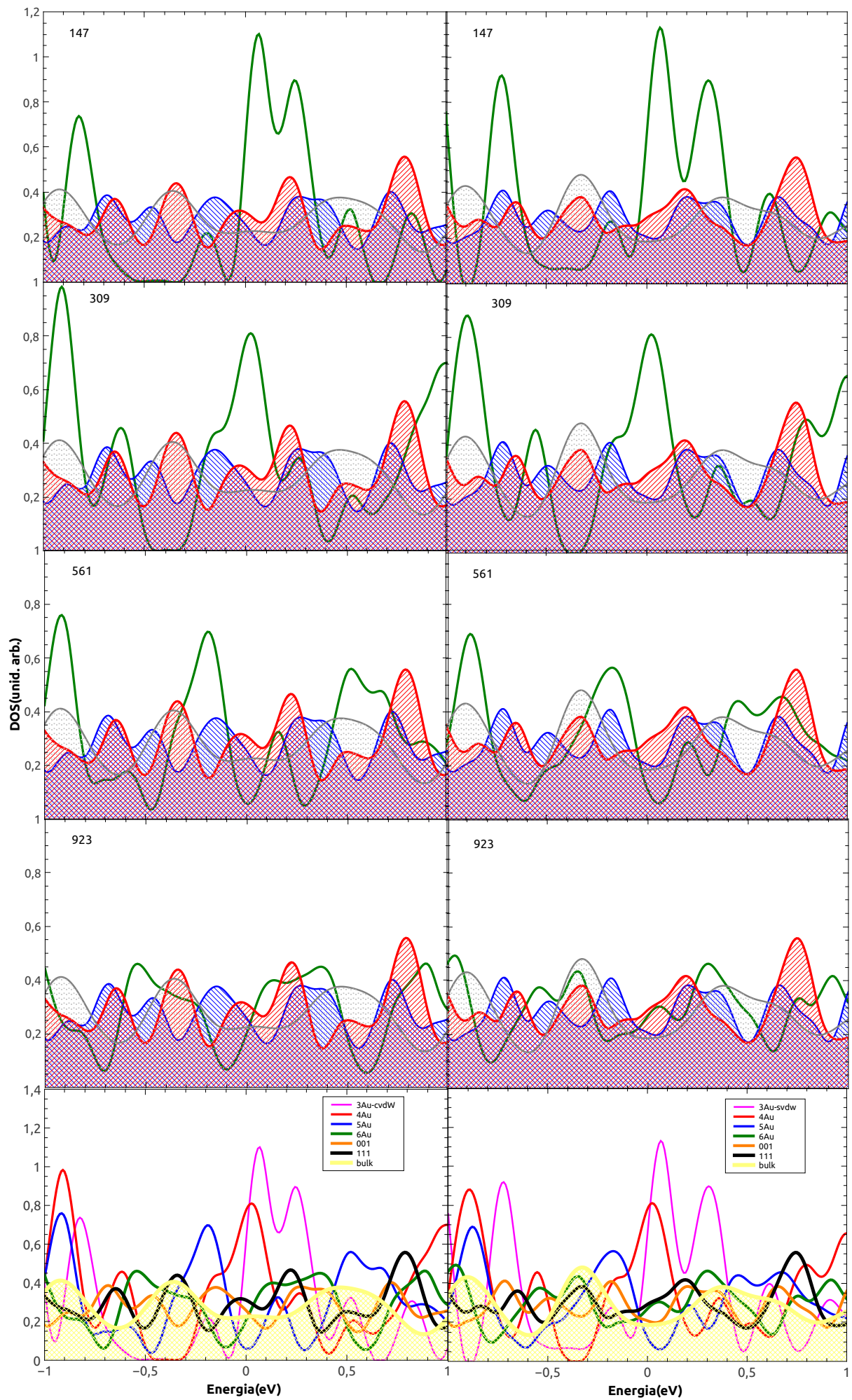

Figura 3.12: Densidade de estados das nanopartículas puras, superfícies [001] e [111] e bulk de Au com e sem a interação de van der Waals. Nos oito primeiros gráficos, de cima para baixo, o esquema de cores é o seguinte: as nanopartículas puras estão representadas por linhas verdes, o cristal pela região sombreada em cinza, a superfície [001] pela região hachurada em azul e a [111] pela região hachurada em vermelho. Gráficos da esquerda, incluíndo a interação de van der Waals e os da direita não incluem esta interação. 

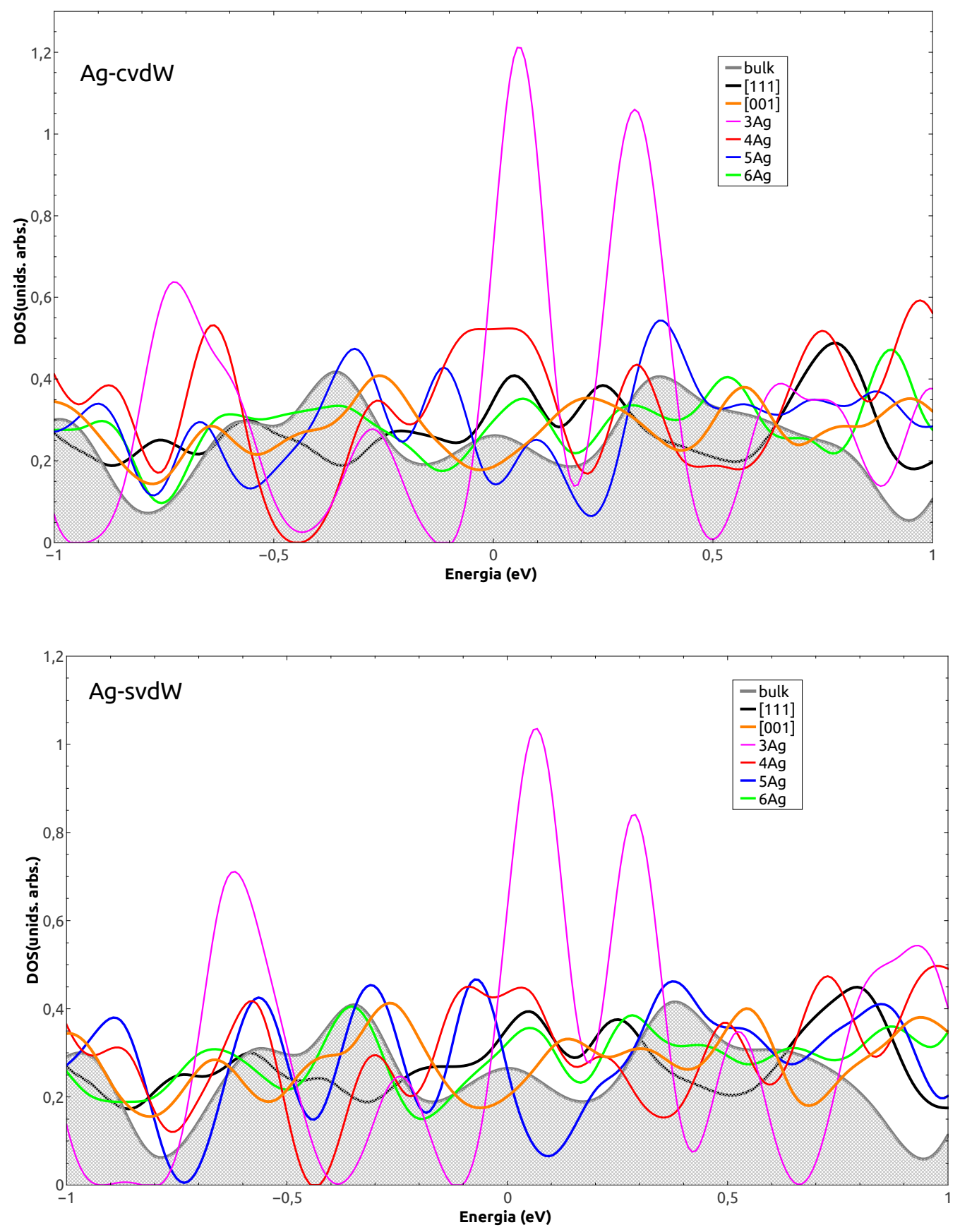

Figura 3.13: Densidade de estados das nanopartículas puras, superfícies [001] e [111] e bulk de Ag com e sem van der Waals. 

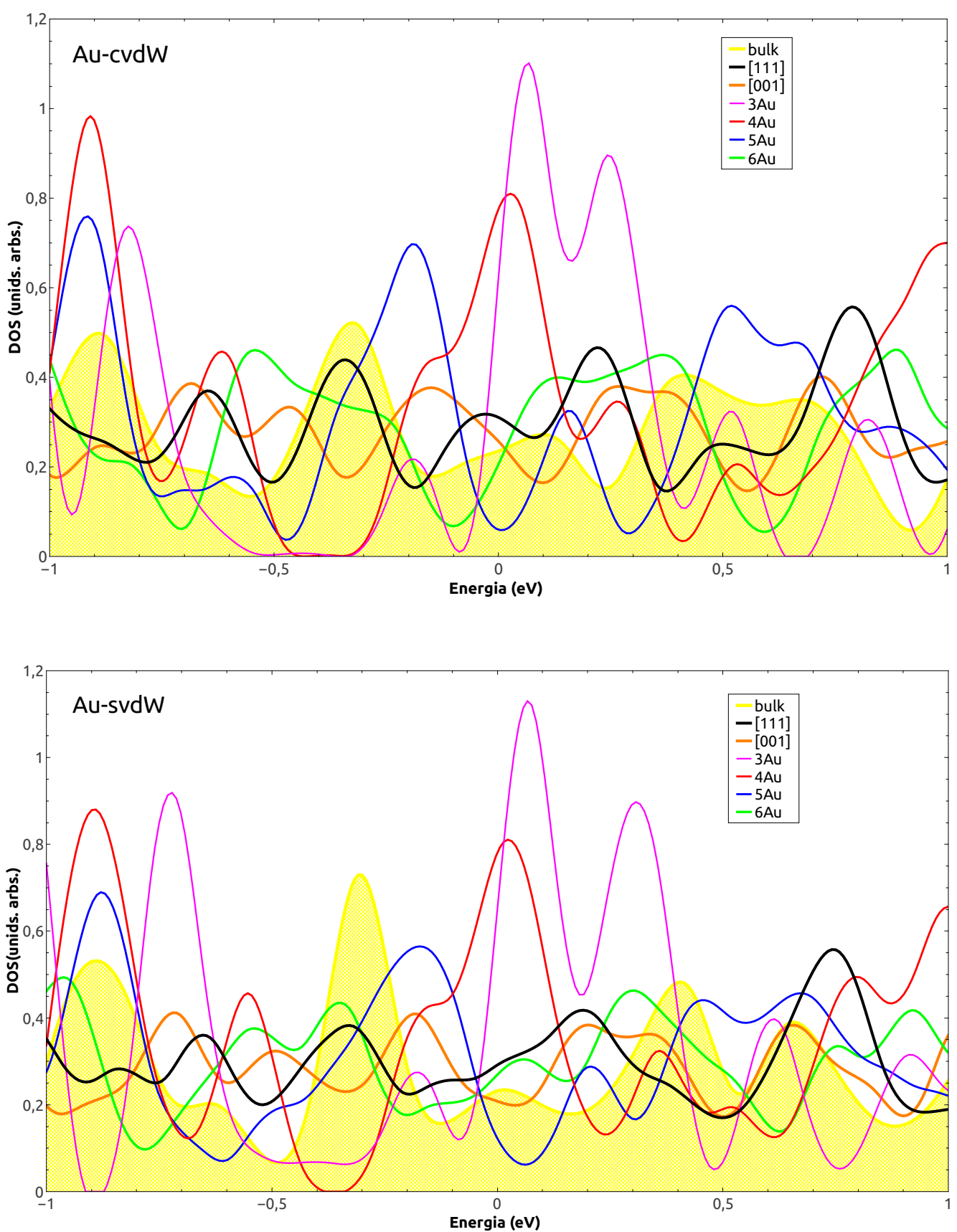

Figura 3.14: Densidade de estados das nanopartículas puras, superfícies [001] e [111] e bulk de Au com e sem van der Waals. 
são predominantes em relação às moleculares, são verificadas nas nanopartículas puras de $\mathrm{Ag}$ com mais de 300 átomos $(\sim 2,5 \mathrm{~nm})$ e com mais de 560 átomos ( 3,0 $\mathrm{nm}$ ) para as nanopartículas puras de Au.

Esses regimes de certa forma também podem ser acompanhados verificando os diagramas superiores das figuras 3.9 e 3.10 referentes as diferenças de energias de formação por átomo das nanopartículas puras (setas verticais à esquerda). A transição das diferenças de energia entre $3 \mathrm{Ag} \longrightarrow 6 \mathrm{Ag}$ acontece mais abruptamente que a transição entre $3 \mathrm{Au} \longrightarrow 6 \mathrm{Au}$, evidenciando que o caráter misto abrange uma região maior nestas últimas nanopartículas.

Finalmente, desses gráficos podemos verificar que não há qualquer diferença significativa das DOS apresentadas pelas nanopartículas puras de Ag e Au considerando ou não o uso das interações de van der Waals.

Os gráficos das figuras 3.15, 3.16, 3.17, 3.18, 3.19, 3.20, 3.21 e 3.22 representam as DOS das core-shell Au@Ag e Ag@Au em função do número de camadas de shell e de caroço, para as nanopartículas estudadas entre 147 e 923 átomos.

Em todos os casos as DOS das core-shell apresentam estados intermediários entre as nanopartículas puras e são definidos pelas camadas de shell. Praticamente uma única camada de shell já orienta a DOS em direção à nanopartícula pura correspondente ao shell.

Aqui também se verifica a tendência de aproximação das DOS das core-shell aos DOS das nanopartículas puras e bulks correspondentes às shell com o aumento das nanopartículas, aproximação esta também mais acentuada no caso das shell de Ag do que de Au. Novamente, como no caso das nanopartículas puras, as maiores core-shell apresentam um caráter mais cristalino correspondentes aos bulks das camadas shell, também moduladas por suas superfícies [001] e [111]. As camadas de caroço praticamente só tem uma maior influência na DOS das menores nanopartículas ou core-shell. Não se percebe alterações significativas entre os cálculos com e sem o uso das interações de van der Waals, mantendo as core-shell praticamente com o mesmo padrão nos dois cálculos. 

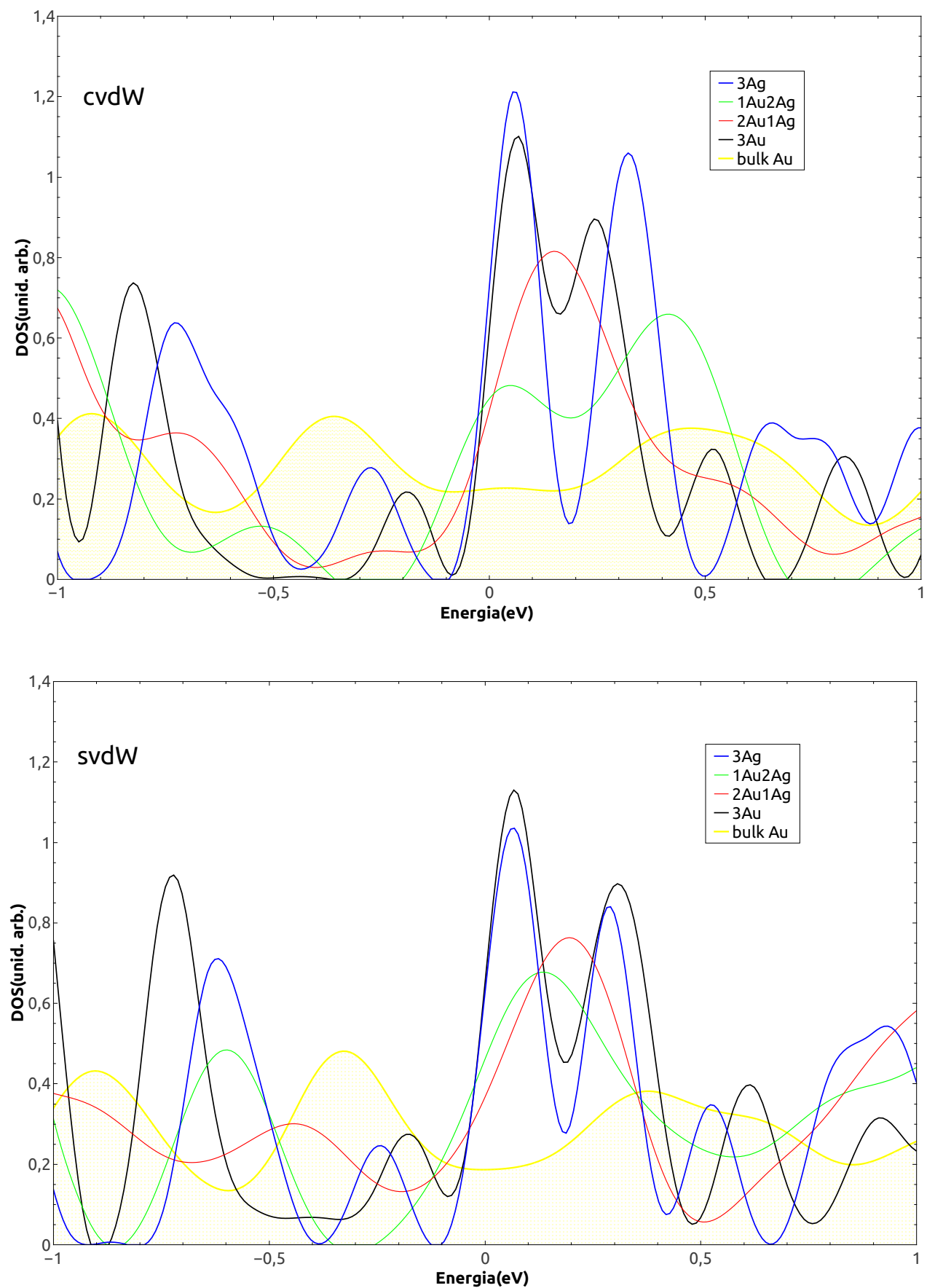

Figura 3.15: Densidade de estados das core-shell 147 com caroço de Ag e variações das camadas de shell de Au com e sem interação de van der Waals. 

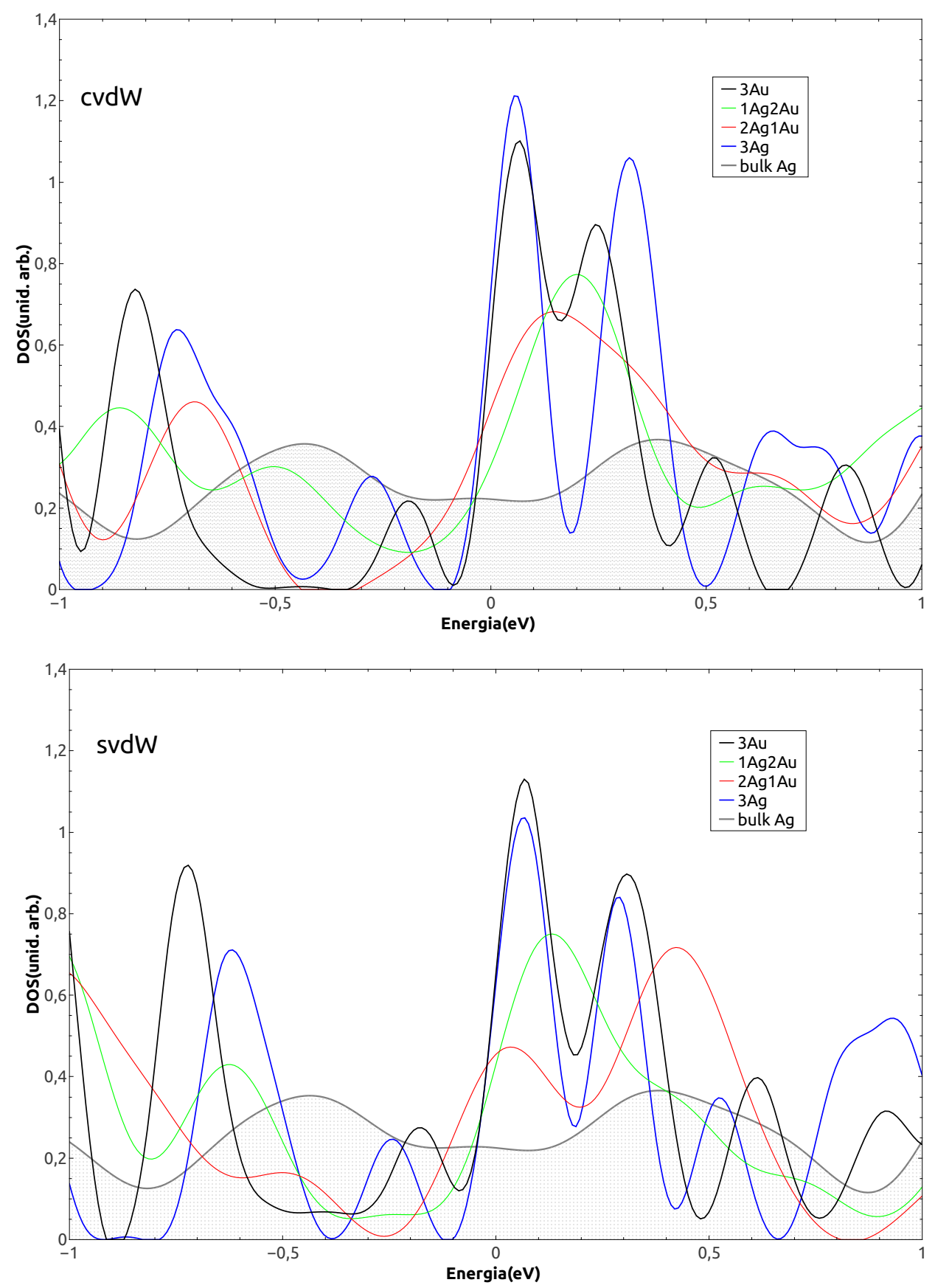

Figura 3.16: Densidade de estados das core-shell 147 com caroço de Au e variações das camadas de shell de Ag com e sem interação de van der Waals. 

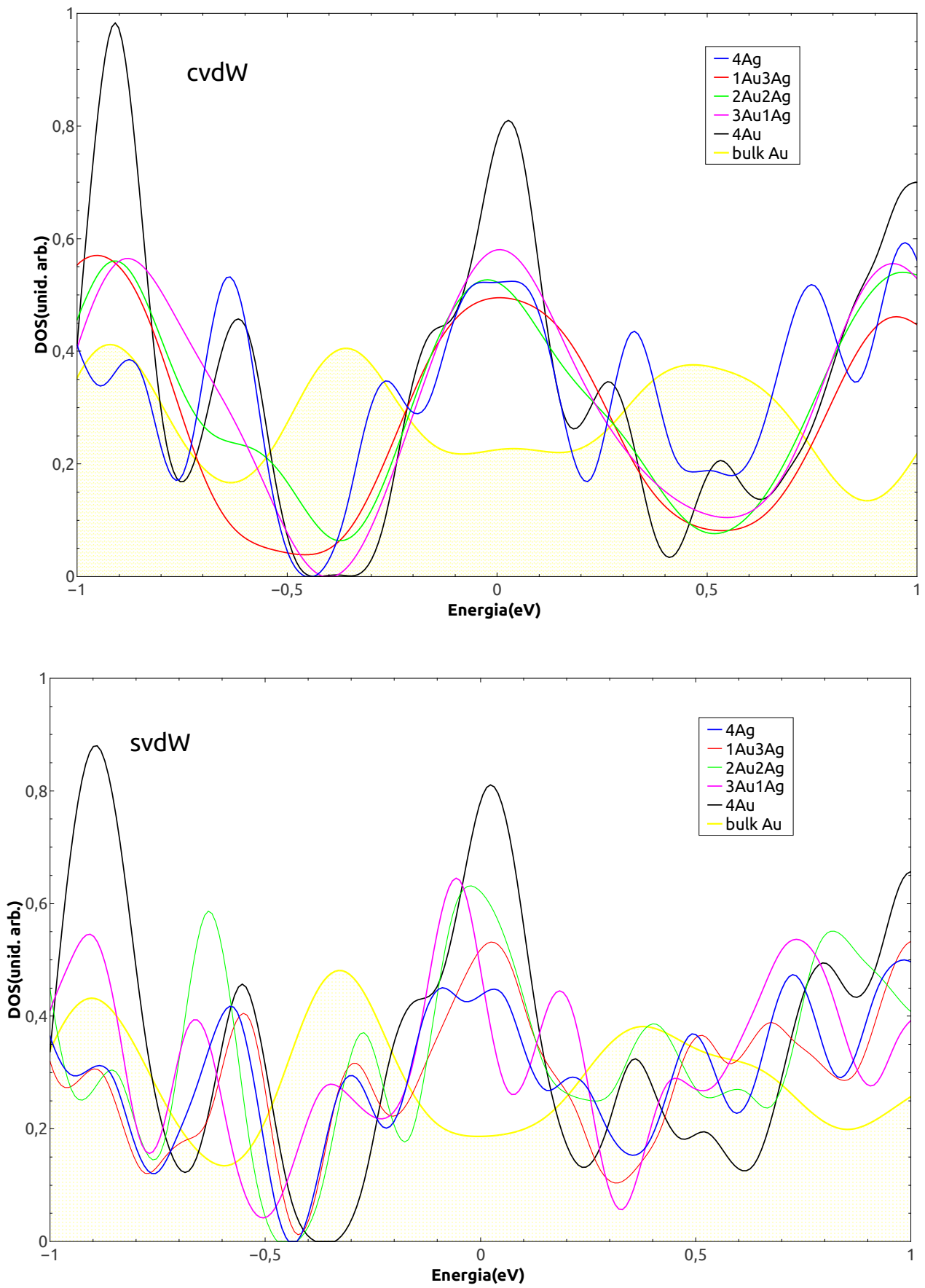

Figura 3.17: Densidade de estados das core-shell 309 com caroço de Ag e variações das camadas de shell de Au com e sem interação de van der Waals. 

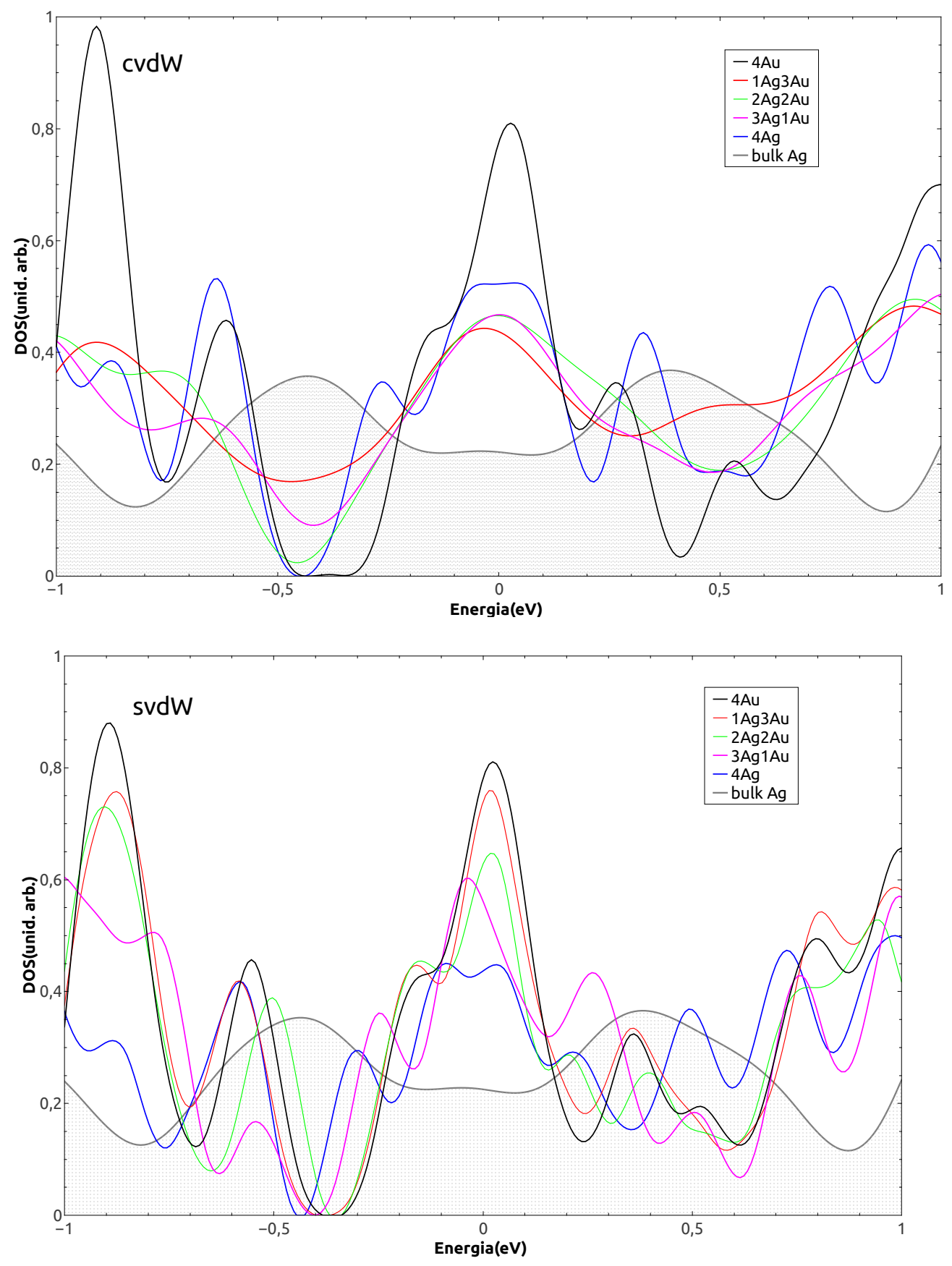

Figura 3.18: Densidade de estados das core-shell 309 com caroço de Au e variações das camadas de shell de Ag com e sem interação de van der Waals. 

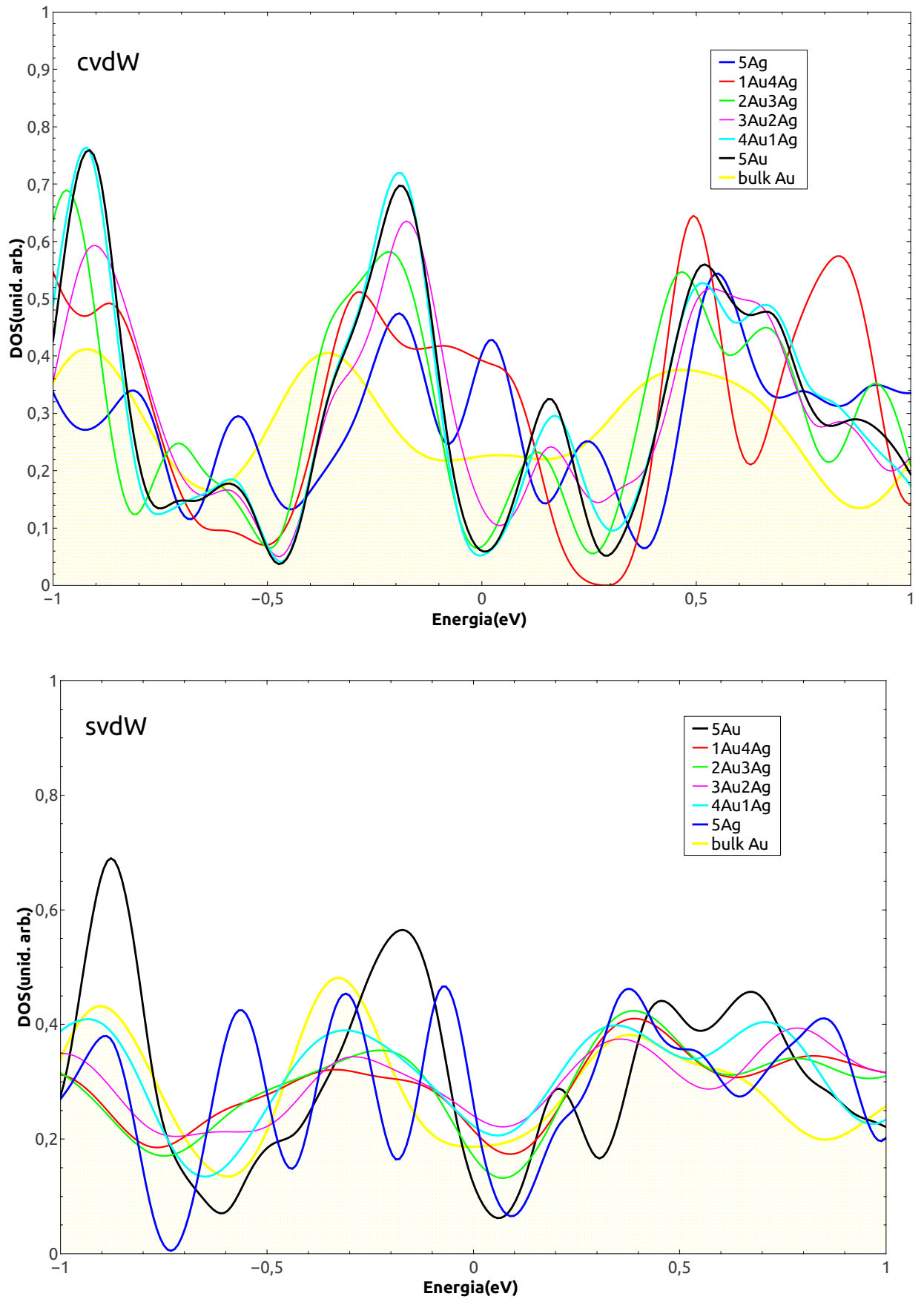

Figura 3.19: Densidade de estados das core-shell 561 com caroço de Ag e variações das camadas de shell de Au com e sem interação de van der Waals. 

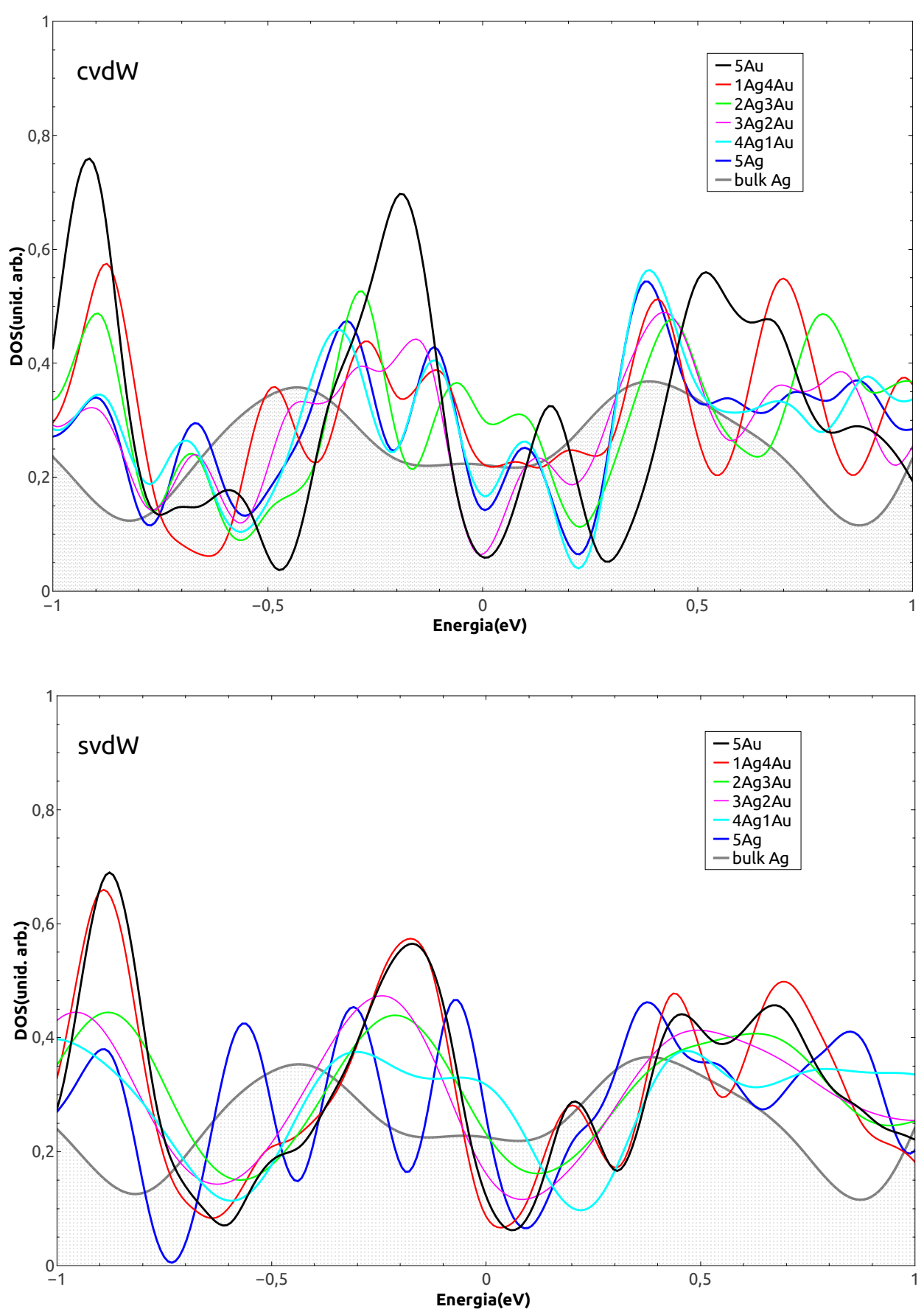

Figura 3.20: Densidade de estados das core-shell 561 com caroço de Au e variações das camadas de shell de Ag com e sem interação de van der Waals. 

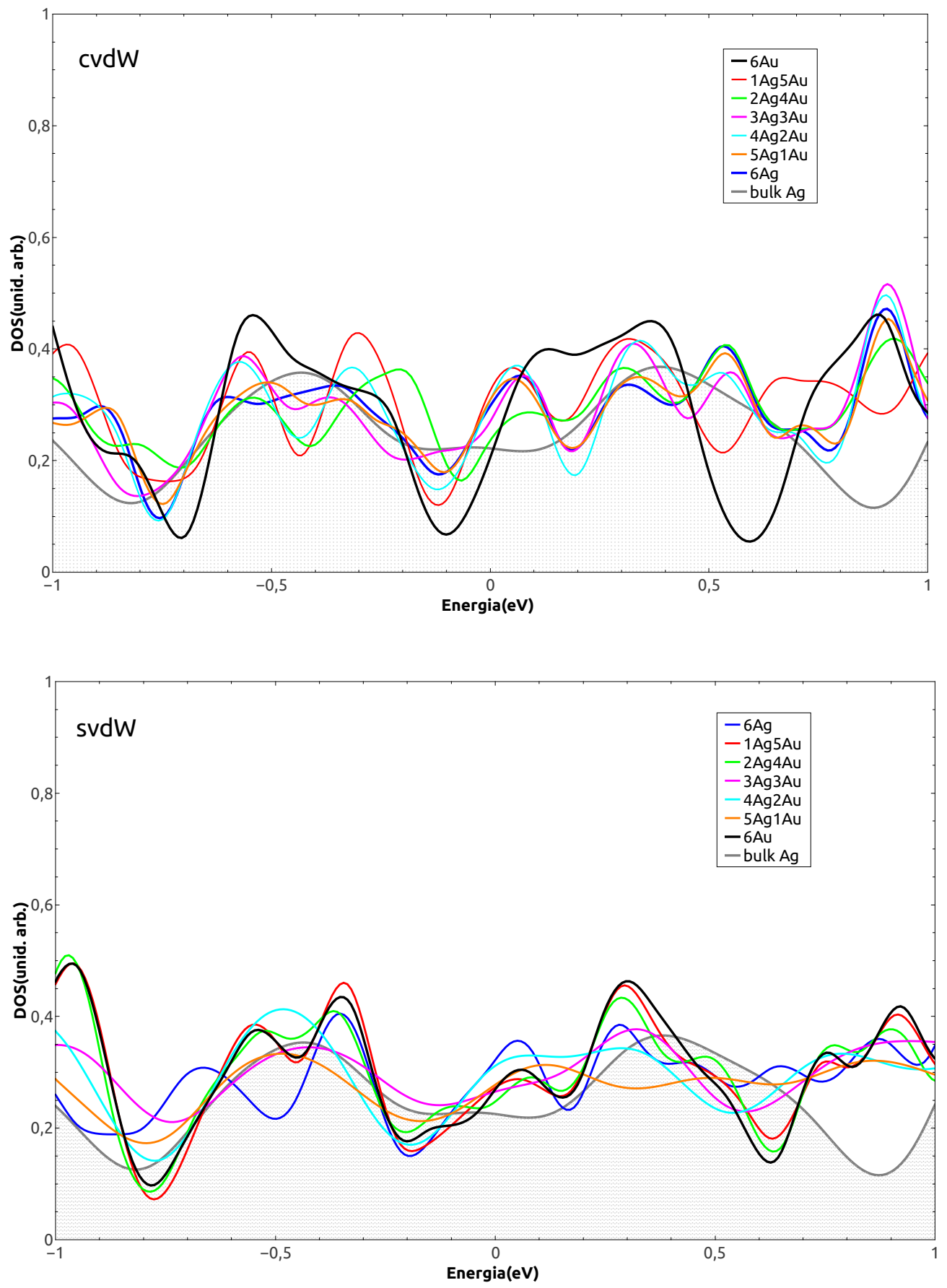

Figura 3.21: Densidade de estados das core-shell 923 com caroço de Ag e variações das camadas de shell de Au com e sem interação de van der Waals. 

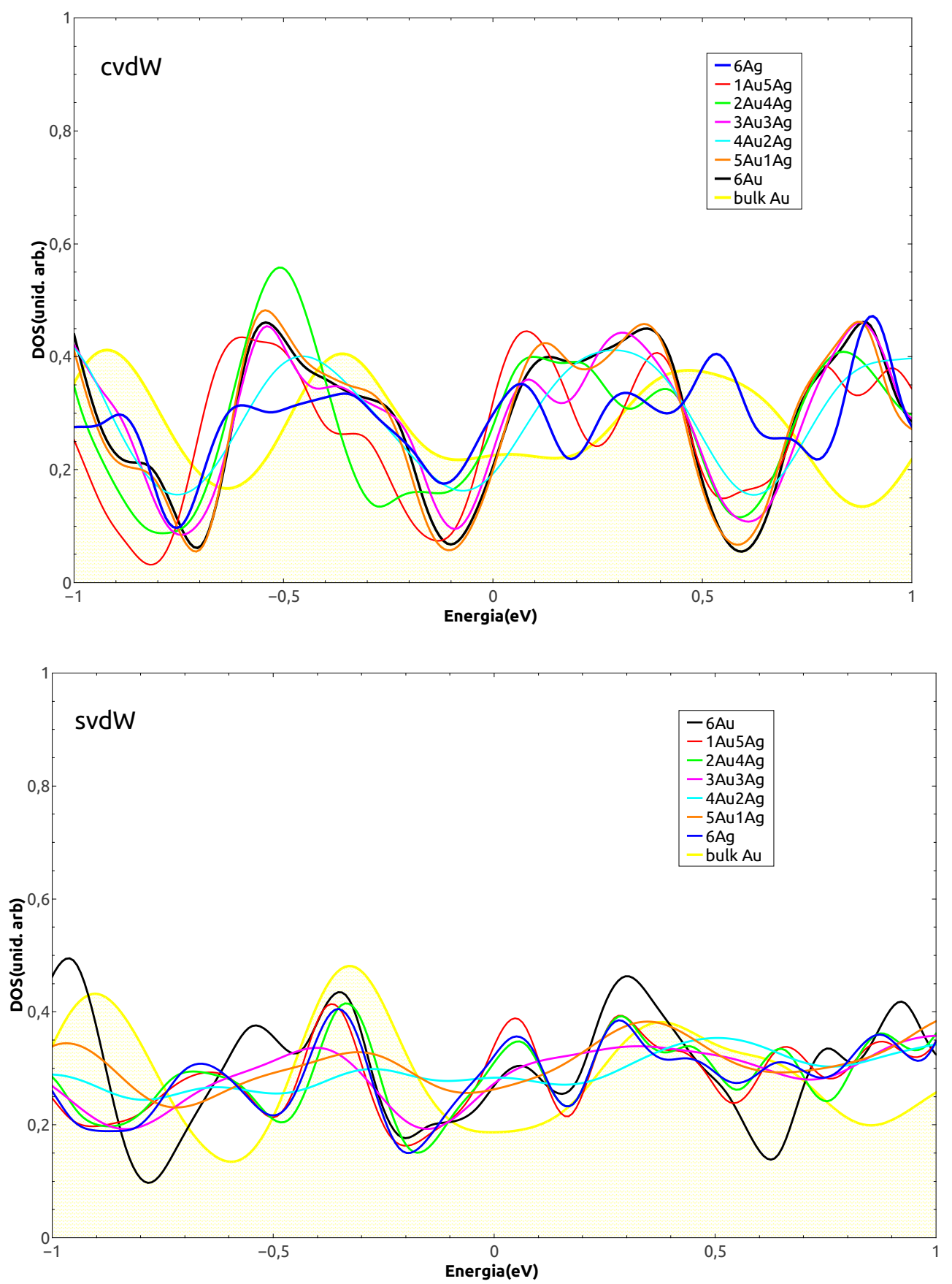

Figura 3.22: Densidade de estados das core-shell 923 com caroço Au e variações das camadas de shell de Ag com e sem interação de van der Waals. 


\section{Capítulo 4}

\section{Adsorção da molécula de metanotiol nas nanopartículas puras e core-shell}

Adicionalmente ao estudo das nanopartículas puras de prata e ouro e de suas coreshell, analisamos também os processos de adsorção da molécula de metanotiol $\left(\mathrm{SCH}_{4}\right)$ sobre a superfície daquelas estruturas em seus diferentes tamanhos.

A escolha da molécula de metanotiol $\left(\mathrm{SCH}_{4}\right)$ está relacionada com a presença dos seus átomos (C, S e H) em estruturas orgânicas de interesse biológico que são adsorvidas em superfícies e em nanopartículas metálicas [91, 101, 102].

As simulações foram realizadas considerando $290 \mathrm{eV}$ para a energia de corte na expansão da função de onda em ondas planas e os resultados obtidos para a molécula livre através do modelamento teórico utilizado, são apresentados no apêndice B. Em todo o estudo, só consideraremos adsorções incluindo a interação de van der Waals.

Nas figuras 4.1 e 4.2 estão representadas as adsorções do $\mathrm{SCH}_{4}$ sobre os sítios distintos (c5, c7, c8 e c9) presentes nas superfícies das nanopartículas 147, 309, 561 e 923.

\subsection{Propriedades energéticas das adsorções}

A energia de adsorção, $E_{a d s}^{n a n o}$, é calculada pela diferença entre a energia total do sistema com a molécula adsorvida e a soma das energias dos sistemas livres,

$$
E_{\text {ads }}^{\text {nano }}=E_{\text {sis }}^{\text {nano }}-\left(E_{\text {livre }}^{\text {nano }}+E_{\text {livre }}^{\text {mol }}\right),
$$

onde $E_{\text {sis }}^{\text {nano }}$, é a energia total do sistema adsorvido, $E_{\text {livre }}^{\text {nano }} E_{\text {livre }}^{\text {mol }}$ são, respectivamente, as energias totais da nanopartícula e da molécula livre. No caso da 


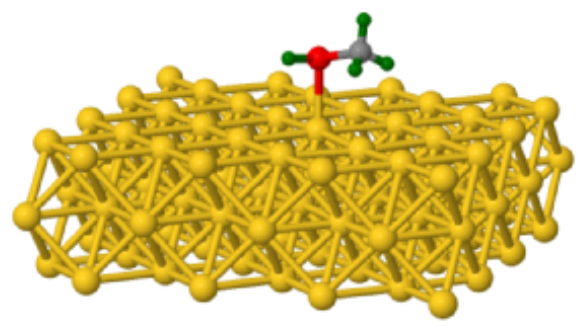

[001]

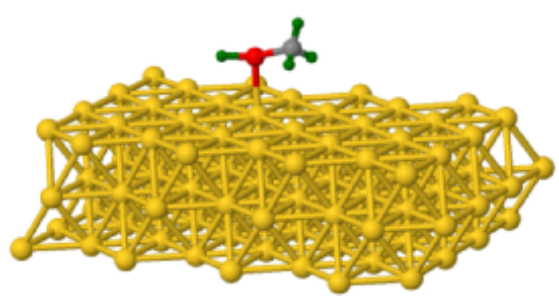

[111]

Figura 4.1: Representação das adsorções do metanotiol no sítio c8 da superfície [001] e no sítio c9 da superfície [111]. 
72 Adsorção da molécula de metanotiol nas nanopartículas puras e core-shell

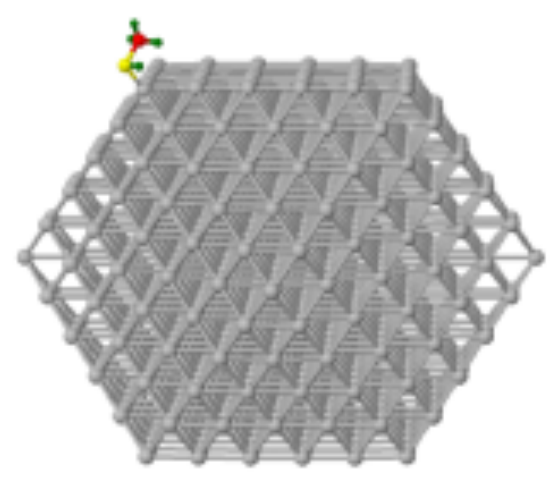

c5

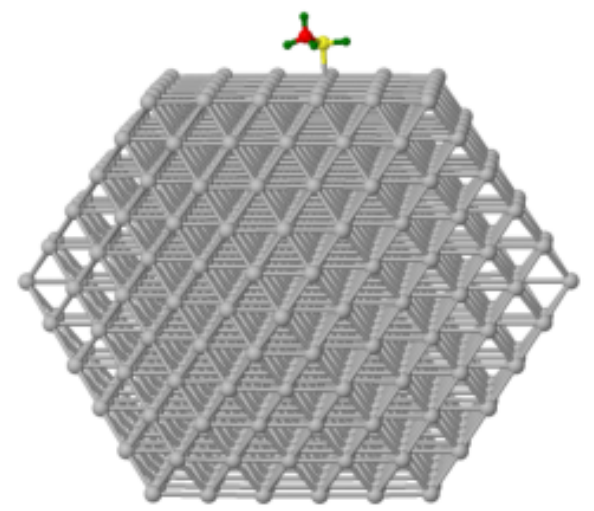

c8

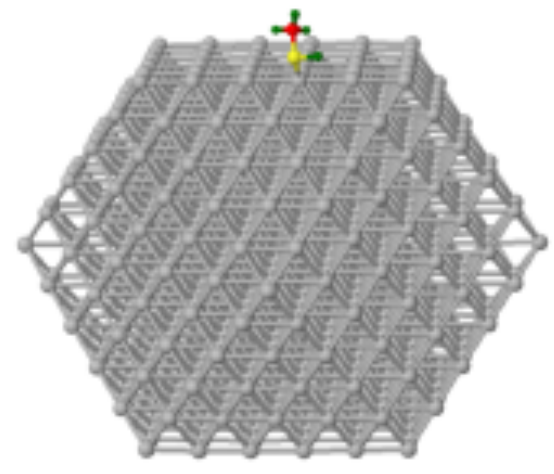

c7

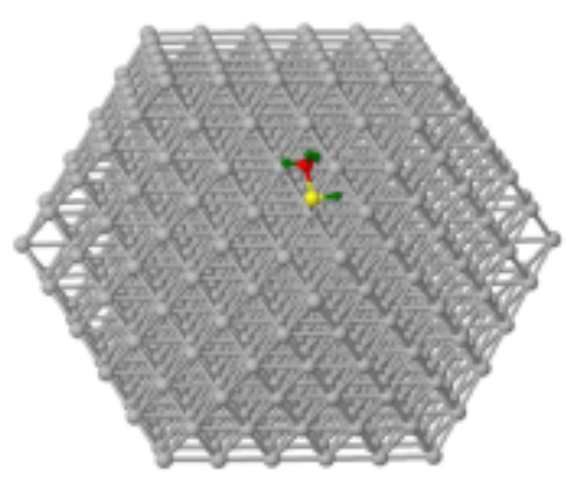

c9

Figura 4.2: Representação das adsorções do metanotiol no sítios c5, c7, c8 e c9 das nanopartículas puras de Ag com 561 átomos. 
adsorção do $\mathrm{SCH}_{4}$ nas superfícies [001] e [111], as energias de adsorção são obtidas por meio de,

$$
E_{\text {ads }}^{\text {sup }}=E_{\text {sis }}^{\text {sup }}-\left(E_{\text {livre }}^{\text {sup }}+E_{\text {livre }}^{\text {mol }}\right),
$$

onde $E_{\text {sis }}^{\text {sup }}$, é a energia total do sistema adsorvido, $E_{\text {livre }}^{\text {sup }} E_{\text {livre }}^{\text {mol }}$ são, respectivamente, as energias totais das superfícies e da molécula livre.

Nas tabelas 4.1 e 4.2 são apresentadas as energias de adsorção do $\mathrm{SCH}_{4}$ nas superfícies livres [001] e [111] do Ag e do Au. Conforme a figura 4.1, o sítio da superfície [001] é o c8 e o da [111] é o c9.

Tabela 4.1: Energia de adsorção, $E_{a d s}^{\text {sup }}$, em eV, da molécula de metanotiol $\left(\mathrm{SCH}_{4}\right)$ sobre as superfícies [001] e [111] da Ag.

\begin{tabular}{cc}
\hline \hline superfícies-Ag & $E_{a d s}^{\text {sup }}(\mathrm{eV})$ \\
{$[001]$} & $-0,4373$ \\
{$[111]$} & $-0,5764$ \\
\hline \hline
\end{tabular}

Tabela 4.2: Energia de adsorção, $E_{a d s}^{\text {sup }}$, em eV, da molécula de metanotiol $\left(\mathrm{SCH}_{4}\right)$ sobre as superfícies [001] e [111] do Au.

\begin{tabular}{cc}
\hline \hline superfícies-Au & $E_{\text {ads }}^{\text {sup }}(\mathrm{eV})$ \\
{$[001]$} & $-0,6451$ \\
{$[111]$} & $-0,6695$ \\
\hline \hline
\end{tabular}

Tabela 4.3: Energias de adsorção, $E_{a d s}^{\text {nano }}$, em eV, da molécula de metanotiol $\left(\mathrm{SCH}_{4}\right)$ sobre as nanopartículas puras de Ag.

\begin{tabular}{ccccc}
\hline \hline \multirow{2}{*}{ nanopartícula } & \multicolumn{4}{c}{ sítios } \\
& $\mathrm{c} 5$ & $\mathrm{c} 7$ & $\mathrm{c} 8$ & $\mathrm{c} 9$ \\
\hline \hline $3 \mathrm{Ag}$ & $-0,5323$ & $-0,4814$ & $-0,4342$ & $-0,3816$ \\
$4 \mathrm{Ag}$ & $-0,5294$ & $-0,4790$ & $-0,4298$ & $-0,3807$ \\
$5 \mathrm{Ag}$ & $-0,5247$ & $-0,4655$ & $-0,4110$ & $-0,3702$ \\
$6 \mathrm{Ag}$ & $-0,5203$ & $-0,4451$ & $-0,4080$ & $-0,3650$ \\
\hline \hline
\end{tabular}

Estudos anteriores realizados com nanopartículas puras de prata [3] indicavam que moléculas adsorvidas nessas estruturas tinham maior probabilidade de serem 
Tabela 4.4: Energias de adsorção, $E_{a d s}^{n a n o}$, em eV, da molécula de metanotiol $\left(\mathrm{SCH}_{4}\right)$ sobre as nanopartículas puras de $\mathrm{Au}$.

\begin{tabular}{ccccc}
\hline \hline nanopartícula & \multicolumn{4}{c}{ sítios } \\
& $\mathrm{c} 5$ & $\mathrm{c} 7$ & $\mathrm{c} 8$ & $\mathrm{c} 9$ \\
\hline \hline $3 \mathrm{Au}$ & $-0,8287$ & $-0,8172$ & $-0,8055$ & $-0,7238$ \\
$4 \mathrm{Au}$ & $-0,7746$ & $-0,7556$ & $-0,7145$ & $-0,6808$ \\
$5 \mathrm{Au}$ & $-0,5557$ & $-0,4129$ & $-0,4119$ & $-0,3592$ \\
$6 \mathrm{Au}$ & $-0,5395$ & $-0,5113$ & $-0,4273$ & $-0,3371$ \\
\hline \hline
\end{tabular}

adsorvidas no sítio de coordenação c5, decrescendo essa probabilidade dos sítios c7 até o c9. As tabelas 4.3 e 4.4 indicam as energias de adsorção da molécula de metanotiol nas nanopartículas puras de Ag e de Au nos sítios c5, c7 (aresta), c8 (superfície [001]) e c9 (superfície [111]) em função da dimensão da nanopartícula. A tabela 4.5 mostra a mesma sequência de adsorção nas core-shell com 561 átomos com uma ou duas camadas de shell de Au ou de Ag. Em todos os casos a sequência c5, c7, c8, c9 do sítio mais provável de adsorção ao menos provável é observada.

Nas nanopartículas puras as adsorções nos vários sítios descrecem com o aumento da nanopartícula sendo esse decréscimo mais acentuado nas nanopartículas de Au. A partir de 561 átomos as energias de adsorção já são praticamente equivalentes (mais ainda no caso da $\mathrm{Ag}$ ) indicando que o regime cristalino, com pequena perturbação das superfícies, é preponderante no caso das adsorções. A maior diferença no caso das nanopartículas de Au decorre do fato verificado nas densidades de estado, onde as nanopartículas de Au tem ainda maior dependência do caráter molecular e de superfície até as nanopartículas de 561 átomos. Além disso, os valores da energia de adsorção no sítio mais provável, c5, nas maiores nanopartículas são muito próximos na prata e no ouro, indicando que nas nanopartículas puras de $\mathrm{Au}$ e de $\mathrm{Ag}$, o metanotiol é adsorvido com a mesma probabilidade.

O mesmo decréscimo de probabilidade de adsorção entre os sítios c5 e c9 é observado nas core-shell, evidenciado na tabela 4.5 de energias de adsorção do metanotiol sobre core-shell com uma ou duas camadas de shell de Au ou de Ag em nanopartículas com 561 átomos. Enquanto as adsorções sobre uma ou duas camadas de shell de Ag já apresentam um comportamento próximo às adsorções sobre as maiores nanopartículas puras de $\mathrm{Ag}$, com regime mais cristalino, as adsorções sobre uma ou duas camadas de shell de Au tem comportamento mais próximo às nanopartículas puras menores de Au que tem maior perturbação dos 
Tabela 4.5: Energias de adsorção, $E_{\text {ads }}^{\text {nano }}$, em eV, da molécula de metanotiol $\left(\mathrm{SCH}_{4}\right)$ sobre as core-shell com 561 átomos.

\begin{tabular}{ccccc}
\hline \hline nanopartícula & \multicolumn{4}{c}{ sítios } \\
& c5 & c7 & c8 & c9 \\
\hline \hline $1 \mathrm{Au} @ 4 \mathrm{Ag}$ & $-0,7407$ & $-0,6453$ & $-0,5906$ & $-0,5834$ \\
$2 \mathrm{Au} 3 \mathrm{Ag}$ & $-0,6706$ & $-0,6295$ & $-0,5733$ & $-0,5163$ \\
$1 \mathrm{Ag} 44 \mathrm{Au}$ & $-0,5522$ & $-0,4481$ & $-0,4202$ & $-0,3479$ \\
$2 \mathrm{Ag} @ 3 \mathrm{Au}$ & $-0,5519$ & $-0,4475$ & $-0,4175$ & $-0,3475$ \\
\hline \hline
\end{tabular}

regimes moleculares e de superfície.

As tabelas 4.6, 4.7, 4.8 e 4.9 mostram as energias de adsorção do metanotiol sobre o sítio c5, de maior probabilidade, em todas as core-shell estudadas, respectivamente com 147, 309, 561 e 923 átomos. Em todos os casos, aumentando-se o número de camadas shell das core-shell, tanto de Au quanto de Ag, a energia de adsorção sobre a core-shell se aproxima da energia de adsorção sobre a nanopartícula pura correspondente. Energias de adsorção em torno de um regime entre -0,52 eV e -0,55 eV já é observado em todas as core-shell com shell de Ag à partir de 561 átomos, enquanto nas com shell de Au só surge claramente com 923 átomos. Novamente aqui nas adsorções sobre as core-shell como sobre as nanopartículas puras, as energias de adsorção sobre o sítio mais provável, c5, nas nanopartículas maiores, praticamente se estabilizam em uma energia de adsorção por volta de $-0,50 \mathrm{eV}$ para todas as core-shell, independente do número de camadas shell tanto de Au quanto de Ag. Uma única camada shell já define o padrão equivalente ao da nanopartícula pura equivalente ao shell.

Tabela 4.6: Energias de adsorção, $E_{a d s}^{\text {nano }}$, em eV, da molécula de metanotiol $\left(\mathrm{SCH}_{4}\right)$ no sítio c5 das nanopartículas puras e core-shell com 147 átomos.

\begin{tabular}{cc}
\hline \hline nanopartícula & $E_{a d s}^{\text {nano }}(\mathrm{eV})$ \\
\hline \hline $1 \mathrm{Ag} @ 2 \mathrm{Au}$ & $-0,5801$ \\
$2 \mathrm{Ag} @ 1 \mathrm{Au}$ & $-0,5524$ \\
$3 \mathrm{Ag}$ & $-0,5323$ \\
$1 \mathrm{Au} @ 2 \mathrm{Ag}$ & $-0,7616$ \\
$2 \mathrm{Au} @ 1 \mathrm{Ag}$ & $-0,7867$ \\
$3 \mathrm{Au}$ & $-0,8287$ \\
\hline \hline
\end{tabular}


76 Adsorção da molécula de metanotiol nas nanopartículas puras e core-shell

Tabela 4.7: Energias de adsorção, $E_{a d s}^{\text {nano }}$, em eV, da molécula de metanotiol $\left(\mathrm{SCH}_{4}\right)$ no sítio c5 das nanopartículas puras e core-shell com 309 átomos.

\begin{tabular}{cc}
\hline \hline nanopartícula & $E_{a d s}^{\text {nano }}(\mathrm{eV})$ \\
\hline \hline $1 \mathrm{Ag} @ 3 \mathrm{Au}$ & $-0,4315$ \\
$2 \mathrm{Ag} @ 2 \mathrm{Au}$ & $-0,4418$ \\
$3 \mathrm{Ag} 1 \mathrm{Au}$ & $-0,5313$ \\
$4 \mathrm{Ag}$ & $-0,5294$ \\
$1 \mathrm{Au} @ 3 \mathrm{Ag}$ & $-0,6467$ \\
$2 \mathrm{Au} @ 2 \mathrm{Ag}$ & $-0,6578$ \\
$3 \mathrm{Au} @ 1 \mathrm{Ag}$ & $-0,6624$ \\
$4 \mathrm{Au}$ & $-0,7746$ \\
\hline \hline
\end{tabular}

Tabela 4.8: Energias de adsorção, $E_{a d s}^{\text {nano }}$, em eV, da molécula de metanotiol $\left(\mathrm{SCH}_{4}\right)$ no sítio c5 das nanopartículas puras e core-shell com 561 átomos.

\begin{tabular}{cc}
\hline \hline nanopartícula & $E_{\text {ads }}^{\text {nano }}(\mathrm{eV})$ \\
\hline \hline $1 \mathrm{Ag} @ 4 \mathrm{Au}$ & $-0,5522$ \\
$2 \mathrm{Ag} @ 3 \mathrm{Au}$ & $-0,5519$ \\
$3 \mathrm{Ag} @ 2 \mathrm{Au}$ & $-0,5514$ \\
$4 \mathrm{Ag} @ 1 \mathrm{Au}$ & $-0,5510$ \\
$5 \mathrm{Ag}$ & $-0,5247$ \\
$1 \mathrm{Au} @ 4 \mathrm{Ag}$ & $-0,7407$ \\
$2 \mathrm{Au} @ 3 \mathrm{Ag}$ & $-0,6706$ \\
$3 \mathrm{Au} @ 2 \mathrm{Ag}$ & $-0,6016$ \\
$4 \mathrm{Au} @ 1 \mathrm{Ag}$ & $-0,5506$ \\
$5 \mathrm{Au}$ & $-0,5557$ \\
\hline \hline
\end{tabular}


Tabela 4.9: Energias de adsorção, $E_{\text {ads }}^{\text {nano }}$, em eV, da molécula de metanotiol $\left(\mathrm{SCH}_{4}\right)$ no sítio c5 das nanopartículas puras e core-shell com 923 átomos.

\begin{tabular}{cc}
\hline \hline nanopartícula & $E_{\text {ads }}^{\text {ano }}(\mathrm{eV})$ \\
\hline \hline $1 \mathrm{Ag} @ 5 \mathrm{Au}$ & $-0,5294$ \\
$2 \mathrm{Ag} @ 4 \mathrm{Au}$ & $-0,5278$ \\
$3 \mathrm{Ag} @ 3 \mathrm{Au}$ & $-0,5223$ \\
$4 \mathrm{Ag} @ 2 \mathrm{Au}$ & $-0,5203$ \\
$5 \mathrm{Ag} @ 1 \mathrm{Au}$ & $-0,5137$ \\
$6 \mathrm{Ag}$ & $-0,5203$ \\
$1 \mathrm{Au} @ 5 \mathrm{Ag}$ & $-0,4944$ \\
$2 \mathrm{Au} @ 4 \mathrm{Ag}$ & $-0,5173$ \\
$3 \mathrm{Au} @ 3 \mathrm{Ag}$ & $-0,5222$ \\
$4 \mathrm{Au} @ 2 \mathrm{Ag}$ & $-0,5242$ \\
$5 \mathrm{Au} @ 1 \mathrm{Ag}$ & $-0,5265$ \\
$6 \mathrm{Au}$ & $-0,5395$ \\
\hline \hline
\end{tabular}

\subsection{Propriedades estruturais das adsorções}

As tabelas 4.10 e 4.11 apresentam os parâmetros estruturais referentes à adsorção da molécula de metanotiol sobre as superfícies livres da prata e do ouro. As distâncias das ligações S-H, S-C e C-H da molécula permanecem as mesmas da molécula livre (apêndice B). Não há qualquer alteração no comprimento das ligações moleculares para a molécula adsorvida sobre as superfícies [001] e [111] tanto da $\mathrm{Ag}$ quanto do Au. As ligações do enxofre com os átomos de prata das superfícies [001], sítio de coordenação c8, e [111], sítio c9, são, respectivamente, $0,09 \AA$ e $0,07 \AA$ maiores do que as mesmas ligações com as superfícies de ouro. Essas distâncias $\mathrm{Au}-\mathrm{S}$ são todas bem inferiores as distâncias entre os átomos da superfície que adsorveu a molécula e seus vizinhos. O comprimento das ligações entre o átomo do sítio c8, superfície [001], de Ag que adsorveu a molécula e seus primeiros vizinhos é somente $0,02 \AA$ superior a distância equivalente na superfície de $\mathrm{Au}$, enquanto que o comprimento entre o átomo do sítio c9, superfície [111], de Ag e seus vizinhos é $0,03 \AA$ superior a seus equivalentes na superfície de $A u$.

A distância média entre um átomo da superfície livre [001] da prata, sítio c8, e seus primeiros vizinhos é de $2,96 \AA$ e de mesmo valor na superfície livre [111], sítio c9. Nas superfícies livres [001] e [111] do ouro, essa distância média é de $2,92 \AA$. Dessa forma, verificamos que quando esses sítios adsorvem a molécula de 
78 Adsorção da molécula de metanotiol nas nanopartículas puras e core-shell

Tabela 4.10: Parâmetros estruturais da adsorção da molécula de metanotiol $\left(\mathrm{SCH}_{4}\right)$ nas superfícies de Ag: distância média entre o sítio de adsorção e os seus primeiros vizinhos na superfície $(\mathrm{Ag}-\mathrm{Ag})$; distância média da ligação entre o átomo de prata $(\mathrm{Ag})$ do sítio adsorvido e o átomo de enxofre $(\mathrm{S})$ da molécula (Ag-S). Distâncias médias entre os átomos que compõe a molécula, S-H, S-C e C-H, respectivamente. Distâncias em Angstrom $(\AA)$.

\begin{tabular}{|c|c|c|c|c|c|}
\hline superfície & $\operatorname{Ag}-\mathrm{Ag}(\AA)$ & $\mathrm{Ag}-\mathrm{S}(\AA)$ & $\mathrm{S}-\mathrm{H}(\AA)$ & $\mathrm{S}-\mathrm{C}(\AA)$ & $\mathrm{C}-\mathrm{H}(\AA)$ \\
\hline \hline 001 & 2,99 & 2,59 & 1,35 & 1,82 & 1,10 \\
\hline 111 & 2,98 & 2,63 & 1,35 & 1,82 & 1,10 \\
\hline
\end{tabular}

Tabela 4.11: Parâmetros estruturais da adsorção da molécula de metanotiol $\left(\mathrm{SCH}_{4}\right)$ nas superfícies de Au: distância média entre o sítio de adsorção e os seus primeiros vizinhos na superfície $(\mathrm{Au}-\mathrm{Au})$; distância média da ligação entre o átomo de ouro $(\mathrm{Au})$ do sítio adsorvido e o átomo de enxofre $(\mathrm{S})$ da molécula $(\mathrm{Ag}-\mathrm{S})$. Distâncias médias entre os átomos que compõe a molécula, S-H, S-C e C-H, respectivamente. Distâncias em Angstrom $(\AA)$.

\begin{tabular}{|c|c|c|c|c|c|}
\hline superfície & $\mathrm{Au}-\mathrm{Au}(\AA)$ & $\mathrm{Au}-\mathrm{S}(\AA)$ & $\mathrm{S}-\mathrm{H}(\AA)$ & $\mathrm{S}-\mathrm{C}(\AA)$ & $\mathrm{C}-\mathrm{H}(\AA)$ \\
\hline \hline 001 & 2,97 & 2,50 & 1,35 & 1,82 & 1,10 \\
\hline 111 & 2,95 & 2,56 & 1,35 & 1,82 & 1,10 \\
\hline
\end{tabular}


Tabela 4.12: Parâmetros estruturais da adsorção da molécula de metanotiol $\left(\mathrm{SCH}_{4}\right)$ nas nanopartículas puras de Ag: distância média entre o sítio de adsorção e os seus primeiros vizinhos na nanopartícula $(\mathrm{Ag}-\mathrm{Ag})$; distância média da ligação entre o átomo de prata $(\mathrm{Ag})$ do sítio adsorvido e o átomo de enxofre (S) da molécula (Ag-S). Distâncias médias entre os átomos que compõe a molécula, S-H, S-C e C-H, respectivamente e deslocamento do sítio c5. Distâncias em $\operatorname{Angstrom}(\AA)$.

\begin{tabular}{|c|c|c|c|c|c|c|c|}
\hline nanopartícula & sítio & $\operatorname{Ag}-\operatorname{Ag}(\AA)$ & $\mathrm{Ag}-\mathrm{S}(\AA)$ & $\mathrm{S}-\mathrm{H}(\AA)$ & $\mathrm{S}-\mathrm{C}(\AA)$ & $\mathrm{C}-\mathrm{H}(\AA)$ & $\mathrm{c} 5(\AA)$ \\
\hline \multirow{4}{*}{$3 \mathrm{Ag}$} & $\mathrm{c} 5$ & 2,88 & 2,56 & 1,35 & 1,83 & 1,10 & $+0,04(0,47 \%)$ \\
\hline & $\mathrm{c} 7$ & 2,93 & 2,58 & 1,35 & 1,82 & 1,10 & \\
\hline & $\mathrm{c} 8$ & 2,99 & 2,59 & 1,35 & 1,82 & 1,10 & \\
\hline & c9 & 3,00 & 2,60 & 1,35 & 1,82 & 1,10 & \\
\hline \multirow{4}{*}{$4 \mathrm{Ag}$} & $\mathrm{c} 5$ & 2,90 & 2,57 & 1,35 & 1,83 & 1,10 & $+0,04(0,35 \%)$ \\
\hline & $\mathrm{c} 7$ & 2,93 & 2,58 & 1,35 & 1,82 & 1,10 & \\
\hline & $\mathrm{c} 8$ & 2,99 & 2,59 & 1,35 & 1,82 & 1,10 & \\
\hline & c9 & 2,99 & 2,60 & 1,35 & 1,83 & 1,10 & \\
\hline \multirow{4}{*}{$5 \mathrm{Ag}$} & $\mathrm{c} 5$ & 2,88 & 2,57 & 1,35 & 1,83 & 1,10 & $+0,01(0,07 \%)$ \\
\hline & $\mathrm{c} 7$ & 2,94 & 2,58 & 1,35 & 1,83 & 1,10 & \\
\hline & $\mathrm{c} 8$ & 2,98 & 2,59 & 1,35 & 1,82 & 1,10 & \\
\hline & c9 & 2,99 & 2,59 & 1,35 & 1,82 & 1,10 & \\
\hline \multirow{4}{*}{$6 \mathrm{Ag}$} & $\mathrm{c} 5$ & 2,88 & 2,57 & 1,35 & 1,82 & 1,10 & $+0,01(0,06 \%)$ \\
\hline & $\mathrm{c} 7$ & 2,93 & 2,58 & 1,35 & 1,82 & 1,10 & \\
\hline & $\mathrm{c} 8$ & 2,99 & 2,59 & 1,35 & 1,83 & 1,10 & \\
\hline & c9 & 2,99 & 2,60 & 1,35 & 1,83 & 1,10 & \\
\hline
\end{tabular}


Tabela 4.13: Parâmetros estruturais da adsorção da molécula de metanotiol $\left(\mathrm{SCH}_{4}\right)$ nas nanopartículas puras de $\mathrm{Au}$ : distância média entre o sítio de adsorção e os seus primeiros vizinhos na nanopartícula $(\mathrm{Au}-\mathrm{Au})$; distância média da ligação entre o átomo de ouro $(\mathrm{Au})$ do sítio adsorvido e o átomo de enxofre (S) da molécula $(\mathrm{Au}-\mathrm{S})$. Distâncias médias entre os átomos que compõe a molécula, S-H, S-C e C-H, respectivamente e deslocamento do sítio c5. Distâncias em $\operatorname{Angstrom}(\AA)$.

\begin{tabular}{|c|c|c|c|c|c|c|c|}
\hline nanopartícula & sítio & $\mathrm{Au}-\mathrm{Au}(\AA)$ & $\mathrm{Au}-\mathrm{S}(\AA)$ & $\mathrm{S}-\mathrm{H}(\AA)$ & $\mathrm{S}-\mathrm{C}(\AA)$ & $\mathrm{C}-\mathrm{H}(\AA)$ & $\mathrm{c} 5(\AA)$ \\
\hline \hline \multirow{5}{*}{$3 \mathrm{Au}$} & $\mathrm{c} 5$ & 2,90 & 2,46 & 1,35 & 1,83 & 1,10 & $+0,04(0,46 \%)$ \\
& $\mathrm{c} 7$ & 2,91 & 2,49 & 1,35 & 1,82 & 1,10 & \\
& $\mathrm{c} 8$ & 2,95 & 2,53 & 1,35 & 1,82 & 1,10 & \\
& $\mathrm{c} 9$ & 2,98 & 2,53 & 1,35 & 1,82 & 1,10 & \\
\hline \multirow{5}{*}{$4 \mathrm{Au}$} & $\mathrm{c} 5$ & 2,91 & 2,45 & 1,35 & 1,83 & 1,10 & $+0,03(0,27 \%)$ \\
& $\mathrm{c} 7$ & 2,91 & 2,47 & 1,35 & 1,82 & 1,10 & \\
& $\mathrm{c} 8$ & 2,95 & 2,50 & 1,35 & 1,82 & 1,10 & \\
& $\mathrm{c} 9$ & 2,97 & 2,54 & 1,35 & 1,83 & 1,10 & \\
\hline \multirow{5}{*}{$5 \mathrm{Au}$} & $\mathrm{c} 5$ & 2,90 & 2,44 & 1,35 & 1,83 & 1,10 & $+0,01(0,07 \%)$ \\
& $\mathrm{c} 7$ & 2,91 & 2,47 & 1,35 & 1,83 & 1,10 & \\
& $\mathrm{c} 8$ & 2,95 & 2,51 & 1,35 & 1,82 & 1,10 & \\
& $\mathrm{c} 9$ & 2,97 & 2,52 & 1,35 & 1,82 & 1,10 & \\
\hline \multirow{5}{*}{$6 \mathrm{Au}$} & $\mathrm{c} 5$ & 2,89 & 2,45 & 1,35 & 1,82 & 1,10 & $+0,01(0,06 \%)$ \\
& $\mathrm{c} 7$ & 2,91 & 2,48 & 1,35 & 1,82 & 1,10 & \\
& $\mathrm{c} 8$ & 2,95 & 2,49 & 1,35 & 1,83 & 1,10 & \\
& $\mathrm{c} 9$ & 2,96 & 2,52 & 1,35 & 1,83 & 1,10 & \\
& & & & & & \\
& & & & & \\
& & & &
\end{tabular}


metanotiol, há um alongamento dessas ligações sendo maior no caso das adsorções no $\mathrm{Au}(+0,03 \AA \longmapsto+0,05 \AA)$. Observa-se ainda que essas ligações (Ag-Ag) ou $(\mathrm{Au}-\mathrm{Au})$ ficam um pouco distintas quando a molécula é adsorvida nas superfícies [001] ou [111]. Diferenças na distância média de 0,01 $\AA$ para as superfícies da prata e de 0,02 $\AA$ para as superfícies de ouro (apêndice B).

Os resultados referentes aos parâmetros estruturais relacionados às adsorções da molécula de metanotiol nos sítios c5, c7, c8 e c9 das nanopartículas puras de $\mathrm{Ag}$ e Au são apresentados nas tabelas 4.12 e 4.13, respectivamente. Novamente, como no caso das superfícies livres, as distâncias das ligações C-S, S-H e C$\mathrm{H}$ permanecem as mesmas que as da molécula livre, com uma muito pequena oscilação de no máximo 0,01 A para a ligação C-S, em todas as nanopartículas de $\mathrm{Ag}$ quanto de Au. Aqui também, como no caso das superfícies livres, as distâncias Ag-S nos vários sítios e em todas nanopartículas são maiores do que as distâncias Au-S.

Enquanto as energias de adsorção crescem, ficam mais estáveis, em todas as nanopartículas, indo do sítio c9 (menos estável) para o sítio c5 (mais estável), o comprimento das ligações $\mathrm{Ag}-\mathrm{S}, \mathrm{Au}-\mathrm{S}, \mathrm{Ag}-\mathrm{Ag}$ e $\mathrm{Au}-\mathrm{Au}$ decresce caminhando entre os sítios c9, c8, c7 e c5. Dessa forma, essas ligações são as menores nas adsorções mais estáveis (sítio c5). Essa ligação, no ouro, Au-S, é cerca de 0,12 Å menor do que a ligação Ag-S. Esse mesmo decréscimo, entre os sítios c5 e c9, acontece com o comprimento das ligação entre o átomo do sítio que adsorveu a molécula e seus vizinhos.

A tabela 4.14 apresenta os parâmetros estruturais referentes à adsorção do metanotiol sobre core-shell com 561 átomos e uma ou duas camadas de shell de $\mathrm{Ag}$ ou Au. Os resultados são idênticos aos das adsorções nas nanopartículas puras referentes aos shells das core-shell. Não há variação no comprimento das ligações moleculares quando adsorvidas. Máxima variação de 0,01 $\AA$ para o comprimento da ligação S-C. As ligações Au-S são todas menores do que as ligações Ag-S. Aqui também observamos o padrão de energia de adsorção mais estável, sobre o sítio c5, com menor comprimento da ligação $\mathrm{Ag}(\mathrm{Au})$-S. Energia de ligação aumenta em valor absoluto e fica mais estável, com a diminuição do comprimento da ligação $\mathrm{Ag}(\mathrm{Au})-\mathrm{S}$ (como também em $\mathrm{Ag}-\mathrm{Ag}$ e $\mathrm{Au}-\mathrm{Au}$ ) indo do sítio c9 para o sítio c5 das superfícies das core-shell. Aqui, entretanto, a diferença entre Ag-S e Au-S, no sítio c5, é bem menor do que no caso das nanopartículas puras e da ordem de $0,03 \AA$ e $0,04 \AA$. Adsorções em uma ou duas camadas de shell de Au ou de Ag, praticamente tem o comportamento estrutural da adsorção na nanopartícula correspondente do shell.

Adicionalmente, a tabela 4.15 apresenta o comportamento da adsorção da molécula de metanotiol sobre as core-shell com 923 átomos somente sobre o sítio mais estável c5. Os resultados são idênticos aos encontrados nas core-shell com 
Tabela 4.14: Parâmetros estruturais da adsorção da molécula de metanotiol $\left(\mathrm{SCH}_{4}\right)$ nas nanopartículas core-shell com 561 átomos: distância média entre o sítio de adsorção e os seus primeiros vizinhos na nanopartícula $\mathrm{Au}-\mathrm{Au}$ ou $\mathrm{Ag}$ $\mathrm{Ag}$; distância média da ligação entre o átomo $\mathrm{Ag}(\mathrm{Au})$ do sítio e o átomo de enxofre (S) da molécula Au-S ou Ag-S. Distâncias médias entre os átomos que compõe a molécula, S-H, S-C e C-H, respectivamente e deslocamento do sítio c5. Distâncias em Angstrom $(\AA)$.

\begin{tabular}{|c|c|c|c|c|c|c|c|}
\hline nanopartícula & sítio & $\begin{array}{l}\mathrm{Au}-\mathrm{Au} \text { ou } \\
\mathrm{Ag}-\mathrm{Ag}(\AA)\end{array}$ & $\begin{array}{l}\mathrm{Au}-\mathrm{S} \text { ou } \\
\mathrm{Ag}-\mathrm{S}(\AA)\end{array}$ & $\mathrm{S}-\mathrm{H}(\AA)$ & $\mathrm{S}-\mathrm{C}(\AA)$ & $\mathrm{C}-\mathrm{H}(\AA)$ & $\mathrm{c} 5(\AA)$ \\
\hline \multirow{4}{*}{$1 \mathrm{Au} @ 4 \mathrm{Ag}$} & $\mathrm{c} 5$ & 2,91 & 2,48 & 1,35 & 1,83 & 1,10 & $\begin{array}{c}+0,01 \\
(0,07 \%)\end{array}$ \\
\hline & $\mathrm{c} 7$ & 2,95 & 2,50 & 1,35 & 1,82 & 1,10 & \\
\hline & c8 & 2,96 & 2,54 & 1,35 & 1,82 & 1,10 & \\
\hline & c9 & 2,98 & 2,56 & 1,35 & 1,82 & 1,10 & \\
\hline \multirow{4}{*}{$2 \mathrm{Au} @ 3 \mathrm{Ag}$} & $\mathrm{c} 5$ & 2,89 & 2,47 & 1,35 & 1,83 & 1,10 & $\begin{array}{c}+0,01 \\
(0,07 \%)\end{array}$ \\
\hline & $\mathrm{c} 7$ & 2,90 & 2,51 & 1,35 & 1,82 & 1,10 & \\
\hline & $\mathrm{c} 8$ & 2,95 & 2,52 & 1,35 & 1,82 & 1,10 & \\
\hline & c9 & 2,99 & 2,56 & 1,35 & 1,82 & 1,10 & \\
\hline \multirow{4}{*}{$2 \mathrm{Ag} @ 3 \mathrm{Au}$} & $\mathrm{c} 5$ & 2,91 & 2,51 & 1,35 & 1,83 & 1,10 & $\begin{array}{c}+0,01 \\
(0,07 \%)\end{array}$ \\
\hline & c7 & 2,92 & 2,53 & 1,35 & 1,83 & 1,10 & \\
\hline & $\mathrm{c} 8$ & 2,94 & 2,56 & 1,35 & 1,82 & 1,10 & \\
\hline & c9 & 2,98 & 2,57 & 1,35 & 1,82 & 1,10 & \\
\hline \multirow{4}{*}{$1 \mathrm{Ag} @ 4 \mathrm{Au}$} & c5 & 2,90 & 2,52 & 1,35 & 1,82 & 1,10 & $\begin{array}{c}+0,03 \\
(0,21 \%)\end{array}$ \\
\hline & $\mathrm{c} 7$ & 2,93 & 2,54 & 1,35 & 1,83 & 1,10 & \\
\hline & $c 8$ & 2,96 & 2,56 & 1,35 & 1,83 & 1,10 & \\
\hline & c9 & 2,99 & 2,59 & 1,35 & 1,83 & 1,10 & \\
\hline
\end{tabular}


Tabela 4.15: Parâmetros estruturais da adsorção da molécula de metanotiol $\left(\mathrm{SCH}_{4}\right)$ nas nanopartículas core-shell com 923 átomos: distância média entre o sítio de adsorção c5 e os seus primeiros vizinhos na nanopartícula $\mathrm{Au}-\mathrm{Au}$ ou $\mathrm{Ag}-\mathrm{Ag}$; distância média da ligação entre o átomo $\mathrm{Ag}(\mathrm{Au})$ do sítio c5 e o átomo de enxofre $(\mathrm{S})$ da molécula Au-S ou Ag-S. Distâncias médias entre os átomos que compõe a molécula, S-H, S-C e C-H, respectivamente e deslocamento do sítio c5. Distâncias em Angstrom $(\AA)$.

\begin{tabular}{|c|c|c|c|c|c|c|}
\hline nanopartícula & $\begin{array}{c}\mathrm{Au}-\mathrm{Au} \text { ou } \\
\mathrm{Ag}-\mathrm{Ag}(\AA)\end{array}$ & $\begin{array}{c}\mathrm{Au}-\mathrm{S} \text { ou } \\
\mathrm{Ag}-\mathrm{S}(\AA)\end{array}$ & $\mathrm{S}-\mathrm{H}(\AA)$ & $\mathrm{S}-\mathrm{C}(\AA)$ & $\mathrm{C}-\mathrm{H}(\AA)$ & $\mathrm{c5}(\AA)$ \\
\hline \hline $1 \mathrm{Au} @ 5 \mathrm{Ag}$ & 2,88 & 2,48 & 1,35 & 1,83 & 1,10 & $+0,01(0,06 \%)$ \\
$2 \mathrm{Au} @ 4 \mathrm{Ag}$ & 2,87 & 2,48 & 1,35 & 1,83 & 1,10 & $+0,01(0,06 \%)$ \\
$3 \mathrm{Au} @ 3 \mathrm{Ag}$ & 2,87 & 2,47 & 1,35 & 1,83 & 1,10 & $+0,02(0,12 \%)$ \\
$4 \mathrm{Au} @ 2 \mathrm{Ag}$ & 2,88 & 2,47 & 1,35 & 1,83 & 1,10 & $+0,02(0,12 \%)$ \\
$5 \mathrm{Au} @ 1 \mathrm{Ag}$ & 2,88 & 2,47 & 1,35 & 1,83 & 1,10 & $+0,01(0,06 \%)$ \\
$1 \mathrm{Ag} @ 5 \mathrm{Au}$ & 2,91 & 2,57 & 1,35 & 1,83 & 1,10 & $+0,02(0,12 \%)$ \\
$2 \mathrm{Ag} @ 4 \mathrm{Au}$ & 2,91 & 2,57 & 1,35 & 1,83 & 1,10 & $+0,02(0,12 \%)$ \\
$3 \mathrm{Ag} @ 3 \mathrm{Au}$ & 2,90 & 2,57 & 1,35 & 1,83 & 1,10 & $+0,01(0,06 \%)$ \\
$4 \mathrm{Ag} @ 2 \mathrm{Au}$ & 2,91 & 2,58 & 1,35 & 1,83 & 1,10 & $+0,01(0,06 \%)$ \\
$5 \mathrm{Ag} @ 1 \mathrm{Au}$ & 2,90 & 2,58 & 1,35 & 1,83 & 1,10 & $+0,02(0,12 \%)$ \\
\hline \hline
\end{tabular}


561 átomos e a ligação Ag-S se aproxima ainda mais do valor encontrado para a nanopartícula pura de prata. Aqui verifica-se claramente um padrão único de adsorção, independente do número de camadas de shell, tanto de prata quanto de ouro. Uma única camada de shell define o padrão de adsorção.

\subsection{Propriedades eletrônicas das adsorções}

As densidades de estado, normalizadas ao número de partículas, das nanopartículas puras e core-shell de 561 e 923 átomos com uma ou duas camadas de shell de $\mathrm{Au}$ e de $\mathrm{Ag}$ são apresentadas nas figuras 4.3 e 4.4. De forma geral a adsorção da molécula de metanotiol sobre as nanopartículas puras e core-shell de Au e Ag maiores (561 e 923 átomos) praticamente não influência a estrutura eletrônica. Somente uma pequena perturbação, que também nem é significativa, é observada.

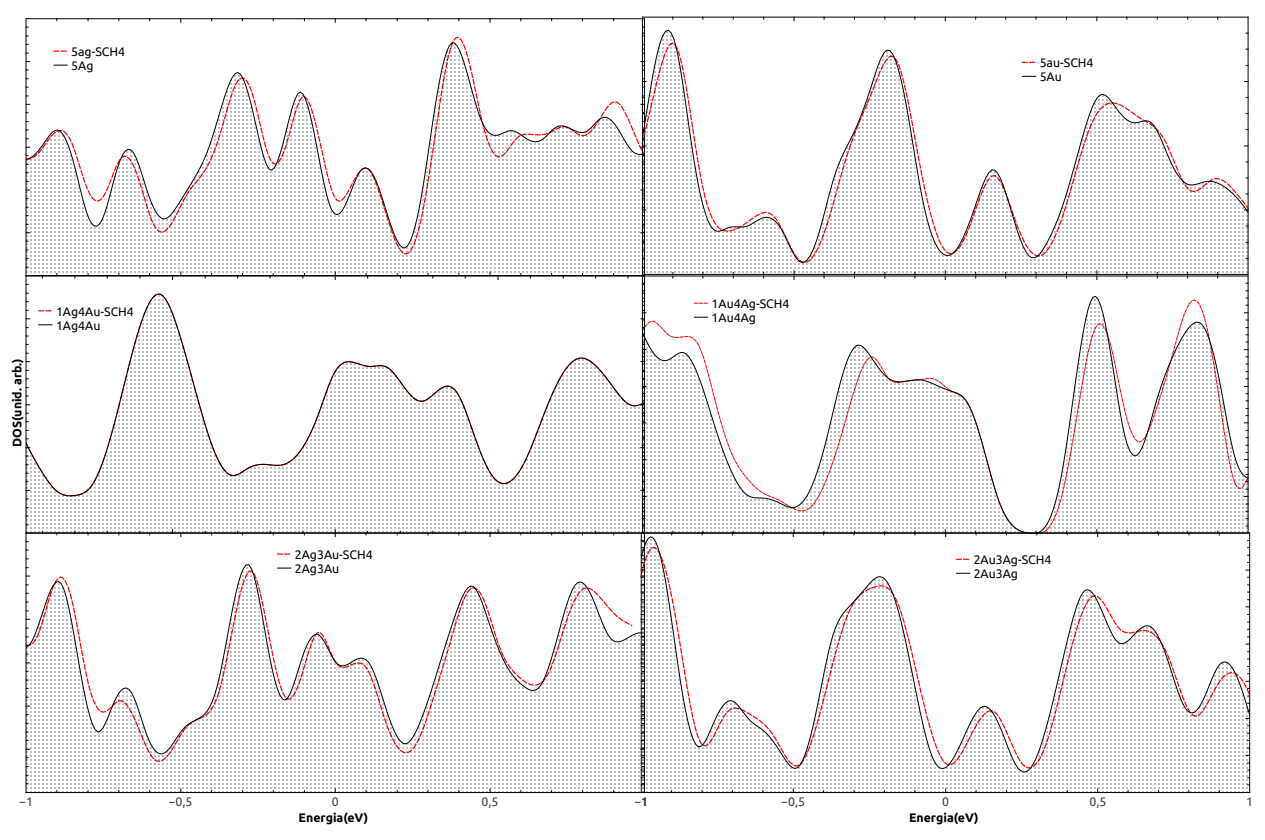

Figura 4.3: Densidade de estados das nanopartículas próxima ao nível de Fermi das nanopartículas puras e core-shell de Ag e de Au com 561 átomos, e comparação com a densidade de estados da adsorção da molécula de metanotiol $\left(\mathrm{SCH}_{4}\right)$. 


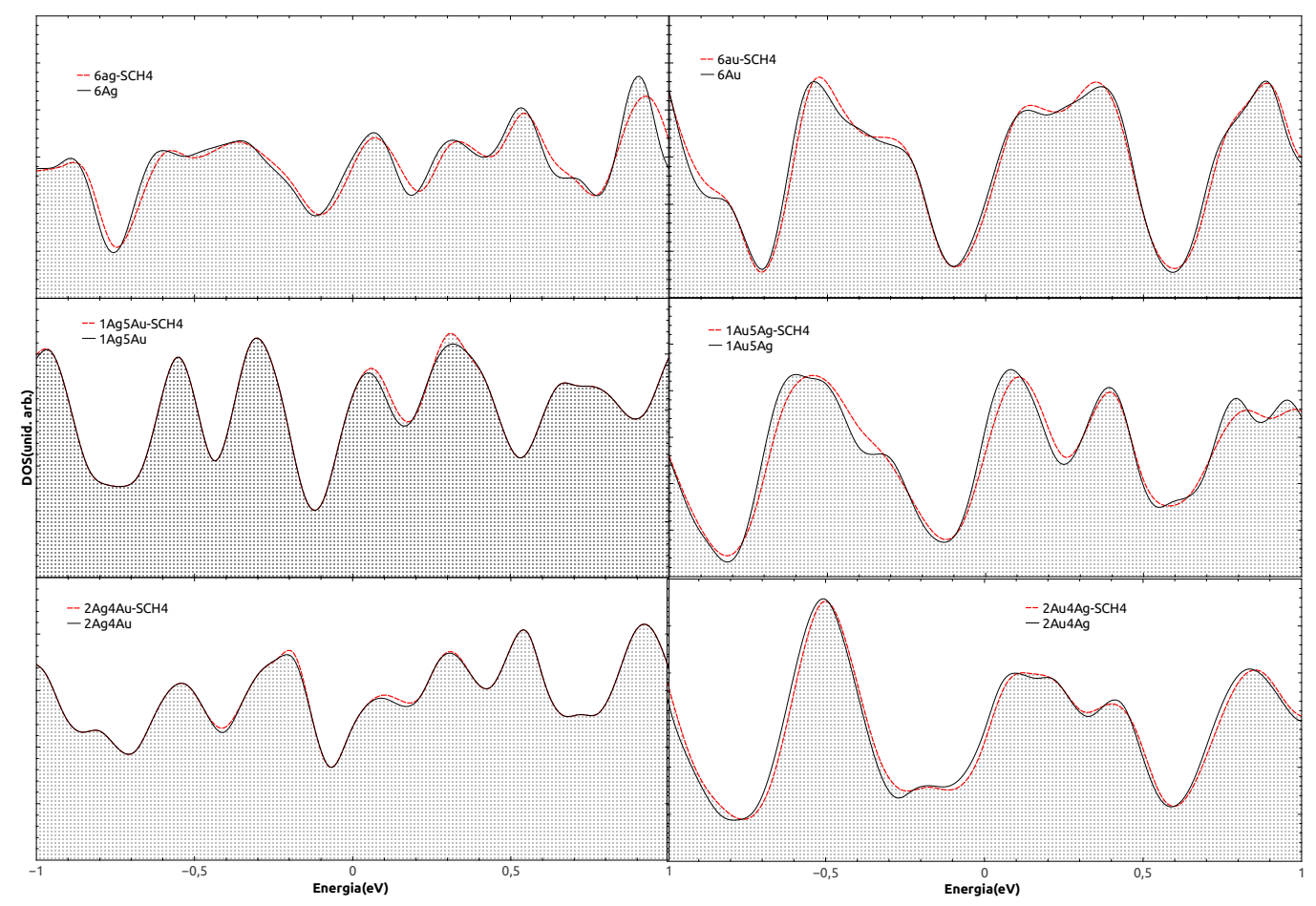

Figura 4.4: Densidade de estados das nanopartículas próxima ao nível de Fermi das nanopartículas puras e core-shell de Ag e de Au com 923 átomos, e comparação com a densidade de estados da adsorção da molécula de metanotiol $\left(\mathrm{SCH}_{4}\right)$. 


\section{Capítulo 5}

\section{Conclusões}

Neste trabalho estudamos as propriedades estruturais, energéticas e eletrônicas com e sem o uso da interação de van der Waals, das nanopartículas puras e core-shell de Ag e de Au, a fim de analisar os efeitos decorrentes do recobrimento de camadas de $\mathrm{Au}$ sobre as de $\mathrm{Ag}$ e das de $\mathrm{Ag}$ sobre as camadas de $\mathrm{Au}$ [11, 88, 89, 90] em função da dimensão destas estruturas [92, 97, 98]. Também estudamos as mesmas propriedades na adsorção da molécula de metanotiol $\left(\mathrm{SCH}_{4}\right)$ sobre os vários sítios de coordenação destas nanopartículas considerando somente o caso incluíndo a interação de van der Waals. Para tanto foram simuladas nanopartículas em formato cubo-octaédrico [84, 85, 86], com número total de átomos variando de 147 à 923, através de cálculos de primeiros princípios, dentro da teoria do funcional da densidade junto com o método de pseudopotenciais ultrassuaves.

As maiores contrações na superficie das nanopartículas puras e core-shell ocorrem com o sítio de coordenação c5 e seguem o mesmo padrão de contração com o aumento da nanopartícula, considerando ou não nos cálculos a interação de van der Waals.

Quanto ao ângulo total entre as ligações do sítio c5 com seus quatro primeiros vizinhos, verificamos que ele aumenta com o aumento da nanopartícula pura ou core-shell, com ou sem a interação de van der Waals. Nas core-shell, os ângulos são definidos pela camada de shell da superfície.

Os valores médios dos deslocamentos dos átomos do plano [001] das superfícies das nanopartículas apresentaram dilatações em todas as core-shell com caroço de $\mathrm{Au}$ e shell de Ag com van der Waals e contrações nas sem van der Waals, com exceção das nanopartículas com 147 átomos. Já para o plano [111], houve contração em todos esses valores de deslocamentos nas core-shell com caroço de Ag e shell de Au com van der Waals e dilatações nas sem van der Waals, com exceção das com 923 átomos, que apresentaram uma pequena contração. Esses

deslocamentos, em todas as nanopartículas puras e core-shell são bem maiores 
do que os observados nas superfícies livres de ouro e de prata.

Os deslocamentos das arestas, dos sítios c5, dos átomos nos planos [001] e [111] e o aumento do ângulo das ligações do sítio c5 mostram que as nanopartículas maiores tendem à uma superfície mais esférica, sendo essa esfericidade maior nas core-shell formadas de shell de Au e caroço de Ag. Esse resultado concorda com imagens de TEM (Transmission electron microscopy-microscopia de transmissão eletrônica) obtidas por Shankar e colaboradores [99].

Nas core-shell os ângulos do sítio c5 e os deslocamentos dos átomos da superfície, não sofrem alteração em função do número de camadas shell de ouro ou de prata, ou com suas respectivas concentrações, em cada core-shell com número definido de átomos.

Os deslocamentos sem van der Waals mostram padrões um pouco diferentes daqueles com van der Waals porque o parâmetro de rede calculado sem van der Waals para o ouro é maior que o da prata, ao contrário do resultado experimental e do valor obtido no cálculo com van der Waals, o que pode provocar distorções nas acomodações das camadas. Assim, acreditamos que os cálculos com van der Waals são mais realistas do que os sem van der Waals.

O padrão observado na superfície das nanopartículas é o que regula suas estruturas e propriedades, pois todos os deslocamentos atômicos encontrados na camada inferior à superfície (sub-superfície), também de contração, são mais de uma ordem de grandeza menores do que os deslocamentos dos átomos da superfície.

As energias total e de formação por átomo das nanopartículas puras de $\mathrm{Ag}$ e $\mathrm{Au}$ possuem comportamentos similares com ou sem a interação de van der Waals com valores tendendo, com o aumento das nanopartículas, às energias das superfícies [001] e [111] e dos respectivos bulks. O efeito da inclusão da interação de van der Waals depende do tamanho da nanopartícula e, de um modo geral, as variações nas energias por átomo são menores para as nanopartículas menores. Isto provavelmente resulta do fato de que as menores nanopartículas possuem menos sítios de coordenação c12 (ideal) e as interações de van der Waals são mais relevantes na descrição de estruturas com menores sítios de coordenação. As energias de formação por átomo das nanopartículas puras tendem, com o aumento das nanopartículas, às energias das superfícies [001] e [111] e dos bulks.

Considerando as core-shell, verificamos que uma única camada de shell de $\mathrm{Ag}$ ou de Au já determina o comportamento energético de sempre serem mais favoráveis aumentando-se o número de camadas do caroço e fixando-se o número de camadas de shell.

Poucas camadas de shell já definem o caráter das core-shell com propriedades energéticas definidas pelas camadas de shell da nanopartícula pura correspondente. Portanto, o aumento das camadas de shell de Ag sobre núcleos de $\mathrm{Au}$ 
representam uma desestabilização das nanopartículas obtidas devido ao aumento da energia de formação por átomo. Por outro lado, o aumento das camadas de shell de Au sobre caroço de Ag representam uma maior estabilidade das core-shell resultantes.

Eletronicamente, verificamos que as menores nanopartículas, com 147 átomos, apresentam características intermediárias entre os regimes moleculares com picos intensos e localizados, e influência da região interna que é tipicamente cristalina. O aumento do tamanho das nanopartículas puras e core-shell reduz gradativamente o caráter molecular destas estruturas, fazendo com que as suas DOS apresentem características mistas de superficie e cristal. A redução do caráter molecular com o aumento da nanopartícula é mais acentuado nas nanopartículas puras de Ag com até 309 átomos, enquanto nas de Au isso ocorre somente nas maiores com até 561 átomos.

Assim, podemos estabelecer que: a) o regime molecular, com forte influência da superfície e poucas propriedades cristalinas, nas nanopartículas menores com cerca de 150 átomos ( 2,0 nm); b) o regime misto, com características de cristal, superfície e molécula, no limite da transição do regime molecular para o regime cristalino, das nanopartículas de Ag que possuem entre 150 e 300 átomos ( 2,0 a 2,5 nm) e das nanopartículas de Au entre 150 e 560 átomos ( 2,0 a 3,0 $\mathrm{nm}$ ); c) o regime cristalino, onde as características cristalinas e de superfície são predominantes em relação às moleculares, são verificadas nas nanopartículas puras de Ag com mais de 300 átomos $(\sim 2,5 \mathrm{~nm})$ e com mais de 560 átomos $(\sim$ 3,0 nm) para as nanopartículas puras de Au. Observamos que não há distinção das DOS incluíndo ou não as interações de van der Waals.

A adsorção do metanotiol $\left(\mathrm{SCH}_{4}\right)$ sobre as nanopartículas puras de $\mathrm{Ag}$ e de $\mathrm{Au}$ é mais provável energeticamente sobre o sítio c5, essa probabilidade diminui do sítio c7 ao c9 e com o aumento da nanopartícula pura, sendo essa redução maior nas de Au. Isso ocorre pela maior influência do caráter molecular e de superfície sobre estas nanopartículas com até 561 átomos. Nas core-shell com uma ou duas camadas de shell de $\mathrm{Ag}$ ou $\mathrm{Au}$ com 561 átomos, o decréscimo de probabilidade de adsorção entre os sítios c5 e c9 também é observado. As adsorções sobre uma ou duas camadas de Ag já apresentam comportamento similar às adsorções sobre as maiores nanopartículas puras de Ag, com características mais cristalinas, enquanto que as adsorções sobre uma ou duas camadas de shell de $\mathrm{Au}$ tem comportamento próximo às menores nanopartículas de Au que tem maior perturbação dos regimes moleculares e de superfície. Considerando a adsorção do metanotiol somente sobre o sítio c5 em todas as core-shell com 147, 309, 561 e 923 átomos, verificamos em todos os casos que aumentando-se o número de camadas de shell, tanto de Au quanto de Ag, a energia de adsorção sobre a core-shell se aproxima da energia de adsorção sobre a nanopartícula pura correspondente. 
As energias de adsorção sobre o sítio c5 das nanopartículas puras e de todas as core-shell maiores, independente do número de camadas shell de $\mathrm{Ag}$ ou de $\mathrm{Au}$, se estabilizam em torno de $-0,50 \mathrm{eV}$.

Estruturalmente, verificamos que tanto nas nanopartículas puras quanto nas core-shell, em todos os casos, as distâncias das ligações S-H, S-C, C-H da molécula de metanotiol $\left(\mathrm{SCH}_{4}\right)$, não sofreram alteração em comparação com as distâncias na molécula livre. O mesmo padrão ocorre na adsorção sobre as superfícies livres [001](sítio c8) e [111](sítio c9). Ainda sobre estas superfícies, as distâncias entre os seus sítios e seus primeiros vizinhos permanecem praticamente inalteradas após a adsorção.

Os comprimentos das ligações $\mathrm{Au}-\mathrm{S}, \mathrm{Ag}-\mathrm{S}, \mathrm{Ag}-\mathrm{Ag}$ e $\mathrm{Au}-\mathrm{Au}$, decrescem entre os sítios c9, c8, c7 e c5 nas nanopartículas puras e core-shell, sendo que as distâncias das ligações Au-S nas nanopartículas puras, core-shell com 561 átomos com uma ou duas camadas de shell de Ag e de Au e superfícies livres são maiores do que os comprimentos das ligações Ag-S. Nas superfícies livres [001] e [111] da Ag e do $\mathrm{Au}$, verificamos que quando esses sítios adsorvem o metanotiol, suas distâncias aos seus primeiros vizinhos aumentam em comparação com as mesmas distâncias nas superfícies livres sem adsorção, sendo maiores os aumentos nas superfícies de $\mathrm{Au}$.

A adsorção do metanotiol sobre as core-shell com 561 e 923 átomos no sítio c5, mais estável, tem o mesmo comportamento, se aproximando dos valores encontrados para a adsorção das nanopartículas puras referentes as camadas de shell. Nas nanopartículas maiores verifica-se um padrão único de adsorção, independente do número de camadas de shell. Uma única camada de shell define o padrão de adsorção.

Nas nanopartículas puras, as distâncias das ligações Au-S e Ag-S, de um modo geral, não dependem do tamanho da nanopartícula. Nas core-shell, as distâncias dessas ligações seguem o mesmo padrão da nanopartícula pura correspondente a camada de shell.

As densidades de estados das maiores nanopartículas (com 561 e 923 átomos), com uma ou duas camadas de shell de Ag e de Au, adsorvidas com o metanotiol, de um modo geral, indicam que a estrutura eletrônica das nanopartículas não sofre qualquer influência devido a adsorção do metanotiol. 


\section{Apêndice A}

\section{Funções $F_{x}(s)$ e $H\left(r_{s}, t, \xi\right)$ das energias de troca e correlação PW91}

A função $F_{x}(s)$ está presente no termo da energia de troca na aproximação proposta por Perdew e Wang [44, 45]. A mesma não depende da polarização de spin e é dada por,

$$
F_{x}(s)=\frac{1+0,19645 s \sinh ^{-1}(7,7956 s)+\left(0,2743-0,1508 \exp \left(-100 s^{2}\right)\right) s^{2}}{1+0,19645 s \sinh ^{-1}(7,7956 s)+0,004 s^{4}}
$$

onde $s=\frac{|\nabla n(\mathbf{r})|}{2 k_{F} \phi n(\mathbf{r})}, \phi=\frac{1}{2}\left((1+\xi)^{\frac{2}{3}}+(1-\xi)^{\frac{2}{3}}\right)$ e $k_{F}=\frac{1}{r_{s}}\left(\frac{9 \pi}{4}\right)^{\frac{1}{3}}$, com $k_{F}$ sendo o momento de Fermi. O raio de Wigner-Seitz é dado em função da densidade eletrônica, $r_{s}(\mathbf{r})=\left(\frac{3}{4 \pi n(\mathbf{r})}\right)^{\frac{1}{3}}$.

Já a função $H\left(r_{s}, \xi, t, n\right)$, presente no termo de correlação, depende da polarização de spin e é definida por,

$$
H\left(r_{s}, \xi, t, n\right)=H_{0}\left(r_{s}, \xi, t\right)+H_{1}\left(r_{s}, \xi, t, n\right)
$$

onde,

$$
H_{0}(r, \xi, t)=\frac{\phi^{3} \beta^{2}}{2 \alpha} \ln \left(1+\frac{2 \alpha}{\beta}\left[\frac{1+A t^{2}}{1+A t^{2}+\left(A t^{2}\right)^{2}}\right]\right),
$$

e,

$$
H_{1}\left(r_{s}, \xi, t, n\right)=v\left(C_{c}-C_{c_{0}}-\frac{3}{7} C_{x}\right) \phi^{3} t^{2} \exp ^{-1}\left(\frac{10 \phi^{2} k_{s} t}{k_{F}}\right)^{2} .
$$

Os termos dependentes da densidade e do spin são dados por, 
Funções $F_{x}(s)$ e $H\left(r_{s}, t, \xi\right)$ das energias de troca e correlação PW91

$$
\begin{gathered}
C_{c}=\frac{1}{1000} \frac{2,568+23,266 r_{s}+0,007389 r_{s}^{2}}{1+8,723 r_{s}+0,472 r_{s}^{2}+0,0738890 r_{s}^{3}}-C_{x} \\
A=\frac{2 \alpha}{\beta} \exp ^{-1}\left(\frac{-2 E_{c}}{\phi^{3} \beta^{2}}\right)
\end{gathered}
$$

As constantes presentes nos termos das equações acima são definidas como, $\beta=v C_{c_{0}}, v=16\left(\frac{3}{\pi}\right)^{\frac{1}{3}}, C_{c_{0}}=0,004235, C_{x}=-0,001667$ e $\alpha=0,09$. 


\section{Apêndice B}

\section{Resultados preliminares para o ouro, prata e molécula de metanotiol}

Efetuamos cálculos preliminares para os cristais (bulks) e superfícies livres [001] e [111] de prata e ouro e para a molécula de metanotiol $\left(\mathrm{SCH}_{4}\right)$ utilizando $290 \mathrm{eV}$ de energia de corte para a expansão das funções de ondas em ondas planas, sendo este valor de energia suficiente para descrever adequadamente as propriedades das estruturas estudadas. Além disso, utilizamos $0,2 \mathrm{eV}$ como parâmetro de espalhamento que define a largura da gaussiana associada ao fator de ocupação de cada orbital de Kohn-Sham.

Os valores dos parâmetros de rede teóricos do cristal de prata assim como, o módulo de compressiblilidade volumétrica (bulk-modulus) e a energia de coesão, incluíndo a interação de van der Waals (com vdW) e também sem esta (sem vdW) constam na tabela B.1.

Tabela B.1: Parâmetro de rede, $\mathrm{a}_{0}$, em Angstrom $(\AA)$, (bulk-modulus) (BM) em Megabars (MBAR) e energia de coesão, $\mathrm{E}_{c}$, em eV, do cristal de prata (Ag).

\begin{tabular}{|c|c|c|c|}
\hline grandeza $/ \mathrm{Ag}$ & com vdW & sem vdW & experimental \\
\hline $\mathrm{a}_{0}(\AA)$ & 4,15 & 4,16 & 4,09 \\
$\mathrm{BM}(\mathrm{MBAR})$ & 0,73 & 0,97 & 1,00 \\
$\mathrm{E}_{c}(\mathrm{eV})$ & $-3,28$ & $-2,72$ & $-2,95$ \\
\hline
\end{tabular}

Esses parâmetros de rede, tabelados em B.1 são cerca de $2 \%$ maiores do que o valor experimental 4,09 $\AA[82,85,86,101,103]$. Estes cálculos foram efetuados, tanto para a prata $(\mathrm{Ag})$ quanto para o ouro $(\mathrm{Au})$, com a célula unitária 
da estrutura cúbica de face centrada utilizando uma malha de $(12 \times 12 \times 12)$ pontos especiais para o mapeamento da primeira zona de Brillouin (1 $\mathrm{ZBB})$.

Analogamente, os parâmetros de rede teóricos, módulos de compressiblilidade volumétrica

(bulk-modulus) e a energia de coesão, do cristal de ouro obtidos incluíndo a interação de Van der Waals (com vdW) e também sem esta (sem vdW) constam na tabela B.2.

Tabela B.2: Parâmetro de rede, $\mathrm{a}_{0}$, em $\operatorname{Angstrom}(\AA)$, (bulk-modulus)(BM) em Megabars(MBAR) e energia de coesão, $\mathrm{E}_{c}$, em eV, do cristal de ouro(Au).

\begin{tabular}{|c|c|c|c|}
\hline grandeza $/ \mathrm{Au}$ & com VdW & sem VdW & experimental \\
\hline $\mathrm{a}_{0}(\AA)$ & 4,11 & 4,18 & 4,08 \\
$\mathrm{BM}(\mathrm{MBAR})$ & 1,51 & 1,44 & 1,73 \\
$\mathrm{E}_{c}(\mathrm{eV})$ & $-3,88$ & $-3,19$ & $-3,81$ \\
\hline
\end{tabular}

Esses parâmetros de rede, tabelados em B.2 são cerca de 0,7\%, no caso com correção de van der Waals, e 2,5\%, no caso sem a mesma correção, maiores do que o valor experimental 4,08 $\AA$ [82, 85, 86, 101, 103].

Nossos resultados indicam claramente que o uso da interação de van der Waals aproxima bem os dados da energia de coesão dos dados experimentais. Os valores encontrados para o módulo de compressiblilidade volumétrica estão de acordo com vários resultados teóricos da literatura [103].

As superfícies livres [001] e [111] tanto da prata quanto do ouro foram construídas em uma supercélula com 8 camadas na geometria $(4 \times 4)$, com 32 átomos por camada, totalizando 256 átomos, e uma região de vácuo de $26 \AA$ entre as imagens adjacentes, equivalendo a 12 camadas de átomos no caso [001] e, no caso [111], uma região de vácuo de $23 \AA$ equivalendo a 10 camadas de átomos. Foram mantidas fixas 3 camadas inferiores de átomos na relaxação estrutural para reproduzir a geometria da região cristalina.

Todos estes cálculos com as superfícies, em todos os casos explicitados, convergiram para uma malha de $(4 \times 4 \times 1)$ pontos especiais de mapeamento na primeira zona de Brillouin (1 $\mathrm{aB})$. Tanto a quantidade de pontos para mapear a primeira zona de Brillouin (1 $\left.{ }^{\mathrm{a}} \mathrm{ZB}\right)$ quanto o tamanho da região de vácuo usada para não haver interação entre as imagens adjacentes das nanopartículas foram baseados nos estudos anteriores de Kiss [1].

Nas tabelas B.3, B.4, B.5 e B.6 constam os valores obtidos das energias de formação e de algumas distâncias das superfícies estudadas.

As energias das tabelas B.3 e B.4, foram obtidas usando a equação, 
Tabela B.3: Energia de formação por átomo $\left(\mathrm{E}_{f}\right)$ e energia total por átomo $\left(\mathrm{E}_{a t}\right)$, em (eV), das superfícies [001] e [111] da prata, com (cvdW) e sem (svdW) a interação de van der Waals.

\begin{tabular}{ccccc}
\hline \hline superfície & \multicolumn{2}{c}{$\mathrm{E}_{f}(\mathrm{eV})$} & \multicolumn{2}{c}{$\mathrm{E}_{a t}(\mathrm{eV})$} \\
$\mathrm{Ag}$ & $\mathrm{cvdW}$ & $\mathrm{svdW}$ & $\mathrm{cvdW}$ & $\mathrm{svdW}$ \\
{$[001]$} & 0,17 & 0,11 & $-3,10$ & $-2,61$ \\
{$[111]$} & 0,16 & 0,09 & $-3,12$ & $-2,63$ \\
\hline \hline
\end{tabular}

Tabela B.4: Energia de formação por átomo $\left(\mathrm{E}_{f}\right)$ e energia total por átomo $\left(\mathrm{E}_{a t}\right)$, em (eV), das superfícies [001] e [111] do ouro, com (cvdW) e sem (svdW) a interação de van der Waals.

\begin{tabular}{ccccc}
\hline \hline superfície & \multicolumn{2}{c}{$\mathrm{E}_{f}(\mathrm{eV})$} & \multicolumn{2}{c}{$\mathrm{E}_{a t}(\mathrm{eV})$} \\
$\mathrm{Au}$ & $\mathrm{cvdW}$ & $\mathrm{svdW}$ & $\mathrm{cvdW}$ & $\mathrm{svdW}$ \\
{$[001]$} & 0,22 & 0,12 & $-3,67$ & $-3,07$ \\
{$[111]$} & 0,18 & 0,09 & $-3,71$ & $-3,11$ \\
\hline \hline
\end{tabular}

$$
E_{f}=\frac{E_{s i s t}-256 \mu_{b u l k}}{256}
$$

onde $E_{\text {sist }}$, é a energia total da superfície obtida na simulação computacional e $\mu_{b u l k}=E_{b u l k}$ é o potencial químico dos bulks de prata e do ouro. A quantidade 256 é o total de átomos de prata ou de ouro utilizado no cálculo das superfícies.

Os valores das distâncias constantes nas tabelas B.5 e B.6, foram calculados considerando as distâncias entre 20 átomos da superfície livre e da primeira camada abaixo dela (sub-superfície), entre ela e a primeira camada fixa que reproduz o bulk e entre a sub-superfície e a camada fixa do bulk.

Notemos, nas tabelas B.5 e B.6, que as relaxações estruturais das superfícies [001] e [111] da prata e do ouro são pequenas. Houve diminuição das distâncias entre a superfície livre e o primeiro plano de átomos abaixo dela. Não houve alteração nas distâncias entre a sub-superfície e a primeira camada fixa, que reproduz a geometria do bulk, e, praticamente, não houve alteração nas distâncias entre a superfície livre e a camada fixa, sendo da mesma ordem de grandeza das outras variações $-0,01 \AA(-0,08 \%)$.

Efetuamos, também, cálculos para a molécula de metanotiol $\left(\mathrm{SCH}_{4}\right)$, representada na figura B.1. Cálculamos a energia de formação, e as diferenças entre as distâncias de ligação entre os átomos da molécula bem como os ângulos entre estas ligações, tabelados em B.7 e B.8, e comparamos os resultados com os dados 
Tabela B.5: Distâncias, em Angstrom, A, entre: a superfície livre e a primeira camada de átomos abaixo dela, $\mathrm{d}_{1}$, entre a primeira camada abaixo da superfície livre e a primeira camada fixa (bulk), $\mathrm{d}_{2}$, e entre a superfície livre e a primeira camada fixa (bulk), $\mathrm{d}_{3}$, das superfícies, [001] e [111] de prata, com (cvdW) e sem (svdW) a interação de van der Waals.

\begin{tabular}{ccccccc}
\hline \hline \multirow{2}{*}{$\begin{array}{c}\text { superfície } \\
\mathrm{Ag}\end{array}$} & \multicolumn{2}{c}{$\mathrm{d}_{1}(\AA)$} & \multicolumn{2}{c}{$\mathrm{d}_{2}(\AA)$} & \multicolumn{2}{c}{$\mathrm{d}_{3}(\AA)$} \\
$\mathrm{cvdW}$ & $\mathrm{svdW}$ & $\mathrm{cvdW}$ & $\mathrm{svdW}$ & $\mathrm{cvdW}$ & $\mathrm{svdW}$ \\
\hline \hline$[001]$ & $-0,02$ & $-0,01$ & 0,00 & 0,00 & $-0,02$ & $-0,01$ \\
& $(-0,96 \%)$ & $(-0,48 \%)$ & $(0,00 \%)$ & $(0,00 \%)$ & $(-0,19 \%)$ & $(-0,10 \%)$ \\
\hline$[111]$ & $-0,01$ & $-0,01$ & 0,00 & 0,00 & $-0,01$ & $-0,01$ \\
& $(-0,42 \%)$ & $(-0,42 \%)$ & $(0,00 \%)$ & $(0,00 \%)$ & $(-0,08 \%)$ & $(-0,08 \%)$ \\
\hline \hline
\end{tabular}

Tabela B.6: Distâncias, em Angstrom, A, entre: a superfície livre e a primeira camada de átomos abaixo dela, $\mathrm{d}_{1}$, entre a primeira camada abaixo da superfície livre e a primeira camada fixa (bulk), $\mathrm{d}_{2}$, e entre a superfície livre e a primeira camada fixa (bulk), $\mathrm{d}_{3}$, das superfícies, [001] e [111] de ouro, com (cvdW) e sem (svdW) a interação de van der Waals.

\begin{tabular}{ccccccc}
\hline \hline superfície & \multicolumn{2}{c}{$\mathrm{d}_{1}(\AA)$} & \multicolumn{2}{c}{$\mathrm{d}_{2}(\AA)$} & \multicolumn{2}{c}{$\mathrm{d}_{3}(\AA)$} \\
$\mathrm{Au}$ & $\mathrm{cvdW}$ & $\mathrm{svdW}$ & $\mathrm{cvdW}$ & $\mathrm{svdW}$ & $\mathrm{cvdW}$ & $\mathrm{svdW}$ \\
\hline \hline$[001]$ & $-0,01$ & $-0,01$ & 0,00 & 0,00 & $-0,01$ & $-0,01$ \\
& $(-0,49 \%)$ & $(-0,48 \%)$ & $(0,00 \%)$ & $(0,00 \%)$ & $(-0,10 \%)$ & $(-0,10 \%)$ \\
\hline$[111]$ & $-0,01$ & $-0,01$ & 0,00 & 0,00 & $-0,01$ & $-0,01$ \\
& $(-0,42 \%)$ & $(-0,41 \%)$ & $(0,00 \%)$ & $(0,00 \%)$ & $(-0,08 \%)$ & $(-0,08 \%)$ \\
\hline \hline
\end{tabular}

Tabela B.7: Medidas dos comprimentos das ligações, em Å, dos átomos da molécula de metanotiol $\left(\mathrm{SCH}_{4}\right)$.

\begin{tabular}{ccc}
\hline \hline ligação & \multicolumn{2}{c}{ comprimento da ligação $(\AA)$} \\
& teórico & experimental \\
C-S & 1,82 & 1,80 \\
C-H & 1,10 & 1,10 \\
S-H & 1,35 & 1,31 \\
\hline \hline
\end{tabular}




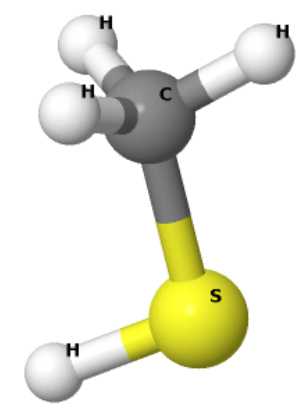

Figura B.1: Representação estrutural da molécula de metanotiol $\left(\mathrm{SCH}_{4}\right)$.

Tabela B.8: Medidas dos ângulos das ligações, em graus, dos átomos da molécula de metanotiol $\left(\mathrm{SCH}_{4}\right)$.

\begin{tabular}{ccc}
\hline \hline ligação & \multicolumn{2}{c}{ ângulo da ligação $\left(^{\circ}\right)$} \\
& teórico & experimental \\
H-C-S & 97,0 & 100,0 \\
C-S-H & 109,6 & 111,3 \\
H-C-H & 109,3 & 107,6 \\
\hline \hline
\end{tabular}

experimentais de [103]. Somente constam valores calculados incluíndo a interação de van der Waals.

A distância da ligação entre enxofre $(\mathrm{S})$ e hidrogênio $(\mathrm{H})$ variou $+0,04 \AA$ $(+3,05 \%)$; entre enxofre e carbono $(\mathrm{C})$, variou $+0,02 \AA(+1,11 \%)$. As distâncias das ligações entre $\mathrm{C}$ e $\mathrm{H}$ não variaram. O ângulo entre $\mathrm{H}, \mathrm{C}$ e $\mathrm{S}$ variou $\mathrm{em}-3,0^{\circ}$ ($3,0 \%)$, entre $\mathrm{C}, \mathrm{S}$ e $\mathrm{H}$, variaram, em média, $+1,7^{\circ}(+1,5 \%)$ e, os ângulos $\mathrm{H}, \mathrm{C}$ e $\mathrm{H}$, variaram, em média, $-1,7^{\circ}(-1,6 \%)$.

Para o cálculo da energia de ligação da molécula, $E_{l i g}$, utilizamos a expressão,

$$
E_{l i g}=E_{m o l}-\sum_{i} E_{a t}^{i}
$$

onde $E_{m o l}$, é a energia da molécula obtida na simulação computacional, $E_{a t}^{i}$ é a energia de cada átomo que compõe a molécula e $i$ representa cada um dos átomos da molécula. O valor de $E_{l i g}$ é de $-27,3360 \mathrm{eV}$. 


\section{Referências Bibliográficas}

[1] Ferenc Diniz Kiss. Efeitos de dimensão nas propriedades físicas e processos de adsorção em nanopartículas de prata. Tese de doutorado, Instituto de Física, Universidade de São Paulo, São Paulo, 2010.

[2] F. D. Kiss, R. Miotto, and A. C. Ferraz. Size effects on silver nanoparticles' properties. Nanotechnology, 22(27):275708, 2011.

[3] R. Miotto, F. D. Kiss, and A. C. Ferraz. Changes in a nanoparticle's spectroscopic signal mediated by the local environment. Nanotechnology, 23(48):485202, 2012.

[4] O. Stranik, T. Schneider, N. Jahr, J. Wirth, F. Garwe, A. Csaki, and W. Fritzsche. Bioanalytics using single plasmonic nanostructures. Proc. SPIE, 8595:85950C-85950C-7, 2013.

[5] N. Sounderya and Y. Zhang. Use of Core/Shell Nanoparticles for Biomedical Applications. Recent Patents on Biomedical Engineering, 1(1):34-42, 2008.

[6] Prashant K. Jain, Kyeong Seok Lee, Ivan H. El-Sayed, and Mostafa A. El-Sayed. Calculated Absorption and Scattering Properties of Gold Nanoparticles of Different Size, Shape, and Composition: Applications in Biological Imaging and Biomedicine. The Journal of Physical Chemistry B, 110(14):7238-7248, 2006.

[7] M.C.Daniel and A. Astruc. Gold nanoparticles: assembly, supramolecular chemistry, quantum-size-related properties, and applications toward biology, catalysis, and nanotechnology. Chemical Review, 1(104):293-346, 2004.

[8] Robin M. Bright, Michael D. Musick, and Michael J. Natan. Preparation and Characterization of Ag Colloid Monolayers. Langmuir, 14(20):56955701, 1998. 
[9] Matthew S. Shore, Junwei Wang, Aaron C. Johnston-Peck, Amy L. Oldenburg, and Joseph B. Tracy. Synthesis of Au(Core)/Ag(Shell) Nanoparticles and their Conversion to AuAg Alloy Nanoparticles. Small, 7(2):230-234, 2011.

[10] Y. Suzuki, M. Yamamoto, T. Saito, T. Miyanaga, S. Ohwada, A. Iwakoshi, T. Nanke, and T. Kobayashi. Anomalous infrared and visible light absorption and local structure of $\mathrm{Ag}-\mathrm{Au}$ core/shell nanoparticles. Applied Physics A, 103(1):81-88, 2011.

[11] Henrique E. Toma, Vitor M. Zamarion, Sergio H. Toma, and Koiti Araki. The coordination chemistry at gold nanoparticles. Journal of the Brazilian Chemical Society, 21:1158 - 1176, 2010.

[12] Chad A. Mirkin YunWei Cao, Rongchao Jin. DNA-Modified CoreShell Ag/Au Nanoparticles. Journal of the American Chemical Society, 123(32):7961-7962, 2001.

[13] Dong-Kwon Lim, In-Jung Kim, and Jwa-Min Nam. DNA-embedded Au/Ag core-shell nanoparticles. Chemical Communications, pages 5312-5314, 2008.

[14] A. M. Reilly and A. Tkatchenko. Understanding the role of vibrations, exact exchange, and many-body van der Waals interactions in the cohesive properties of molecular crystals. The Journal of Chemical Physics, 139(2), 2013.

[15] K. Tonigold and A. Groß. Adsorption of small aromatic molecules on the (111) surfaces of noble metals: A density functional theory study with semiempirical corrections for dispersion effects. The Journal of Chemical Physics, 132(22), 2010.

[16] H. Yildirim, T. Greber, and Ab. Kara. Trends in Adsorption Characteristics of Benzene on Transition Metal Surfaces: Role of Surface Chemistry and van der Waals Interactions. The Journal of Physical Chemistry C, 117(40):20572-20583, 2013.

[17] J. Klimes, D. R. Bowler, and A. Michaelides. Van der Waals density functionals applied to solids. Physical Review B, 83:195131, 2011.

[18] J. Klimes and A. Michaelides. Perspective: Advances and challenges in treating van der Waals dispersion forces in density functional theory. The Journal of Chemical Physics, 137(12), 2012. 
[19] P. Hohenberg and W. Kohn. Inhomogeneous Electron Gas. Physical Review, 136(3B):B864-B871, 1964.

[20] W. Kohn and L. J. Sham. Self-Consistent Equations Including Exchange and Correlation Effects. Physical Review, 140(4A):A1133-A1138, 1965.

[21] John P. Perdew, J. A. Chevary, S. H. Vosko, Koblar A. Jackson, Mark R. Pederson, D. J. Singh, and Carlos Fiolhais. Atoms, molecules, solids, and surfaces: Applications of the generalized gradient approximation for exchange and correlation. Physical Review B, 46(11):6671-6687, 1992.

[22] John P. Perdew, Kieron Burke, and Matthias Ernzerhof. Generalized Gradient Approximation Made Simple. Physical Review Letters, 77(18):38653868, 1996.

[23] David Vanderbilt. Optimally smooth norm-conserving pseudopotentials. Physical Review B, 32(12):8412-8415, 1985.

[24] G. Kresse and D. Joubert. From ultrasoft pseudopotentials to the projector augmented-wave method. Physical Review B, 59(3):1758-1775, 1999.

[25] B. J. Austin, V. Heine, and L. J. Sham. General Theory of Pseudopotentials. Physical Review, 127(1):276-282, 1962.

[26] D. R. Hamann, M. Schlüter, and C. Chiang. Norm-Conserving Pseudopotentials. Physical Review Letters, 43(20):1494-1497, 1979.

[27] G. P. Kerker. Non-singular atomic pseudopotentials for solid state applications. Journal of Physics C: Solid State Physics, 13(9):L189, 1980.

[28] G. B. Bachelet, D. R. Hamann, and M. Schlüter. Pseudopotentials that work: From H to Pu. Physical Review B, 26(8):4199-4228, 1982.

[29] N. Troullier and José Luriaas Martins. Efficient pseudopotentials for planewave calculations. Physical Review B, 43(3):1993-2006, 1991.

[30] David Vanderbilt. Soft self-consistent pseudopotentials in a generalized eigenvalue formalism. Physical Review B, 41(11):7892-7895, 1990.

[31] Leonard Kleinman and D. M. Bylander. Efficacious Form for Model Pseudopotentials. Physical Review Letters, 48(20):1425-1428, 1982.

[32] Kari Laasonen, Alfredo Pasquarello, Roberto Car, Changyol Lee, and David Vanderbilt. Car-Parrinello molecular dynamics with Vanderbilt ultrasoft pseudopotentials. Physical Review B, 47(16):10142-10153, 1993. 
[33] Stefan Grimme, Jens Antony, Stephan Ehrlich, and Helge Krieg. A consistent and accurate ab initio parametrization of density functional dispersion correction (DFT-D) for the 94 elements H-Pu. The Journal of Chemical Physics, 132(15):-, 2010.

[34] Stefan Grimme. Accurate description of van der Waals complexes by density functional theory including empirical corrections. Journal of Computational Chemistry, 25(12):1463-1473, 2004.

[35] H. Margenau. Van der Waals forces. Modern Physics Review, 11:1-35, Jan 1939.

[36] Stefan Grimme, Stephan Ehrlich, and Lars Goerigk. Effect of the damping function in dispersion corrected density functional theory. Journal of Computational Chemistry, 32(7):1456-1465, 2011.

[37] V.A. Parsegian. Van der Waals Forces: A Handbook for Biologists, Chemists, Engineers, and Physicists. Cambridge University Press, 2005.

[38] T. S. Chwee and M. B. Sullivan. Adsorption studies of C6H6 on Cu (111), $\mathrm{Ag}$ (111), and $\mathrm{Au}$ (111) within dispersion corrected density functional theory. The Journal of Chemical Physics, 137(13), 2012.

[39] P. Hohenberg and W. Kohn. Inhomogeneous Electron Gas. Physical Review, 136:B864, 1964.

[40] J. C. Slater. A Simplification of the Hartree-Fock Method. Physical Review, 81:385, 1951.

[41] W. Kohn and L. J. Sham. Self-Consistent Equations Including Exchange and Correlation Effects. Physical Review, 140:A1133, 1965.

[42] J. P. Perdew and A. Zunger. Self-interaction correction to densityfunctional approximations for many-electron systems. Physical Review B, 23:5048, 1981.

[43] D. M. Ceperley and B. J. Alder. Ground State of the Electron Gas by a Stochastic Method. Physical Review Letters, 45:566, 1980.

[44] Y. Wang and J. P. Perdew. Spin scaling of the electron-gas correlation energy in the high-density limit. Physical Review B, 43:8911, 1991.

[45] Y. Wang and J. P. Perdew. Accurate and simple analytic representation of the electron-gas correlation energy. Physical Review B, 42:13244, 1992. 
[46] Reiner M. Dreizler and Gross E.K.U. Density Functional Theory: An Approach to the Quantum Many-Body Problem . Springer-Verlag, 1990.

[47] C. Herring. A New Method for Calculating Wave Functions in Crystals. Physical Review, 57:1169, 1940.

[48] J. C. Phillips and L. Kleinman. New Method for Calculating Wave Functions in Crystals and Molecules. Physical Review, 116:287, 1959.

[49] M. L. Cohen and V. Heine. The fitting of pseudopotentials to experimental data and their subsequent application. Solid State Physics, 24:37, 1970.

[50] D. R. Hamann, M. Schlter, and C. Chiang. Norm-Conserving Pseudopotentials. Physical Review Letters, 43:1494, 1979.

[51] L. Kleinman and D. M. Bylander. Efficacious Form for Model Pseudopotentials. Physical Review Letters, 48:1425, 1982.

[52] R. P. Feynman. Forces in Molecules. Physical Review, 56(4):340-343, 1939.

[53] H. Hellmann. Einfuhrung in die Quantenchemie. 1937.

[54] G. Kresse and J. Furthmller. Efficiency of ab-initio total energy calculations for metals and semiconductors using a plane-wave basis set. Computational Materials Science, 6:15, 1996.

[55] S. Goedecker and K. Maschke. Operator approach in the linearized augmented-plane-wave method: Efficient electronic-structure calculations including forces. Physical Review B, 45(4):1597-1604, 1992.

[56] R. Car and M. Parrinello. Unified Approach for Molecular Dynamics and Density-Functional Theory. Physical Review Letters, 55(22):2471-2474, 1985.

[57] Michael P. Teter, Michael C. Payne, and Douglas C. Allan. Solution of Schrodinger's equation for large systems. Physical Review B, 40(18):1225512263, Dec 1989.

[58] G. Kresse and J. Furthmüller. Efficient iterative schemes for ab initio total-energy calculations using a plane-wave basis set. Physical Review B, 54(16):11169-11186, 1996.

[59] Richard P. Brent. Algorithms for Minimisation without Derivatives (Automatic Computation). Prentice Hall, 1972. 
[60] J.D.M. Vianna, A. Fazzio, and S. Canuto. Teoria quântica de moléculas e sólidos: simulação computacional. Livraria da Física, 2004.

[61] Stefan Grimme. Semiempirical GGA-type density functional constructed with a long-range dispersion correction. Journal of Computational Chemistry, 27(15):1787-1799, 2006.

[62] VASP Group. Vienna Ab-initio Simulation Package. http://cms.mpi.univie.ac.at/vasp/, abril de 2010.

[63] J. Gottschalck and B. Hammer. A density functional theory study of the adsorption of sulfur, mercapto, and methylthiolate on $\mathrm{Au}(111)$. The Journal of Chemical Physics, 116(2):784-790, 2002.

[64] S. Tosoni and J. Sauer. Accurate quantum chemical energies for the interaction of hydrocarbons with oxide surfaces: $\mathrm{CH} 4 / \mathrm{MgO}(001)$. Physical Chemistry, 12:14330-14340, 2010.

[65] M. Amft, S. Lebègue, O. Eriksson, and N. V. Skorodumova. Adsorption of $\mathrm{Cu}, \mathrm{Ag}$, and $\mathrm{Au}$ atoms on graphene including van der Waals interactions. Journal of Physics: Condensed Matter, 23(39):395001, 2011.

[66] H. Yildirim, T. Greber, and A. Kara. Trends in Adsorption Characteristics of Benzene on Transition Metal Surfaces: Role of Surface Chemistry and van der Waals Interactions. The Journal of Physical Chemistry C, 117(40):20572-20583, 2013.

[67] O. Akhavan. Silver nanocube crystals on titanium nitride buffer layer. Journal of Physics D: Applied Physics, 42(10), 2009.

[68] T. P. Martin. Shells of atoms. Physics Reports, 273(4):199 - 241, 1996.

[69] Emil Roduner. Size matters: why nanomaterials are different. Chemical Society reviews, 35(7):583-92, 2006.

[70] Sukdeb Pal, Yu Kyung Tak, and Joon Myong Song. Does the Antibacterial Activity of Silver Nanoparticles Depend on the Shape of the Nanoparticle? A Study of the Gram-Negative Bacterium Escherichia coli. Applied and Environmental Microbiology, 73(6):1712-1720, 2007.

[71] J. J. Mock, M. Barbic, D. R. Smith, D. A. Schultz, and S. Schultz. Shape effects in plasmon resonance of individual colloidal silver nanoparticles. The Journal of Chemical Physics, 116(15):6755-6759, 2002. 
[72] D. Schooss, M. N. Blom, Joel H. Parks, Bernd Issendorff, Hellmut Haberland, and Manfred M. Kappes. The structures of $\mathrm{Ag}_{55}^{+}$and $\mathrm{Ag}_{55}^{-}$: trapped ion electron diffraction and density functional theory. Nano letters, 5(10), 2005.

[73] D. R. Jennison, P. A. Schultz, and M. P. Sears. Ab initio calculations of $\mathrm{Ru}, \mathrm{Pd}$, and $\mathrm{Ag}$ cluster structure with 55, 135, and 140 atoms. The Journal of Chemical Physics, 106(5):1856-1862, 1997.

[74] Martine N. Blom, Detlef Schooss, Jason Stairs, and Manfred M. Kappes. Experimental structure determination of silver cluster ions $(\operatorname{Ag}(\mathrm{n})+, 19$ $<$ or $=\mathrm{n}<$ or $=79)$. The Journal of Chemical Physics, 124(24):244308, 2006.

[75] Jonathan P. K. Doye and David J. Wales. Global minima for transition metal clusters described by Sutton-Chen potentials. New Journal of Chemistry, 22(7):733-744, 1998.

[76] R. Poteau and F. Spiegelmann. Structural properties of sodium microclusters $(\mathrm{n}=4-34)$ using a Monte Carlo growth method. The Journal of Chemical Physics, 98(8):6540-6557, 1993.

[77] Clemens Burda, Xiaobo Chen, Radha Narayanan, and Mostafa a El-Sayed. Chemistry and properties of nanocrystals of different shapes. Chemical Reviews, 105(4):1025-102, 2005.

[78] Yugang Sun and Younan Xia. Shape-Controlled Synthesis of Gold and Silver Nanoparticles. Science, 298(5601):2176-2179, 2002.

[79] K. J. Koski, N. M. Kamp, R. K. Smith, M. Kunz, J. K. Knight, and A. P. Alivisatos. Structural distortions in 5-10 nm silver nanoparticles under high pressure. Physical Review B, 78(16):165410, 2008.

[80] Cai-Xia Kan, Jie-Jun Zhu, and Xiao-Guang Zhu. Silver nanostructures with well-controlled shapes: synthesis, characterization and growth mechanisms. Journal of Physics D: Applied Physics, 41(15), 2008.

[81] I. Maliszewska, K. Szewczyk, and K. Waszak. Biological synthesis of silver nanoparticles. Journal of Physics: Conference Series, 146(1):012025, 2009.

[82] Charles Kittel. Introduction to Solid State Physics. John Wiley and Sons, New York, 2004. 
[83] R. Poteau, J.-L. Heully, and F. Spiegelmann. Structure, stability, and vibrational properties of small silver cluster. Zeitschrift für Physik D Atoms, Molecules and Clusters, 40(1-4):479-482, 1997.

[84] F. Calvo. Influence of Size, Composition, and Chemical Order on the Vibrational Properties of Gold-Silver Nanoalloys. The Journal of Physical Chemistry C, 115(36):17730-17735, 2011.

[85] Sami Malola and Hannu Hakkinen. Electronic Structure and Bonding of Icosahedral Core-Shell Gold-Silver Nanoalloy Clusters $\mathrm{Au}(144-\mathrm{x}) \mathrm{Ag}(\mathrm{x})(\mathrm{SR}) 60$. The Journal of Physical Chemistry Letters, 2(18):2316-2321, 2011.

[86] Samit Guha, Subhasish Roy, and Arindam Banerjee. Fluorescent Au@Ag Core-Shell Nanoparticles with Controlled Shell Thickness and HgII Sensing. Langmuir, 27(21):13198-13205, 2011.

[87] D. Reinhard, B. D. Hall, D. Ugarte, and R. Monot. Size-independent fcc-toicosahedral structural transition in unsupported silver clusters: An electron diffraction study of clusters produced by inert-gas aggregation. Physical Review B, 55(12):7868-7881, 1997.

[88] E.K. Beloglazkina, A. G. Majouga, R. B. Romashkina, N. V. Zyk, and N. S. Zefirov. Gold nanoparticles modified with coordination compounds of metals: synthesis and application. Russian Chemical Reviews, 81(1):65, 2012.

[89] Maria do Carmo Ferreira e Hadma Sousa Rangel. Nanotecnologia: aspectos gerais e potencial de aplicação em catálise. Química Nova, 32:1860 - 1870, 2009.

[90] Juan P. Holgado, Fatima Ternero, Victor M. Gonzalez-delaCruz, and Alfonso Caballero. Promotional Effect of the Base Metal on Bimetallic $\mathrm{Au}-\mathrm{Ni} / \mathrm{CeO} 2$ Catalysts Prepared from Core-Shell Nanoparticles. ACS Catalysis, 3(9):2169-2180, 2013.

[91] L. A. Dykman and V. A. Bogatyrev. Gold nanoparticles: preparation, functionalisation and applications in biochemistry and immunochemistry. Russian Chemical Reviews, 76(2):181, 2007.

[92] H. Zhang, J. Okuni, and N. Toshima. One-pot synthesis of Ag-Au bimetallic nanoparticles with Au shell and their high catalytic activity for aerobic glucose oxidation. Journal of Colloid and Interface Science, 354(1):131 138, 2011. 
[93] Quang Huy Tran, Van Quy Nguyen, and Anh-Tuan Le. Silver nanoparticles: synthesis, properties, toxicology, applications and perspectives. Advances in Natural Sciences: Nanoscience and Nanotechnology, 4(3):033001, 2013.

[94] Anil K. Suresh, Dale A. Pelletier, Wei Wang, Jennifer L. Morrell-Falvey, Baohua Gu, and Mitchel J. Doktycz. Cytotoxicity Induced by Engineered Silver Nanocrystallites Is Dependent on Surface Coatings and Cell Types. Langmuir, 28(5):2727-2735, 2012.

[95] Olesja Bondarenko, Angela Ivask, Aleksandr Käkinen, Imbi Kurvet, and Anne Kahru. Particle-Cell Contact Enhances Antibacterial Activity of Silver Nanoparticles. PLoS ONE, 8(5):e64060, 052013.

[96] K. C. Nguyen, V. L. Seligy, A. Massarsky, T. W. Moon, P. Rippstein, J. Tan, and A. F. Tayabali. Comparison of toxicity of uncoated and coated silver nanoparticles. Journal of Physics: Conference Series, 429(1):012025, 2013.

[97] J. B. Jackson and N. J. Halas. Silver nanoshells: variations in morphologies and optical properties. The Journal of Physical Chemistry B, 105(14):2743$2746,2001$.

[98] Z. Y. Li, J. Yuan, Y. Chen, R. Palmer, and J. Wilcoxon. Direct Imaging of Core-shell Structure in Ag-Au Nanoparticles. Microscopy and Microanalysis, 11:1450-1451, 82005.

[99] S.Shiv Shankar, Akhilesh Rai, Absar Ahmad, and Murali Sastry. Rapid synthesis of $\mathrm{Au}, \mathrm{Ag}$, and bimetallic $\mathrm{Au}$ core- $\mathrm{Ag}$ shell nanoparticles using Neem (Azadirachta indica) leaf broth. Journal of Colloid and Interface Science, 275(2):496 - 502, 2004.

[100] Qing-Song Chen, Francisco J. Vidal-Iglesias, Jose Solla-Gullon, Shi-Gang Sun, and Juan M. Feliu. Role of surface defect sites: from Pt model surfaces to shape-controlled nanoparticles. Chemical Science, 3:136-147, 2012.

[101] J. Petroski, M. Chou, and C. Creutz. The coordination chemistry of gold surfaces: Formation and far-infrared spectra of alkanethiolate-capped gold nanoparticles. Journal of Organometallic Chemistry, 694(7-8):1138 - 1143, 2009. Organo-Transition Metal Complexes Dedicated to Prof. Dr. Ch. Elschenbroich. 
[102] J. Meyer, T. Bredow, C. Tegenkamp, and H. Pfnür. Thiol and thiolate bond formation of ferrocene-1,1-dithiol to a $\mathrm{Ag}(111)$ surface. The Journal of Chemical Physics, 125(19):194705, 2006.

[103] NIST. National Institute of Standards and Technology.

http://www.nist.gov/, janeiro de 2015. 